University of Rhode Island

DigitalCommons@URI

Open Access Master's Theses

1979

\title{
A COMPARISON BETWEEN THE SELF-ADMINISTRATION OF CLONIDINE AND FENTANYL
}

Gary Terence Shearman

University of Rhode Island

Follow this and additional works at: https://digitalcommons.uri.edu/theses

\section{Recommended Citation}

Shearman, Gary Terence, "A COMPARISON BETWEEN THE SELF-ADMINISTRATION OF CLONIDINE AND FENTANYL" (1979). Open Access Master's Theses. Paper 225.

https://digitalcommons.uri.edu/theses/225

This Thesis is brought to you for free and open access by DigitalCommons@URI. It has been accepted for inclusion in Open Access Master's Theses by an authorized administrator of DigitalCommons@URI. For more information, please contact digitalcommons-group@uri.edu. 


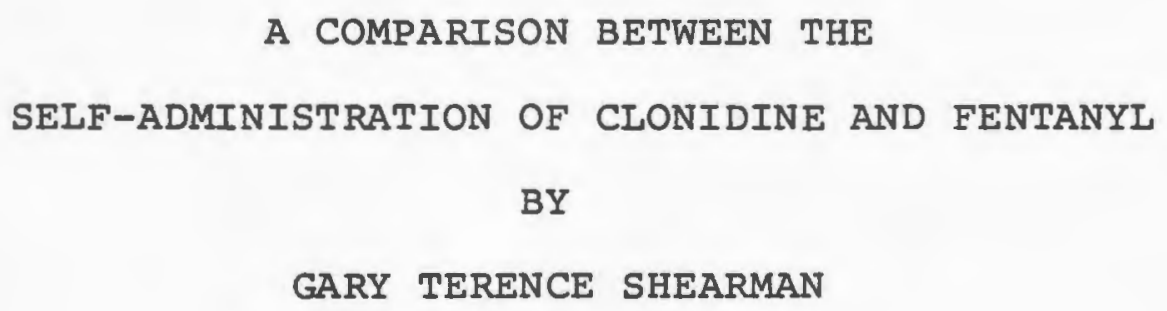

A COMPARISON BETWEEN THE SELF-ADMINISTRATION OF CLONIDINE AND FENTANYL BY

GARY TERENCE SHEARMAN

A THESIS SUBMITTED IN PARTIAL FULFILLMENT OF THE REQUIREMENTS FOR THE DEGREE OF MASTER OF SCIENCE IN PHARMACOLOGY AND TOXICOLOGY 


\section{MASTER OF SCIENCE THESIS \\ OF}

GARY TERENCE SHEARMAN

Approved:

Thesis Committee Major Professor

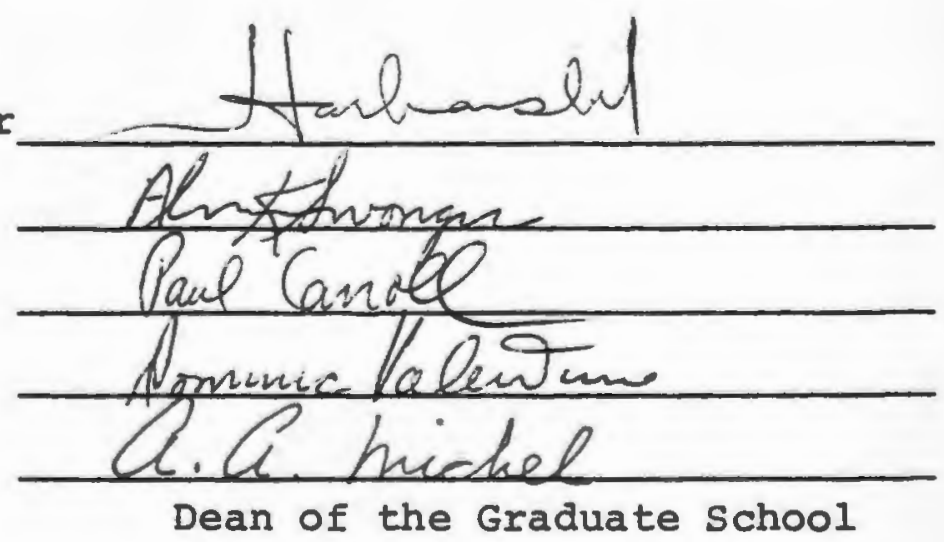

UNIVERSITY OF RHODE ISLAND 
ABSTRACT

Intravenous self-administration of drugs by experimental animals has importance as a laboratory model for the study of drug abuse and for the investigation of the neurochemical mechanisms underlying the reinforcing properties of drugs. Utilizing the drug self-administration technique, pharmacological investigations of the neurochemical basis of drug reinforcement suggest that opiate reinforcement is mediated through activation of central noradrenergic systems, whereas the reinforcing effects of psychomotor stimulants are mediated via activation of dopaminergic systems. The major purpose of the present study was to determine if the alpha noradrenergic receptor agonist, clonidine, would be self-administered by rats and furthermore to determine if clonidine is self-administered for its positive reinforcing effects. The latter was investigated by increasing the response requirement to obtain each clonidine injection. In view of the opiate-like effects of clonidine, the ability of clonidine to maintain self-administration behavior in rats self-administering the synthetic narcotic fentanyl was investigated. Also, the effect of response-contingent naloxone injections on clonidine-reinforced responding were compared with. their effect on fentanyl-reinforced responding. Since stimulation of the noradrenergic system is suggested to be involved in mediating the reinforcing effects 
of opiates, preliminary experiments compared the characteristics of clonidine-reinforced responding with the characteristics of fentanyl-reinforced responding by independently adding selected butyrophenones to the clonidine and fentanyl solutions. Under pentobarbital anesthesia male hooded rats of the Long-Evans strain were implanted with chronic indwelling jugular catheters and allowed to self-administer either clonidine (15 ug/ $\mathrm{kg} /$ injection), fentanyl $(0.1$ and 1.0 $\mathrm{ug} / \mathrm{Kg} /$ injection) or saline on a continuous reinforcement schedule. The drug solutions were delivered, in a constant volume of $100 \mathrm{ul} / \mathrm{Kg}$, into the vein in less than one second. Subjects readily acquired the self-administration of clonidine and fentanyl ( $1 \mathrm{ug} / \mathrm{Kg} /$ injection) but not fentanyl $(0.1 \mathrm{ug} / \mathrm{Kg} /$ injection) nor saline. Stable rates of clonidine and fentanyl-reinforced responding were attained after 3 or 5 days, respectively. When the fixed ratio (FR) requirement to obtain each clonidine injection was increased from $I$ to 3, a significant increase in lever pressing was observed; however, total daily clonidine intake decreased significantly. When the FR requirement was further increased from 3 to 10 , response rate increased so that total daily clonidine intake at the FR-3 and FR-10 schedules of clonidine reinforcement remained the same. Substitution of clonidine ( $15 \mathrm{ug} / \mathrm{Kg} /$ injection but not clonidine ( $\mathrm{ug} / \mathrm{kg} / \mathrm{injection)}$ nor saline maintained self-administration behavior in rats previously self-administering fentanyl. Extinction of self-administration 
behavior was observed following the substitution of both clonidine ( $1 \mathrm{ug} / \mathrm{Kg} /$ injection) and saline for the fentanyl solution. Addition of naloxone (64 ug/ $\mathrm{kg} / \mathrm{injection}$ ) to the clonidine and fentanyl solutions significantly decreased fentanyl-reinforced responding but appeared to have no effect on clonidine-reinforced responding. Fentanyl reinforced responding returned to pre-naloxone rates following the removal of naloxone from the fentanyl solution. Addition of either haloperidol or azaperone to the clonidine and fentanyl solutions, so that the subjects received $64 \mathrm{ug} / \mathrm{Kg} /$ injection, tended to decrease the rates of self-administration of rats previously self-administering either clonidine or fentanyl alone. Removal of haloperidol and azaperone from the clonidine and fentanyl solutions tended to result in a return to pre-haloperidol and pre-azaperone response rates. Addition of aceperone (64 ug/ $\mathrm{kg} /$ injection) produced no significant change in the rate of clonidine-reinforced responding but resulted in a significant increase in the rate of fentanyl-reinforced responding. Self-administration of clonidine by rats suggests that stimulation of central alpha-noradrenergic receptors results in positive reinforcement. Clonidine's self-administration by rats and its ability to maintain self-administration behavior in rats previously self-administering fentanyl suggests this drug may have abuse potential. Preliminary experiments suggest some similarities between clonidine- and fentanyl-reinforced 
responding; however, the exact nature of these similarities remain to be determined. The reinforcing effects of clonidine, unlike the reinforcing effects of fentanyl, seem to be mediated by opioid independent mechanisms. 


\section{ACKNOWLEDGEMENTS}

It gives me great pleasure to dedicate this thesis to my parents whose constant encouragement sparked the motivational forces needed for its completion. I am grateful for the understanding, guidance and emotional support provided by Drs. Harbans Lal, Paul Carrol, Alvin Swonger and Domenic Valentino when most needed. 
CIONIDINE: ITS ACTIONS ON CENTRAL NEURO-

A. Clonidine and the Central Noradrenergic System . . . . . . . . . . . . . . .

B. Clonidine and the Central Serotoninergic system. . . . . . . . . . . . . .

C. Clonidine and the Central Dopaminergic system. . . . . . . . . . . . . .

D. Clonidine and other Central Transmitter Systems . . . . . . . . . . . . . 15 PSYCHOPHARMACOLOGICAL ACTIONS OF CLONIDINE. . . 16

A. Motor Behavior. . . . . . . . . . 16

B. Operant Behavior. . . . . . . . . . 23

c. Aggressive Behavior . . . . . . . . 31

D. Drug Self-Administration. . . . . . . 35

E. Drug Discrimination . . . . . . . . 36

F. Learning and Memory . . . . . . . . 37

G. Arousal Mechanisms. . . . . . . . 38

H. Analgesia. . . . . . . . . . . . 4 41

I. Antiwithdrawal. . . . . . . . . . 49

J. Food and Water Consumption. . . . . . . 51 
PAGE

K. Body Temperature. . . . . . . . . 53

ᄂ. Conclusion . . . . . . . . . 57

METHODS . . . . . . . . . . . . . 58

subjects. . . . . . . . . .... 58

Surgical procedure. . ............. 58

Apparatus . . . . . . . . . . . . . 60

Drugs ................... 61

Experimental Design............ 61

A. Fentanyl Self-Administration. . . . . . 62

B. Clonidine Self-Administration ....... 64

RESULTS . . . . . . . . . . . . 66

Acquisition of Fentanyl Self-Administration . . . 66

Acquisition of Clonidine Self-Administration. . . 66

Effect of Increasing the Fixed Ratio Requirement on Lever Pressing to Obtain Clonidine

Injections ........... 70

Effect of Substituting Clonidine and Saline on Self-Administration Rates in Rats Previously Self-Administering Fentanyl .........

Effect of Adding Naloxone to the Clonidine and Fentanyl Solutions for Self-Administration of the Drug Mixture...............

Effect of Adding Haloperidol to the Clonidine and Fentanyl Solutions for Self-Administration of the Drug Mixture ..............

Effect of Adding Aceperone to the Clonidine and Fentanyl Solutions for Self-Administration of the Drug Mixture ..............

Effect of Adding Azaperone to the Clonidine and Fentanyl Solutions for Self-Administration of the Drug Mixture

DISCUSSION. . . . . . . . . . . . . .

Acquisition of Fentanyl Self-Administration . . 82

Acquisition of Clonidine Self-Administration. . 85

Effect of Increasing Fixed-Ratio Requirement on Clonidine Self-Administration Behavior . . 89

Effect of Substituting Clonidine and Saline on

Self-Administration Behavior in Rats Previously Self-Administering Fentanyl . . . . . . 92

Effect of Adding Naloxone to Clonidine and

Fentanyl Solutions for Self-Administration

of the Drug Mixture ............ 
Effect of Adding Some Butyrophenone to the Clonidine and Fentanyl Solution for Self-Administration of the Drug Mixture. . . . . . . . . 100

1. Haloperidol . . . . . . . . . . . . 100

2. Aceperone .. . . . . . . . . . . . 104

3. Azaperone .................. . . . . . . . . 8

SUMMARY AND CONCLUSIONS . . . . . . . . . . . . . . 111 REFERENCES . . . . . . . . . . . . . . . . . . . . . . . . . 


\section{LIST OF TABLES}

TABLE

PAGE

1 Effect of Increasing the Fixed Ratio (FR)

Requirement on the Total Daily Clonidine Intake of One Rat. . . . . . . . . . . . . .

2 Effect of Adding Naloxone to the Clonidine and Fentanyl Solutions for Self-Administration of the Drug Mixture . . . . . . . . . . . .

3 Effect of Adding Haloperidol to the clonidine and Fentanyl Solutions for Self-Administration of the Drug Mixture. . . . . . . . . . .

4 Effect of Adding Aceperone to the Clonidine and Fentanyl Solutions for Self-Administration of the Drug Mixture. . . . . . . . . . . .

Effect of Adding Azaperone to the Clonidine and Fentanyl Solutions for Self-Administration 5 of the Drug Mixture. . . . . . . . . . . 


\section{LIST OF FIGURES}

FIGURE

PAGE

1 Acquisition of fentanyl self-administration in drug-naive rats. . . . . . . . . . .

2 Acquisition of self-administration behavior upon substitution . . . . . . . . . . .

3 Acquisition of clonidine self-administration in drug-naive rats. . . . . . . . . . .

4 Effect of increasing the fixed ratio (FR) requirement on the rate of clonidine selfadministration in one rat.........

5 Effect of substituting clonidine and saline on rate of self-administration. . . . . . . 


\section{INTRODUCTION}

Intravenous self-administration of drugs by experimental animals has importance as both a laboratory model for experimental addiction and for the study of the neurochemical mechanisms underlying the reinforcing property of drugs. Utilizing the drug self-administration technique it has been established that drugs of several pharmacological classes which are abused by humans for their positive reinforcing effects are also self-administered by experimental animals (Seiden and Dykstra, 1977). The exact nature of the reinforcing effects of drugs is unclear but several investigations have suggested that catecholaminergic brain mechanisms are involved in mediating the positive reinforcing effects of opiates and psychomotor stimulants (Pickens et al., 1968; Davis and Smith, 1972, 1973a, 1973b, 1974, 1975; Pozuello and Kerr, 1972; Glick

et al., 1973; Baxter et al., 1974; Davis et al., 1975; Yokel and Wise, 1975, 1976; Wilson and Schuster, 1972, 1974). Early experiments demonstrated that the catecholamine synthesis inhibitor, alpha-methyl-para-tyrosine, blocked the primary reinforcing action of morphine and psychomotor stimulant drugs (Pickens et al., 1968; Davis and Smith, 1972, 1973; Pozuello and Kerr, 1972; Glick et al., 1973). It was also reported that alpha-methyl-para-tyrosine prevented the establishment of conditioned reinforcement based 
on the primary reinforcing properties of morphine and d-amphetamine suggesting that the effect of alpha-methylpara-tyrosine was not due to a non-specific motor deficit (Davis and Smith, 1973a, 1973b). In addition, Jonsson et al., (1969, 1971) reported that alpha-methyl-para- tyrosine blocked those subjective effects of d-amphetamine in man which are considered related to its positive reinforcing effects. Furthermore, Wilson and Schuster (1972) demonstrated that the catecholamine receptor blocker, chlorpromazine, antagonized the positive reinforcing effects of cocaine and other psychomotor stimulant compounds in rats.

Based on the above reports it was suggested that stimulation of catecholaminergic mechanisms of the brain underlie the positive reinforcing properties of opiates and psychomotor stimulants. However, because brain levels of both dopamine and norepinephrine are depleted by alphamethyl-para-tyrosine and both dopaminergic and noradrenergic receptors are blocked by chlorpromazine, the exact role (for each catecholamine in mediating the positive reinforcing effects of opiates and psychomotor stimulants remained unclear.

Investigations attempting to differentiate between dopaminergic and noradrenergic mechanisms utilized drugs which selectively depleted brain norepinephrine but not dopamine (Davis and Smith, 1974; Davis et al., 1975) are selectively blocked dopaminergic but not noradrenergic receptors (or vice versa) (Smith and Davis, 1973; Davis and 
Smith, 1974, 1975; Yokel and Wise, 1975, 1976). Utilizing the dopamine beta hydroxylase inhibitors, diethyldithiocarbamate (DDC) and U-14,624, to selectively deplete brain norepinephrine, Davis and Smith (1974) and Davis et al. (1975) reported that $D D C$ and $U-14,624$ inhibited the primary reinforcing action of morphine while U-14,624 inhibited the primary reinforcing action of d-amphetamine. Furthermore, DDC or U-14,624 pretreatment prevented the establishment of a conditioned reinforcer based on primary reinforcement associated with morphine and d-amphetamine injections (Davis and Smith, 1974; Davis et al., 1975).

These data suggested that the reinforcing properties of morphine and d-amphetamine are mediated by noradrenergic and not dopaminergic brain mechanisms. However, while other studies provided further support that noradrenergic mechanisms and not dopaminergic mechanisms are important in mediating the reinforcing effects of morphine (Davis and Smith, 1973, 1974, 1975) it appeared that dopaminergic and not noradrenergic systems are important in mediating the reinforcing effects of d-amphetamine (Davis and Smith, 1975; Yokel and Wise, 1975, 1976).

Smith and Davis $(1973,1974)$ concluded that prevention of reacquisition of morphine-reinforced responding by the dopamine receptor blocking agent haloperidol was due to a motor deficit produced by this drug and was not due to its ability to block the reinforcing effects produced by morphine 
self-administration. This conclusion was supported by the finding that haloperidol did not block the establishment of a morphine-based conditioned reinforcer (Smith and Davis, 1973, 1974). Therefore based on this evidence and the study of Davis et al. (1975) the reinforcing property of morphine seems to depend on noradrenergic and not dopaminergic mechanism in the brain.

On the other hand, Davis and Smith (1975) reported that haloperidol blocked the primary reinforcing effects of d-amphetamine and prevented the establishment of a conditioned reinforcer based on d-amphetamine as a primary reinforcer. These data suggested that haloperidol can block the

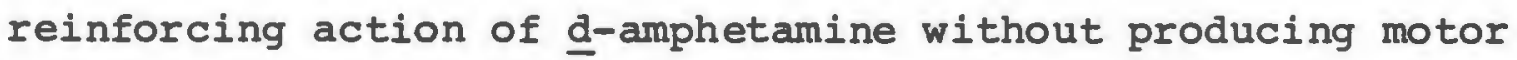
deficits. Similarly, Yokel and wise $(1975,1976)$ reported that the dopamine receptor blockers pimozide and $(+)$-butaclamol blocked the reinforcing effects produced by d-amphetamine self-administration in rats. In a clinical study, Gunne et al. (1972) reported that pimozide reduced amphetamine euphoria in humans.

Additional support for a role of dopamine but not norepinephrine in the reinforcing action of psychomotor stimulants was provided by Wilson and Schuster (1974) who demonstrated that the alpha-noradrenergic receptor blocker, phentolamine, had no effect on cocaine self-administration. Furthermore, Yokel and Wise $(1975,1976)$ demonstrated that the alpha-noradrenergic receptor blocker phenoxybenzamine had no effect on d-amphetamine self-administration while 
decreased rates of d-amphetamine self-administration produced by phentolamine and the beta-adrenergic receptor blocker propranolol were due to actions other than reward attenuation. Thus several studies suggest that dopamine is an important mediator of the reinforcing effects of psychomotor stimulants. That direct stimulation of dopamine receptors can result in positive reinforcement was demonstrated by the finding that rats will self-administer the dopamine receptor agonist apomorphine (Baxter et al., 1974).

In conclusion the reinforcing property of opiates appear to depend on noradrenergic mechanisms (Smith and Davis, 1973, 1974, 1975; Davis et al., 1975) whereas the reinforcing actions of psychomotor stimulants appear to depend on dopaminergic mechanisms (Davis and Smith, 1975; Yokel and Wise, 1975, 1976). Furthermore, self-administration of the dopamine receptor agonist apomorphine demonstrates that stimulation of central dopamine receptors results in positive reinforcement (Baxter et al., 1974).

The major purpose of the present experiment was to investigate if rats will self-administer the alpha-noradrenergic receptor agonist (Anden et al., 1970), clonidine, It was hypothesized that clonidine would be self-administered by rats since it had been previously reported (Smith and Davis, 1975) that the reinforcing properties of opiates are mediated through activation of noradrenergic mechanisms 
in the brain. It was also of interest to determine if clonidine was self-administered for its positive reinforcing effects and not because of the drug's direct behavioral effects. This was accomplished by increasing the response requirement to obtain each clonidine injection. Selfadministration rates to obtain morphine (Weeks, 1962) and psychomotor stimulants (Pickens, 1968; Pickens and Harris, 1968; Pickens and Thompson, 1968; Goldberg et al., 1971c) increase as the response requirement to obtain these drugs is increased, therefore, it was hypothesized that if clonidine was self-administered for its positive reinforcing effects self-administration rates to obtain clonidine injections would increase as the response requirement to obtain clonidine injections was increased.

Fentanyl is a synthetic narcotic which is known to be self-administered by rats (Lal et al., 1977). Since the noradrenergic system seems to be involved in mediating narcotic reinforcement (Davis and Smith, 1973, 1974, 1975), preliminary experiments compared the characteristics of fentanyl-reinforced responding with the characteristics of clonidine-reinforced responding. For this purpose three different butyrophenone neuroleptics with differential potencies versus dopaminergic and noradrenergic receptors were added to the clonidine and fentanyl solutions for selfadministration of the drug mixture. The effect of the butyrophenones on clonidine-reinforced responding were compared to their effect on fentanyl-reinforced responding. 
The butyrophenones were added to the clonidine and fentanyl solutions for self-administration of the drug mixture since the effect of intraperitoneal administration of these drugs was already known. Furthermore, this procedure may have potential for the treatment of drug abuse since concomitant administration of an antagonist with the reinforcing agonist should result in extinction of the drug-seeking behavior. Because butyrophenone' heuroleptics decrease 'noradrenergic transmission and narcotic reinforcement depends on activation of noradrenergic mechanisms, it was hypothesized that addition of the butyrophenones to the clonidine and fentanyl solutions would result in decreased rates of clonidine- and fentanyl-reinforced responding.

Finally, it has been demonstrated that clonidine and opiates have similar actions on noradrenergic neurons (Redmond, 1977) and produce similar pharmacological effects such as inhibition of narcotic withdrawal (Tseng et al., 1975; Vetulani and Bednarczyk, 1977; Fielding et al., 1977, in press; Gold et al., 1978) and analgesia (Paalzow, 1974; Paalzow and Paalzow, 1976; Schmitt et al., 1974; Sewell and Spencer, 1975; Fielding et al., 1977, in press; Bentley et al., 1977). In view of these similarities the ability of clonidine to maintain fentanyl-reinforced responding was investigated by substituting clonidine for the fentanyl solution. It was hypothesized that clonidine would maintain the previously established self-administration behavior. 
All actions of narcotics, including their positive reinforcing action (Goldberg et al., 1972) and their ability to impart secondary reinforcing properties on previously neutral stimuli (Davis and Smith, 1974a; Marcus et al.. 1976), are antagonized by the narcotic antagonist naloxone. In contrast, however, the pharmacological actions of clonidine which are similar to those produced by narcotics are not antagonized by naloxone suggesting that these actions of clonidine occur through opioid independent mechanisms (Paalzow and Paalzow, 1976; Fielding et al., 1977, in press; Meyer et al., 1977; Washton et al., 1978). A preliminary experiment was performed to determine the effect of adding naloxone to the clonidine and fentanyl solutions for selfadministration of the drug mixture. The effect of naloxone on clonidine-reinforced responding was compared to its effect on fentanyl-reinforced responding to determine if clonidine reinforcement is mediated via opioid dependent mechanisms. It was hypothesized that naloxone would decrease fentanyl- but not clonidine-reinforced responding. 
CLONIDINE: ITS ACTIONS ON CENTRAL NEUROTRANSMITTER SYSTEMS

A. Clonidine and the Central Noradrenergic System

Clonidine (2-[2,6-dichlorophenylamino-2-imidazoline hydrochloride) is a very potent antihypertensive drug (Nickerson and Ruedy, 1975) which can stimulate peripheral alpha-adrenergic receptors (Boissier et al., 1968; Constantine and McShane, 1968). However, the antihypertensive action of clonidine appears to be mediated by alphaadrenergic stimulatory activity at alpha-adrenergic receptors within the medulla oblongata (Kobinger and Walland, 1967; Schmitt and Schmitt, 1970; Van Zwieten, 1975) which are inhibitory to sympathetic nerve stimulation, thereby reducing sympathetic outflow from the vasomotor center of the medulla.

Studies on the central noradrenergic system show that clonidine reduces the turnover rate of norepinephrine in whole brain (Anden et al., 1970) and some of its regions (Rochette et al., 1974) as measured by a slowing of the disappearance of this amine following synthesis inhibition with the tyrosine hydroxylase inhibitor, alpha-methyl-paratyrosine. This effect was counteracted by pretreatment with the alpha-noradrenergic receptor blocking agents haloperidol and phenoxybenzamine (Anden et al., 1970), thus suggesting a post-synaptic noradrenergic receptor stimulating action of clonidine. 
Clonidine has also been found to reduce the rate of formation of norepinephrine from labelled tyrosine (Rochette et al., 1974) and lower brain levels of the major norepinephrine metabolite 3-methoxy-4-hydroxy-phenylglycol (MOPEG) (Braestrup, 1974).

Whole brain levels of norepinephrine are not changed by low ( 30 or $400 \mathrm{ug} / \mathrm{Kg}$ ) doses of clonidine (Anden et al... 1970). However, higher doses $(0.5-2.5 \mathrm{mg} / \mathrm{kg})$ produce a significant increase in norepinephrine levels in all brain regions except the striatum (Laverty and Taylor, 1969). Radioisotope studies indicated an increase in norepinephrine storage without significant changes in metabolism.

clonidine was found to diminish the stimulation-evoked tritum overflow from rat cerebral cortical slices preincubated with tritrated noradrenaline (Farnebo and Hamberger, 1971; Starke and Montel, 1973) and abolish the increase in tritium overflow produced by phenoxybenzamine and phentolamine (Farnebo and Hamberger, 1971; Starke and Montel, 1973) but not cocaine (Starke and Montel, 1973). Since phenoxybenzamine and phentolamine block alpha-noradrenergic receptors while cocaine primarily blocks the reuptake of norepinephrine it was conlcuded that clonidine stimulates alphareceptors.

Although the latter experiments and those of Anden et al. $(1970,1976)$ suggest that clonidine stimulates central post-synaptic alpha-noradrenergic receptors, some postsynaptic alpha-noradrenergic receptors appear to be inhibited 
by the drug. While clonidine has no significant effect on basal levels of cyclic $3^{\prime}, 5^{\prime}$ adenosine monophosphate in incubated slices of rat cerebral cortex (Skolnick and Daly, 1975a) it antagonized the norepinephrine elicited accumulation of cyclic AMP to a degree which corresponds to the alpha adrenergic component of the norepinephrine response. Clonidine also completely blocked the increase in cyclic AMP produced by methoxamine (Skolnick and Daly, 1975b), an alpha adrenergic agonist. However, clonidine did not attenuate the accumulation of cyclic AMP elicited by maximal concentrations of the beta adrenergic agonist, isoproteronol, and markedly potentiated the effects of submaximal concentration of this agent (Skolnick and Daly, 1975a). The locus of clonidine's action appears to be post-synaptic since destruction of pre-synaptic noradrenergic terminals with 6-hydroxydopamine had no effect on the norepinephrine and isoproteronol induced accumulation of cyclic AMP (Skolnick and Daly, 1976). Furthermore, the results of Skolnick and Daly (1975a) suggest that clonidine may sensitize the beta-adrenergic receptor.

In addition to its action on central post-synaptic noradrenergic receptors, clonidine also stimulates presynaptic noradrenergic receptors. Svensson et al. (1975) demonstrated that clonidine, administered intravenously or applied microiontophoretically, inhibited the spontaneous firing of brain norepinephrine containing neurons (Dahlstrom and Fuxe, 1965) in the locus coeruleus. These findings 
suggest that neurons in the locus coerileus possess presynaptic alpha-adrenergic receptors located on or near their soma and that activation of these receptor sites by clonidine may be responsible for its ability to inhibit the activity of these noradrenergic neurons. Further support for a presynaptic noradrenergic receptor stimulation by clonidine was provided by Cedarbaum and Aghajanian (1976) who found that the presynaptic alpha-noradrenergic receptor blocker (Cubeddu et al., 1974), piperoxane, blocked the clonidine-induced inhibition of firing of locus coeruleus neurons.

\section{B. Clonidine and the Central Serotoninergic System}

Clonidine has been found to affect the central serotoninergic system. The majority of evidence indicates that clonidine's effect on this system is indirect and probably occurs via central noradrenergic neurons. However, a direct action of clonidine on the central serotoninergic system cannot be ruled out.

Anden et al. (1970) found that clonidine reduced the turnover rate of serotonin as measured by a slowing of the disappearance of this amine in rat brain after synthesis inhibition with the tryptophan hydroxylase inhibitior alphapropylacetaminde. This effect was counteracted by pretreatment with the noradrenergic receptor blocking agents phenoxybenzamine and haloperidol suggesting that noradrenergic receptor stimulation directly or indirectly inhibits the 
activity of serotonin neurons. Similar reductions in the turnover of serotonin in whole brain and some of its regions were observed by Scheel-Kruger and Hasselager (1974) and Rochette and Bralet (1975).

Although clonidine does not affect whole brain levels of serotonin in rats and mice (Anden et al., 1970; Maj et al., 1973) it markedly elevates the serotonin content of the pons plus medulla (Maj et al., 1973), a region rich in serotonin neurons (Dahlstrom and Fuxe, 1965). Furthermore, decreased whole brain levels of serotonin produced by L-dopa were prevented by clonidine (Maj et al., 1973).

Apomorphine and L-dopa induced elevation of brain concentrations of the serotonin metabolite, 5-hydroxyindoleacetic acid (5-HIAA) was antagonized by clonidine although clonidine by itself did not affect 5-HIAA levels (Maj et al., 1973). However, when measured at a different time following clonidine administration Scheel-Kruger and Hasselager (1974) reported that clonidine produced a significant decrease in the concentration of 5-HIAA. These findings suggest that clonidine may inhibit the release of serotonin. Following blockade of central noradrenergic receptors by haloperidol or phenoxybenazamine, Anden et al. (1970) found that clonidine did not produce effects on spinal reflexes similar to those observed after treatment with 5-hydroxytryptophan indicating that clonidine has no direct stimulating action on cerebral serotonin receptors like ISD (Anden et al., 1968). 
Utilizing single cell recording techniques, svensson et al. (1975) investigated the effect of clonidine on the firing rate of serotonin neurons. When administered intravenously clonidine inhibited the firing rate of a great majority of serotonin neurons in the midbrain dorsal raphe nucleus. However, this action did not seem to be a direct one since clonidine had relatively weak or variable effects when applied microiontophoretically to raphe neurons. These findings suggest that clonidine-induced depression of raphe firing may be secondary to an impairment in noradrenergic transmission as prior destruction of noradrenergic neurons by 6-hydroxydopamine rendered the raphe neurons insensitive to the depressant effect of intravenous clonidine. Also much higher doses of clonidine, which have been reported to have post-synaptic receptor activity (Anden et al., 1970), reversed the depression produced by a low dose of clonidine itself.

\section{Clonidine and the Central Dopaminergic System}

The effect of clonidine on the central dopaminergic system is not well documented, however, investigations studying this interaction demonstrate in general that clonidine has no effect on the central dopaminrgic system.

Anden et al. (1970) measured the effect of clonidine on the turnover rate of dopamine in rat brain as measured by disappearance of this amine following synthesis inhibition with the tyrosine hydroxylase inhibitior alpha-methyl-para- 
tyrosine and found that clonidine had little or no effect. It was also demonstrated that clonidine did not change levels of dopamine in whole brain.

Treatment with reserpine plus the dopamine precursor I-dopa, produces turning to the operated side in rats with a unilateral lesion of the corpus striatum (Anden et al., 1966). However, no turning to the operated side was observed in rats with one intact corpus striatum after treatment with reserpine plus clonidine, indicating that clonidine has no stimulating effect on central dopamine receptors (Anden et al.., 1970).

Clonidine had no effect on dopaminergic neuronal firing when applied microiontophoretically to dopaminergic neuronal soma in the substantia nigra (zona compacta) and adjacent medial ventral tegmentum; however, apomorphine inhibited dopaminergic neuronal firing (Aghajanian and Bunney, 1977). These findings also suggest a lack of dopaminergic receptor stimulation by clonidine.

\section{Clonidine and Other Central Transmitter Systems}

Recent evidence suggests that clonidine may have effects on other central neurotransmitter systems.

Maj et al. (1975) reported that atropine and scopolamine block clonidine-induced decreases in locomotor activity of rats, indicating a possible cholinergic mechanism of action. It was also found that clonidine increased the acetylcholine concentration in rats' striatum but did not 
influence its content in cortex, hypothalamus, thalamus, pons or medulla oblangata (Maj et al., 1975).

The possible involvement of central histamine $\mathrm{H}_{2}-$ receptors in mediating the hypotensive effect of clonidine has recently been demonstrated (Karppanen, 1976). Furthermore, it was found that histamine, clonidine or norepinephrine decreased the firing rate of cerebral cortical neurons, when applied microiontophoretically (Sastry and Phyllis, 1977). Metiamide, an $\mathrm{H}_{2}$-histamine receptor antagonist, reversed the depressant effects of clonidine and histamine but not norepinephrine. These results suggest that clonidine can activate histamine $\mathrm{H}_{2}$-receptors on central neurons.

\section{PSYCHOPHARMACOLOGICAI ACTIONS OF CLONIDINE}

A. Motor Behavior

1. Rotorod Test

Rotorod performance is measured by the ability of an animal to stay on a revolving drum or cylinder over a period of time. Clonidine $(1.0 \mathrm{mg} / \mathrm{Kg}$, i.p.) reduced rotorod performance in rats (Laverty and Taylor, 1969) and mice $\left(E D_{50} 0.24 \mathrm{mg} / \mathrm{Kg}\right.$, s.c.) (Cornfeldt et al., 1978).

2. Open Field and Hole Test

In the open field and hole test, clonidine 10.1 $\mathrm{mg} / \mathrm{Kg}$ ) was reported to potentiate the depressant effect on rats behavior produced by intracerebroventricular administration of 6-hydroxy-dopamine (Herman et al., 1976). 


\section{Locomotor Activity}

Locomotor activity has been suggested to be controlled by both the dopaminergic and noradrenergic system within the brain (Anden et al., 1976). Locomotor activity in laboratory animals is often measured by the number of times the subject interrupts a light beam in a photocell chamber (Seiden and Dykstra, 1977). Each time the light beam is interrupted a count is recorded and thus the number of counts varies proportionately with the subject's locomotor activity.

When measured in the above manner, clonidine $(0.05-$ $25.0 \mathrm{mg} / \mathrm{Kg}$ ) has been reported to produce a dose-dependent decrease in the locomotor activity of mice and rats (Maj et al., 1972, 1975; Tilson et al., 1977) in spite of marked sympathomimetic signs (Maj et al., 1972).

While clonidine $(1-25 \mathrm{mg} / \mathrm{Kg})$ potentiated the decrease in locomotor activity in mice produced by pretreatment with the neuroleptic, spiroperidol (Maj et al., 1972), it did not influence the depression of locomotor activity produced by pretreatment with reserpine (Anden et al., 1970a, 1973, 1976; Maj et al., 1972; Menon et al., 1977), alpha-methylpara-tyrosine (Anden et al., 1972; Maj et al., 1972), FLA63 or phenoxybenzamine (Maj et al., 1972) despite marked sympathomimetic signs. However, clonidine $(1-25 \mathrm{mg} / \mathrm{Kg}) \mathrm{po-}$ tentiated the partial reversal of locomotor activity produced by apomorphine in mice pretreated with reserpine (Anden et al., 1970a, 1973, 1976; Jenner and Pycock, 1976; 
Maj et al.., 1972; Menon et al.., 1977), alpha-methyl-paratyrosine (Anden et al., 1970a, Maj et al., 1972) and FLA-63 (Maj et al., 1972) at doses which do not interfere with the metabolism of apomorphine (Anden et al., 1973). Furthermore, increased locomotor activity induced by the dopamine receptor stimulant metatyrosine (Anden et al., 1973) or ISD (Menon et al., 1977) in reserpine treated mice was enhanced by clonidine $(1.0 \mathrm{mg} / \mathrm{Kg}, \mathrm{i} . \mathrm{p}$.$) pretreatment. Clonidine$ ( 5 and $25 \mathrm{mg} / \mathrm{Kg}$ ) did not potentiate the antagonism of phenoxybenzamine induced decrease in locomotor activity produced by apomorphine, but resulted in a decreased effect of apomorphine (Maj et al., 1972). The potentiation by clonidine of the apomorphine-induced locomotor stimulation in reserpinetreated mice was almost completely blocked by phenoxybenzamine $(20 \mathrm{mg} / \mathrm{kg})$, partially antagonized by tolazoline (50 $\mathrm{mg} / \mathrm{Kg}$ ) and not significantly affected by yohimbine ( 3 and $10 \mathrm{mg} / \mathrm{Kg}$ ) (Anden et al., 1976).

Locomotor activity decreased by clonidine in mice and rats was antagonized by atropine and scopolamine (Maj et al., 1975). The peripheral cholinolytics atropine methyl nitrate and scopolamine butyl bromide were ineffective in mice and partly effective in rats in antagonizing the clonidineinduced decrease in locomotor activity (Maj et al., 1975). In conclusion, these studies demonstrate that clonidine produces a dose-dependent decrease in the locomotor activity of both mice and rats. However, clonidine may potentiate 
the increased locomotor activity produced by other drugs under certain pharmacological conditions. Results of studies investigating the mechanism by which clonidine affects locomotor activity suggest the involvement of cholinergic (Maj et al., 1975) and noradrenergic (Anden et al., 1976) mechanisms. These studies also strengthen the suggestion of Maj et al., 1972 that stimulation of both dopaminergic and noradrenergic systems are required for maximal 1ocomotor activity.

\section{Circling}

Circling or rotational behavior in rats with unilateral lesions of the nigrostriatal pathway is considered to be a dopamine dependent behavior. This consideration is based upon the finding that administration of drugs which increase dopaminergic activity in the central nervous system after the lesion produce rotational behavior (Ungerstedt et al., 1969).

Using a rotometer which measures the number of full turns the subject makes per unit time, Satoh et al., 1976 reported that, in rats with unilateral 6-hydroxydopamineinduced lesions of the substania nigra, intraventricular injection of apomorphine, dopamine and norepinephrine at doses of 64 ug induced turning of the rats towards the intact side whereas intraventricular injection of methamphetamine (250 ug) induced turning towards the lesioned side. on the other hand, intraventricular injection of clonidine (64 ug) did not induce any turning. It was suggested by 
Satoh et al. that dopamine, norepinephrine and apomorphine directly stimulate the supersensitive dopamine receptors on the side of the lesion whereas methamphetamine indirectly stimulates dopamine receptors on the intact side. Since clonidine is considered to be an alpha-noradrenergic agonist (Anden et al., 1970), norepinephrine-induced turning was considered to be due to a non-specific stimulation of dopamine receptors.

Direct injection of clonidine (100 ug) into one striatum of rats with intact nigrostriatal systems did not produce circling, nor did this pretreatment result in circling following the subcutaneous administration of the dopamine agonist apomorphine $(0.5 \mathrm{mg} / \mathrm{Kg}$ ) (Jenner and Pycock, 1976). However, circling behavior induced by either apomorphine $(0.25 \mathrm{mg} / \mathrm{Kg}$, s.c.) or d-amphetamine ( $3 \mathrm{mg} / \mathrm{Kg}, \mathrm{i} . \mathrm{p}$.$) in mice$ with unilateral lesions of the nigriostriatal pathway was potentiated by pretreatment with clonidine $(0.06-2.0 \mathrm{mg} / \mathrm{Kg}$, i.p.) (Jenner and Pycock, 1976; Pycock et al., 1977). In contrast to this latter finding, Cornfeldt et al., 1978 reported that clonidine ( $\left.E D_{50} 0.08 \mathrm{mg} / \mathrm{Kg}, \mathrm{i.p.}\right)$ blocked amphetamine- but not apomorphine-induced circling in rats with striatal lesions.

Unilateral electrolytic destruction of the locus coeruleus in rats results in spontaneous ipsilateral turning behavior which is soon replaced by contralateral turning (Pycock et al., 1975). One week after locus coeruleus lesioning, when spontaneous turning has stopped, intraperi- 
toneal administration of the dopamine agonists apomorphine, d-amphetamine and piribedil but not the noradrenergic agonist, clonidine $(0.05-0.5 \mathrm{mg} / \mathrm{Kg})$ elicited contralateral circling (Donaldson et al., 1977). It was suggested by Donaldson et al., that circling behavior seen after unilateral locus coeruleus lesions was the result of supersensitive striatal dopamine receptors in the nigrostriatal pathway on the side of the lesion.

The results of the above studies investigating the effect of clonidine on rotational behavior suggest that clonidine does not stimulate dopamine receptors and provides further evidence that rotational behavior depends on dopaminergic and not noradrenergic mechanisms. However, it appears rotational behavior induced by dopaminergic agonists may be modified by clonidine (Jenner and Pycock, 1976; Pycock et al., 1977).

\section{Stereotypy}

Stereotypic behavior consists of the repeated spontaneous occurrence of motor responses which are within the animal's normal behavior such as licking, sniffing, gnawing and head bobbing (Seiden and Dykstra, 1977). Stereotypic behavior is believed to be the result of heightened dopaminergic activity in the corpus striatum (Seiden and Dykstra, 1977). Both direct and indirect dopaminergic agonists such as apomorphine and d-amphetamine, elicit stereotypic behavior (Seiden and Dykstra, 1977). 
Intraperitoneal administration of clonidine $(0.5 \mathrm{mg} / \mathrm{Kg})$ did not affect the stereotyped behavior induced by apomorphine $(0.1-5.0 \mathrm{mg} / \mathrm{Kg}$, s.c.) in rats (Jenner and Pycock, 1976; Pycock et al., 1977) suggesting that clonidine does not stimulate striatal dopamine receptors.

\section{Catalepsy}

Catalepsy is generally defined as the condition of an animal when it is amenable to being positioned in awkward positions by an experimenter and where these postures are maintained until altered by the experimenter (Rech and Moore, 1971). Catalepsy may be caused by decreased dopaminergic activity within the nigrostriatal system (Seiden and Dykstra, 1977). Neuroleptic drugs, such as haloperidol, which decrease dopaminergic activity induce catalepsy (Rech and Moore, 1971).

Clonidine $(0.5 \mathrm{mg} / \mathrm{kg}, \mathrm{i} . \mathrm{p}$.$) has been reported to poten-$ tiate the cataleptic action of haloperidol $(0.1-2.0 \mathrm{mg} / \mathrm{Kg}$, i.p.) in rats; however, this action is probably non-specific and is the result of clonidine's sedative effect (Jenner and Pycock, 1976; Pycock et al., 1977).

\section{Tremor-like Motor Dysfunctions (wet-shakes)}

"Wet dog shakes" in rats have been suggested to be due to heat gain mechanisms (Wei et al., 1974). Clonidine has been reported to inhibit the "wet dog shakes" produced in rats by immersion in ice-cold water (Wei, 1975) or by administration of the drug AG-3-5[1-(2-hydroxyphenyl)-4- 
(3-nitropheny 1)-1, 2, 3,6 tetrahydropyrimidine-2-one] (Wei,

1976). Jahn and Mixich (1976) reported that clonidine (0.01-0.1 mg/Kg, s.c.) produced a dose-dependent reduction of "wet dog shakes" produced by the benzylideneaminooxycarbonic acid derivative sgd 8473 . The ability of clonidine to reduce "wet dog shakes" may be non-specific since several other drugs including narcotics, narcotic antagonists, psychosedatives, cocaine, dl-amphetamine and apomorphine were also effective in this regard (Jahn and Mixich, 1976).

\section{B. Operant Behavior}

1. Schedule Control

Clonidine $(0.006-.3 \mathrm{mg} / \mathrm{Kg})$ produced a dose-dependent suppression of operant behavior maintained by fixedratio (Colelli et al., 1976), fixed-interval (Harris et al.., 1977) and differential reinforcement of low rates (Tilson et al., 1977) schedules of food-reinforced responding.

When chronically administered, tolerance to the behavioral depressant effect of clonidine on food-reinforced responding was evident after 5 days and was complete by 2 weeks (Meyer et al., 1977). Abrupt termination of clonidine treatment in tolerant rats resulted in an abstinence reaction characterized by suppression of operant behavior for as long as one week (Meyer et al., 1977).

clonidine antagonized the disruption of fixed-ratio operant behavior produced by naloxone injection in morphinedependent rats (Colelli et al.., 1976). 
Whereas the rate decreasing effect of apomorphine under a fixed-interval schedule of food reinforcement was potentiated by naloxone, the effect of clonidine was unaltered (Harris et al., 1977). At doses capable of suppressing operant behavior in morphine-dependent rats (Gellert and Sparber, 1977), naloxone failed to disrupt operant behavior in clonidine tolerant rats (Meyer et al., 1977).

Suppression of fixed-ratio food-reinforced operant behavior in rats produced by depletion of brain catecholamines with alpha-methyl-para-tyrosine or tetrabenzaine was not antagonized by apomorphine or clonidine; however, L-dopa reversed the suppression produced by alpha-methyl-paratyrosine but not tetrabenazine (Ahlenius et al., 1971).

In rats trained to respond on a fixed-interval schedule of water-reinforced responding, Glick and Cox (1976) reported that both apomorphine $(0.25-10.0 \mathrm{mg} / \mathrm{Kg})$ and clonidine $(0.002-0.1 \mathrm{mg} / \mathrm{Kg})$ produced a dose-dependent suppression of responding. Following frontal cortical lesions the sensitivity to apomorphine but not clonidine was increased (Glick and Cox, 1976).

Intraventricular administration of 1-norepinephrine (10 ug), but not clonidine $(0.5 \mathrm{ug})$, restored the doserelated decrease in the rate of substania nigra self-stimulation produced by norepinephrine synthesis inhibition with diethyldithiocarbamate (Belluzi et al., 1975).

In summary, these findings indicate that clonidine produces a suppression of operant behavior maintained by 
different schedules of food reinforced responding and by a fixed-interval schedule of water-reinforced responding. Because clonidine also reduces food intake (Le Douarec et al., 1972), water intake (Le Douarec, 1971) and locomotor activity (Tilson et al., 1977) in rats it cannot be stated with certainty whether clonidine suppresses operant behavior for food and water reinforcement because of its anorexic and adipsic effect or its sedative effect. Since a reduction in operant behavior is observed following a reduction in noradrenergic transmission (Belluzi et al., 1975) the suppressant effect of clonidine on operant behavior may be related to its stimulatory action at pre-synaptic alpha-adrenergic receptors, thus reducing noradrenergic transmission. This is supported by the finding that norepinephrine but not clonidine (Belluzi et al., 1975) will restore operant behavior suppressed by norepinephrine, synthesis inhibition. Finally, the suppressant action of clonidine on operant responding appears to be independent of an action on endogenous opioid mechanisms since naloxone fails to alter the effect of clonidine (Harris et al., 1977; Gellert and Sparber, 1977).

\section{Conditioned Avoidance Response}

In the conditioned avoidance response (CAR) paradigm animals are trained to avoid an aversive stimulus by responding during a stimulus which precedes the delivery of the aversive stimulus (Seiden and Dykstra, 1977). Animals thus 
trained become conditioned to avoid the aversive stimulus by responding during the pre-aversive stimulus signal. If the subject responds during the aversive stimulus it is considered to have escaped the aversive stimulus. Both dopamine and norpinephrine are considered to be involved in the mediation of an avoidance response (for review see Seiden and Dykstra, 1977). Neuroleptic drugs selectively disrupt avoidance responding at doses which do not disrupt escape (for review see Seiden and Dykstra, 1977).

Laverty and Taylor (1969) reported that intraperitoneal administration of clonidine $(0.1-1.0 \mathrm{mg} / \mathrm{Kg})$, in rats trained to climb a pole to avoid a shock, produced a dosedependent inhibition of conditioned avoidance behavior. This may be a non-specific effect, however, and may be the result of sedation since these doses have been reported to decrease locomotor activity (Maj et al., 1972, 1975; Tilson et al., 1977).

Depletion of brain catecholamines by 6-hydroxydopamine has been demonstrated to interfere with the maintenance and acquisition of avoidance responding (for review see seiden and Dykstra, 1977). Suppression of a previously learned conditioned avoidance response in rats produced by intraventricular administration of 6-hydroxydopamine was reported to be reversed by intraventricular administration of norepinephrine, dopamine, L-dopa or by intraperitoneal administration of amphetamine, phenylzine, desipramine, apomorphine and clonidine (Ruiz and Monti, 1975; Lenard and Beer, 1975). 
Pretreatment with the neuroleptic, spiroperidol, prevented the recovery produced by the above drugs, however, clonidineinduced recovery was least affected (Lenard and Beer, 1975).

The above studies demonstrate an effect of clonidine on conditioned avoidance responding and support the suggestion for the involvement of both dopaminergic and noradrenergic systems in its mediation.

\section{Brain Self-Stimulation}

It is well established that laboratory animals will lever press to obtain electrical stimulation when electrodes are placed in various brain areas. Investigations of the neurochemical mechanisms underlying the reinforcing property of intracranial self-stimulation(ICSS) suggest the possible involvement of both dopaminergic and noradrenergic systems (for review see Seiden and Dykstra, 1977). However, it has recently been reported that a stronger case can be made for the involvement of dopaminergic mechanisms (for review see Fibiger, 1978).

Utilizing a shuttle-box technique that provides a rate-independent index of the rewarding and aversivecomponents of ICSS, Hunt et al. (1976) reported that intraperitoneal administration of clonidine $(.004-.063 \mathrm{mg} / \mathrm{kg})$ produced a dose-dependent increase in the latency to initiate lateral hypothalamic ICSS, whereas the latency to escape ICSS was largely unaffected except at doses which caused depression of performance. The peripheral alpha-adrenergic 
agonist 1-phenylephrine $(0.05-1.0 \mathrm{mg} / \mathrm{Kg})$ was ineffective in this regard indicating that inhibition of reward by clonidine was a central effect (Hunt et al., 1976). Clonidine acted in a synergistic manner with the catecholamine synthesis inhibitor, alpha-methyl-para-tyrosine $(250 \mathrm{mg} / \mathrm{Kg})$ to greatly increase $(>5008)$ the initiate latency magnitude and prolong the duration of inhibition of reward while leaving the escape latency magnitude largely unaffected (Hunt et al., 1976). Whereas administration of clonidine (0.016-0.064 $\mathrm{mg} / \mathrm{Kg}$ ) or alpha-methyl-para-tyrosine alone 24 hours before testing had no effect, when given together they produced a complete elimination of the initiate behavior while escape behavior remained unaffected (Hunt et al., 1976).

High rates of lateral hypothalamic ICSS in squirrel monkeys were blocked by clonidine $(0.1 \mathrm{mg} / \mathrm{Kg})$, whereas in the same animal caudate ICSS was much less affected at this dose (Spencer and Revzin, 1976). A higher dose of clonidine $(0.25 \mathrm{mg} / \mathrm{Kg})$ which produced sedation depressed ICSS equally well at both sites (Spencer and Revzin, 1976). In contrast, amphetamine $(10 \mathrm{mg} / \mathrm{Kg})$ and chlorpromazine $(0.5$ or $1.0 \mathrm{mg} / \mathrm{Kg}$ ) had significantly more effect on caudate ICSS than lateral hypothalamic ICSS (Spencer and Revzin, 1976).

Depression of lateral hypothalamic ICSS produced by clonidine $(0.15 \mathrm{mg} / \mathrm{Kg})$ was antagonized by doses of piperoxane $(1.7-15.0 \mathrm{mg} / \mathrm{Kg})$ which selectively block pre-synaptic alpha adrenergic or adrenaline-receptors while a higher dose of piperoxane $(45 \mathrm{mg} / \mathrm{Kg})$, phentolamine $(0.55-15.0 \mathrm{mg} / \mathrm{Kg})$ and 
phenoxybenzamine $(0.1-10.0 \mathrm{mg} / \mathrm{Kg})$ which block both pre- and post-synaptic receptors were ineffective (Franklin and Herberg, 1977).

At doses not producing motor deficits, Vetulani et al. (1977) reported that intraperitoneal administration of clonidine $(0.05-.20 \mathrm{mg} / \mathrm{Kg})$ in rats produced a dose-dependent depression of medial forebrain bundle ICSS. Furthermore, clonidine $(0.10 \mathrm{mg} / \mathrm{Kg})$ blocked the facilitation of medial forebrain bundle ICSS produced by d-amphetamine $(0.5 \mathrm{mg} / \mathrm{Kg})$ (Vetulani et al., 1977). Since d-amphetamine has been reported to release norepinephrine it was suggested that clonidine's blockade of medial forebrain bundle ICSS was the result of its stimulatory action at pre-synaptic alphanoradrenergic receptors or its blockade of post-synaptic noradrenergic receptors (Vetulani et al., 1977).

Based on the results of the above experiments demonstrating a depression of ICSS by clonidine it is not surprising that inhibition of substania nigra ICSS in rats produced by the norepinephrine synthesis inhibitors, diethyldithiocarbamate (Belluzi et al., 1975) or inhibition of lateral hypothalamic ICSS by the norepinephrine synthesis inhibitor, disulfiram (Shaw and Rolls, 1976) was not restored by clonidine (0.5-3 ug, i.v.t. or $0.037-3 \mathrm{mg} / \mathrm{kg}, \mathrm{i} . \mathrm{p}$.$) .$

In conclusion these findings suggest that clonidine attenuates the rewarding component of ICSS. Furthermore, this action appears to be mediated through its stimulatory action at central pre-synaptic alpha-noradrenergic receptors 
thus decreasing noradrenergic transmission (Hunt et al., 1976; Franklin and Herberg, 1977; Vetulani et al., 1977). This suggestion is supported by other investigations (Wise et al., 1973; Hastings and Stutz, 1943; Franklin and Herberg, 1974; German and Bowden, 1974; Belluzi et al., 1975; Shaw and Rolls, 1976), which demonstrate that reduced noradrenergic transmission inhibits self-stimulation. It must be noted, however, that although inhibition of ICSS is reported at doses which do not produce motor deficits the same doses are reported to decrease locomotor activity when measured in an activity chamber (Tilson et al., 1977).

\section{Conflict-induced Suppression}

The Geller conflict procedure consists of a punishment component and a non-punished component (Seiden and Dykstra, 1977). During the punishment component of this procedure, punishment (usually an electric grid shock) is superimposed on behavior (usually lever pressing for food reward) whereas during the non-punished component no punishment is superimposed. Behavior is usually reduced during the punished component. Anxiolytic drugs increase behavior which has been suppressed by punishment (for review see Seiden and Dykstra, 1977), and therefore the Geller conflict procedure is widely used as a screening test for possible anxiolytic agents.

Bullock et al. (1978), reported that intraperitoneal administration of clonidine $(0.025-0.10 \mathrm{mg} / \mathrm{Kg})$ in rats 
produced a significant increase in responding during the punishment component of the Geller conflict procedure while responding during the non-punished component was relatively unaffected except at the highest dose $(0.1 \mathrm{mg} / \mathrm{Kg})$ where sedation was observed. These data suggest a possible anxiolytic action of clonidine.

\section{Aggressive Behavior}

It has been suggested that central catecholamines and serotonin are involved in the mediation of aggressive behavior (for review see Seiden and Dykstra, 1977). Ozawa et al. (1975) reported that clonidine $(40 \mathrm{mg} / \mathrm{Kg})$ induced aggressive behavior in mice without altering the levels of brain serotonin, norepinephrine or dopamine. In contrast, however, Razzak et al., 1977 reported that a large dose of clonidine, which induced automutilation in mice, markedly increased brain norepinephrine; slightly increased brain dopamine levels and did not change cerebral serotonin levels. The results of these studies suggest further investigation of the effect of clonidine on cerebral neurotransmitter levels and their turnover in relationship to aggression induced by this drug.

Morpurgo (1968) first reported that intraperitoneal administration of high doses (10 and $50 \mathrm{mg} / \mathrm{Kg}$ ) of clonidine induced aggression (biting attacks) in mice but not rats nor rabbits. This behavior was also produced when clonidine was administered orally, intravenously or subcutaneously. 
Intracerebral injection of a 0.58 solution of clonidine immediately elicited biting attacks (Morpurgo, 1968).

other imidazoline derivatives (naphazoline, oxymetazoline), with similar peripheral sympathomimetic effects as clonidine did not induce biting even when administered intracerebrally (Morpurgo, 1968). This is particularly interesting in view of the finding that the imidazoline derivatives, including naphazoline and oxymetazoline, which do not cross the blood-brain barrier produce analgesia when administered intracerebroventricularly (schmitt et al., $1974)$.

Pretreatment with neuroleptic drugs (e.g. haloperidol $\mathrm{ED}_{50} 1.6 \mathrm{mg} / \mathrm{Kg}$ ) inhibited the occurrence of clonidine-induced biting attacks. However, pretreatment with the alphaadrenergic blocking agent, phentolamine, or the anti-cholinergic drug, atropine, were ineffective in preventing the occurrence of aggressive behavior (Morpurgo, 1968). Since the sympathomimetic effects of clonidine were still evident following neuroleptic pretreatment, the findings of Morpurgo (1968) suggested that clonidine-induced aggression in mice is independent of its alpha-adrenergic action.

In contrast, however, ozawa et al. (1975) reported that aggressive behavior in mice induced by intraperitoneal administration of clonidine $(40 \mathrm{mg} / \mathrm{Kg})$ was markedly inhibited by intraperitoneal pretreatment with the alpha-blocking agent phenoxybenzamine $(20 \mathrm{mg} / \mathrm{Kg})$. Similarly, Razzak et al. (1977) reported that automutilation induced by a large dose of clonidine was inhibited by reserpine, alpha-methyl-para- 
tyrosine, phenoxybenzamine, phentolamine or chlorpromazine pretreatment.

Pretreatment with amytriptyline, PCPA, L-dopa, 5-HTP or glycine had no effect on the clonidine-induced aggression and self-mutilation (Ozawa et al., 1975; Stern and Catovic, 1975; Razzak et al., 1977).

Aggression and automutilation induced by clonidine was reported to be potentiated by disulfarim, lithium chloride (Ozawa et al., 1975); nalorphine, mephenesin (Stern and Catovic, 1975); methamphetamine, caffeine and theophylline (Razzak et al., 1977).

These results suggest therefore, that central noradrenergic mechanisms are involved in the mediation of aggression and automutilation induced by clonidine.

In rats aggression can be induced by sufficiently high doses of the dopaminergic agonist, apomorphine (McKenzie, 1971) or by termination of chronic narcotic administration (Lal, 1975). It has been suggested that both of these forms of aggression are due to hyperstimulation of dopaminergic neurons in the central nervous system (Lal, 1975; Lal et al., 1975). Clonidine by itself at doses of 0.25 and $0.5 \mathrm{mg} / \mathrm{Kg}$ administration subcutaneously did not produce aggression in drug-naive rats; however it dose-dependently (0.0625-0.25 $\mathrm{mg} / \mathrm{Kg}$ ) enhanced aggression produced by a sub-threshold (for aggression) dose $(2.5 \mathrm{mg} / \mathrm{Kg})$ of apomorphine and enhanced aggression when administered to 72 hour morphine-withdrawn rats (Gianutsos et al., 1976). 
It has also been reported that irritability and violent aggressive behavior occurs in rats following chronic treatment..with clonidine (Laverty and Taylor, 1969) and that rats become irritable and aggressive while receiving clonidine $(5 \mathrm{ug} / \mathrm{ml}$ ) in their drinking water (Dix and Johnson, 1977).

While all of the previously cited studies suggest that clonidine may act to promote aggressive behavior in mice and rats, Laverty and Taylor (1969) reported that subcutaneous administration of clonidine $(0.2-1.0 \mathrm{mg} / \mathrm{Kg})$ produced a dose dependent inhibition of pain-induced aggressive behavior produced by application of electric shocks to the grid floor of a cage in which a pair of rats were placed and Cornfeldt et al. (1978) reported that clonidine $\left(E D_{50}\right.$ $3.8 \mathrm{mg} / \mathrm{kg}$ p.o.) inhibited foot-shock induced aggression in mice. However, clonidine is known to produce analgesia (see Analgesia section) as measured by an increase in the threshold for vocalization (Paalzow, 1974; Schmitt et al., 1974) and vocalization after discharge (Paalzow, 1974; Paalzow and Paalzow, 1976) following electrical stimulation of the rat's tail, and several other procedures. Therefore, clonidine-induced inhibition of pain-induced fighting (produced by electrical shock application to the grid floor) may be the result of its analgesic action and not the result of its ability to modulate aggressive behavior.

In conclusion it has been demonstrated that clonidine may promote, inhibit or have no effect on aggressive behavior. 
Clonidine's action on aggressive behavior appears to depend on several factors including species, dose, treatment regimen (acute vs. chronic) and method of inducing aggression. Aggressive behavior produced by clonidine appears to be dependent on both dopaminergic and noradrenergic brain mechanisms.

\section{Drug Self-Administration}

Drugs of several pharmacological classes are selfadministered for their positive reinforcing properties (for review see Seiden and Dykstra, 1977). Investigations of the neurochemical basis of reinforcement resulting from the self-administration of narcotics (Davis and Smith, 1972, 1973a; Glick et al., 1973) and psychomotor stimulants (Davis and Smith, 1972, 1973b) have implicated the involvement of central catecholaminergic systems (for review see seiden and Dykstra, 1977). Attempts to differentiate between noradrenergic and dopaminergic mechanism suggest the involvement of noradrenergic mechanisms in opiate reinforcement (Davis et al., 1975) while both dopaminergic and noradrenergic mechanisms appear to be involved in psychomotor stimulant reinforcement (Davis et al., 1975; Davis and Smith, 1975).

Davis and Smith (1977) reported that clonidine (15 but not $1 \mathrm{ug} / \mathrm{Kg} /$ injection) was self-administered by rats when this drug was made contingent on lever pressing. It was suggested that the reinforcing action of clonidine was the result of its stimulatory action at post-synaptic 
alpha-noradrenergic receptors since intraperitoneal pretreatment with the alpha-blocking agent phenoxybenzamine (15 $\mathrm{mg} / \mathrm{Kg}$ ) prevented the reinforcement associated with clonidine administration (Davis and Smith, 1977). Furthermore, intraperitoneal pretreatment with phenoxybenzamine $(15 \mathrm{mg} / \mathrm{Kg}$ ) but not haloperidol $(5 \mathrm{mg} / \mathrm{Kg})$ prevented the establishment of a stimulus paired with injections of clonidine as a conditioned reinforcer (Davis and Smith, 1977). These results suggest that stimulation of alpha-noradrenergic receptors by clonidine results in positive reinforcement.

In rats self-administering the synthetic narcotic fentanyl (1 ug/ $\mathrm{kg}$ injection), Shearman et al. (1977) reported that substitution of clonidine ( 15 but not $1 \mathrm{ug} / \mathrm{Kg} /$ injection) for the fentanyl solution maintained selfadministration behavior. Since activation of noradrenergic systems is considered to be involved in the mediation of narcotic reinforcement (Davis, 1975), the maintenance of fentanyl-reinforced responding by clonidine may be the result of its ability to stimulate central noradrenergic receptors.

\section{E. Drug Discrimination}

It is now widely established that drugs of several pharmacological classes can function as discriminative stimuli (for review see Lal, 1977). Usually in these experiments laboratory animals are trained to emit one response when treated with a drug and an alternate response 
when treated with the drug vehicle, another dose of the same drug or a different drug. When acquisition of such response differentiation is reliably shown the drug is said to produce a discriminative stimulus that controls the differential responding in the trained subjects.

In rats trained to discriminate morphine (10 $\mathrm{mg} / \mathrm{Kg})$ from saline, Miksic et al. (in press) reported that intraperitoneal administration of clonidine $(0.08-0.64 \mathrm{mg} / \mathrm{Kg})$ produced saline lever selection. Since the discriminative stimulus produced by morphine is considered to be related to its subjective effect in man (Lal and Gianutsos, 1976; Lal et al., 1977), this data suggests that clonidine and morphine may produce dissimilar subjective effects. In view of the fact that clonidine produces analgesia (see Analgesia section) and reduces narcotic withdrawal symptoms in animals and humans (see Antiwithdrawal section), this data becomes particularly interesting for it suggests that clonidine may provide a non-narcotic treatment for opiate addiction.

\section{F. Learning and Memory}

While an important rolefor each of the central neurotransmitters in learning and memory processes has been postulated (for review see Seiden and Dykstra, 1977), the exact role of each remains unclear. Furthermore, studies measuring the effect of pharmacological agents on learning and memory processes must be interpreted with caution since 
factors unrelated to their effect on learning and memory (i.e., sedation, impairment of motor function) can affect the results.

Gazzani and Izqueirdo (1976) reported that post-trial intraperitoneal administration of clonidine $(0.1 \mathrm{mg} / \mathrm{Kg})$ or haloperidol $(0.5 \mathrm{mg} / \mathrm{Kg})$ to rats trained in a shuttle avoidance paradigm resulted in a lower retention of this task in a retest session carried out seven days later compared to animals which received a post-trial saline injection. This effect of clonidine was prevented by pretreatment with either phenoxybenzamine $(10 \mathrm{mg} / \mathrm{kg}$ ) or phentolamine $(10 \mathrm{mg} / \mathrm{Kg}$ ) whereas the effect of haloperidol was prevented by apomorphine ( $4 \mathrm{mg} / \mathrm{Kg}$; but not $0.5 \mathrm{mg} / \mathrm{Kg}$ ) pretreatment. These data suggest that clonidine may impair memory consolidation. In contrast to the above study, however, McEntee and Mair (1978) reported that administration of clonidine to Korsakoff syndrome patients (who had low CSF MHPG levels which correlated with memory impairment) resulted in a consistent improvement of memory function. Since clonidine is a presumed alpha-noradrenergic agonist in the central nervous system, improvement of memory by clonidine (McEntee and Mair, 1978), provides additional evidence for an important role of norepinephrine in learning and memory processes.

\section{G. Arousal Mechanisms}

Investigations of the neurochemical mechanisms underlying arousal processes suggest that involvement of both 
serotonin and catecholamines (for review see seiden and Dykstra, 1977) .

clonidine has been reported to produce sedation and sleep when administered via several routes to young chicks, rats, cats, rabbits and man (Zamis, 1970; Holman et al.. 1971; Florio et al., 1975; Marley and Nistico, 1975; Walland, 1977). Given intravenously clonidine-induced sleep is indistinguishable from normal sleep or that elicited by intravenous noradrenaline or adrenaline (Holman et al., 1971).

Behavioral depression and EEG synchronization induced by clonidine $(0.1 \mathrm{mg} / \mathrm{Kg})$ in rats, cats and rabbits were attenuated by pretreatment with the alpha-noradrenergic receptor blocking agents phentolamine (10 mg/Kg), tolazoline (10 $\mathrm{mg} / \mathrm{Kg}$ ) and yohimbine $(0.5 \mathrm{mg} / \mathrm{Kg}$ ) but not phenoxybenzamine (10 mg/Kg) (Florio et al., 1975). Similarly, Holman et al. (1971) and Delbarre and Schmitt (1971) noted that the sedative effect of clonidine was antagonized by phentolamine. Whereas pretreatment with the serotonin receptor antagonist methysergide or the serotonin synthesis inhibitor failed to prevent the sleep-inducing effect of clonidine, LSD pretreatment effectively prevented the sleep-producing effect of clonidine (Holman et al., 1971). Pretreatment with alpha-methyl-para-tyrosine ester (100 mg/kg, 3 days) or reserpine $(2 \mathrm{mg} / \mathrm{Kg})$ potentiated the clonidine $(0.1 \mathrm{mg} / \mathrm{Kg})$ induced sedation and EEG synchronization (Florio et al., 1975). 
Amphetamine ( 1 or $2 \mathrm{mg} / \mathrm{kg}$ ) reversed the behavioral depression and EEG synchronization produced by clonidine $(0.2 \mathrm{mg} / \mathrm{Kg}$ ) (Florio et al., 1975). Furthermore, clonidine abolished the behavioral activation and EEG desynchronization induced by amphetamine (Florio et al., 1975; Marley and Nistico, 1975) and methamphetamine (Gogolak and Stumpf, 1969); however, the EEG arousal produced by physostigmine was unaffected by clonidine (Gogolak and Stumpf, 1969). Clonidine also increased the threshold of the EEG-arousal reaction caused by reticular stimulation (Gogolak and Stumpf, 1969).

Behavioral and electrocortical sleep induced by intraventricular administration of clonidine $(5-15 \mathrm{ug})$ was easily interrupted by an arousing stimulus (Holman et al., 1971) and presentation of sensory stimuli during clonidine-induced sleep, induced behavioral and phasic electrocortical arousal (Marley and Nistico, 1975).

In conclusion, several studies have demonstrated a sedative or sleep-inducing action of clonidine. These investigations suggest that the sleep-inducing effect of clonidine occurs through a stimulatory action of this drug at central alpha-noradrenergic receptors (Florio et al., 1975; Marley and Nistico, 1975). It does not appear that the sleep-inducing action of clonidine depends on serotonergic transmission (Holman et al., 1971). 


\section{H. Analgesia}

Investigations of the neurochemical mechanisms underlying the perception of painful stimuli suggest the involvement of serotonin, and catecholamines and possibly other neurotransmitters (for review see Seiden and Dykstra, 1977). Furthermore, data suggests that serotonin and catecholamines are involved in the mediation of narcotic analgesia (for review see Seiden and Dykstra, 1977).

The antinociceptive activity of clonidine has been demonstrated in a variety of procedures believed to induce pain in laboratory animals including electrical stimulation of the tail; Charpentier's test (Paalzow, 1974; Paalzow and Paalzow, 1976; Schmitt et al., 1974), placing the animal on a hot $\left(56^{\circ} \mathrm{C}\right)$ plate; hot-plate test (Schmitt et al., 1974), immersion of the tail in hot $\left(55^{\circ} \mathrm{C}\right)$ water; tail withdrawal test (Sewell and Spencer, 1975; Fielding et al., 1977, in press), exposure of the tail to radiant heat; tail flick test (Fielding et al., 1977, 1978), application of pressure to an inflamed paw; Randall-Selitto test (Fielding et al., 1977, in press) and intraperitoneal injection of phenylp-benzoquinone (Fielding et al., 1977, in press), acetic acid or acetylcholine; writhing tests (Bentley et al., 1977). Furthermore, in all of the above procedures (except the tail withdrawal test in rats, Fielding et al., 1977, in press) clonidine was found to be more potent than morphine. 


\section{Charpentier's Test}

Paalzow (1974) measured the changes in the threshold for vocalization in mice and the threshold for motor response (spinal reflex), vocalization and vocalization after discharge in mice and rats produced by electrical stimulation of the tail. Subcutaneous administration of clonidine $(0.08-1.25 \mathrm{mg} / \mathrm{Kg})$ produced a dose-dependent increase (1005008 ) of the threshold for vocalization and vocalization after discharge in rats while the threshold for motor response was unaffected (Paalzow, 1974). The threshold for a motor response was raised 1008 at a dose of $10 \mathrm{mg} / \mathrm{Kg}$, however, this dose produced sedation and marked sympathometic signs (Paalzow, 1974). Clonidine also increased the threshold for vocalization in mice; however, the dose was higher $(2.5-10.0 \mathrm{mg} / \mathrm{Kg})$ than that required to produce a similar elevation in rats (Paalzow, 1974).

Chlorpromazine ( $5 \mathrm{mg} / \mathrm{kg}, \mathrm{s.c}$ ), atropine (1 mg/ $\mathrm{kg}$, s.c.) and p-chlorophenylalanine $(400 \mathrm{mg} / \mathrm{kg}, \mathrm{i.p.})$ pretreatment increased the antinociceptive activity of clonidine $(0.625 \mathrm{mg} / \mathrm{Kg}$, s.c.) at both the threshold for vocalization and vocalization after discharge while phenoxybenzamine (10 $\mathrm{mg} / \mathrm{Kg}$, i.p.) and reserpine (10 mg/Kg, i.p.) pretreatment increased the activity at the threshold for vocalization only leaving the threshold for vocalization after discharge unaffected (Paalzow and Paalzow, 1976). Yohimbine (2 $\mathrm{mg} / \mathrm{Kg}$, i.p.) pretreatment decreased the antinociceptive activity of clonidine at both thresholds while 5-hydroxy- 
tryptophan (50 mg/Kg, i.p.) and alpha-methyl-para-p-tyrosine $(250 \mathrm{mg} / \mathrm{Kg}$, i.p.) pretreatment decreased the effects at the threshold for vocalization after discharge only (Paalzow and Paalzow, 1976). Naloxone ( $8 \mathrm{mg} / \mathrm{kg}$, s.c.) pretreatment or concomitant LSD $(50 \mathrm{ug} / \mathrm{Kg}$, s.c.) did not alter the antinociceptive activity of clonidine at either pain response studied (Paalzow and Paalzow, 1976).

Schmitt et al. (1974) reported the effect of clonidine on four types of behavioral reactions to the electrical stimulation of the rat's tail: startle, flight, vocalization and biting of the electrodes. Intraperitoneal administration of clonidine $(0.5-3 \mathrm{mg} / \mathrm{Kg})$ produced a dose-dependent reduction on the startle, the cry and the biting of electrodes; however, clonidine was weakly effective on flight (Schmitt et al., 1974). Intraventricular administration of clonidine (30 ug) reduced the startle and the biting of electrodes but was less effective on the startle and on the flight (Schmitt et al., 1974). Intraventricular administration of clonidine was 5-7 times as potent as clonidine administered intraperitoneally (Schmitt et al., 1974).

2. Hot Plate Test

The hot plate test measures the ability of drugs to inhibit reflex responses of mice placed on a hot place maintained at a constant temperature between $55^{\circ}$ and $70^{\circ} \mathrm{C}$ (Seiden and Dykstra, 1977). A drug is said to produce analgesia when the reaction time to the heat is significantly 
increased. Schmitt et al. (1974) reported that intraperitoneal $(0.1$ and $1.0 \mathrm{mg} / \mathrm{Kg})$ and intraventricular $(.3-1 \mathrm{ug})$ administration of clonidine increased the reaction time to heat. The antinociceptive activity of clonidine in Charpentier's and the hot plate test appears to be mediated centrally, since other alpha-sympathomimetics of the imidazoline series (naphazoline, tetryzoline and oxymetazoline) which do not cross the blood-brain barrier possess antinociceptive action only when administered intracerebroventricularly (Schmitt et al., 1974).

\section{Tail Withdrawal Test}

The tail withdrawal test measures the ability of drugs to alter the amount of time required of mice or rats to withdraw their tail from hot water usually maintained at $55^{\circ} \mathrm{C}$. A drug is said to produce analgesia in this test if the time required for tail withdrawal is significantly increased.

Using the tail-withdrawal test in mice, Sewell and Spencer (1975) reported that subcutaneous administration of clonidine $(0.3 \mathrm{mg} / \mathrm{Kg})$ produced analgesia. However, when clonidine $(0.5 \mathrm{mg})$ was injected intracerebroventricularly it possessed only marginal antinociceptive activity and furthermore substantially reduced the analgesic action of morphine ( $3 \mathrm{mg} / \mathrm{Kg}, \mathrm{s.c.}$ ) when given concurrently (Sewell and Spencer, 1975). The antinociceptive activity of subcutaneously administered clonidine $(0.3 \mathrm{mg} / \mathrm{Kg})$ was significantly antagonized by concurrent intraventricular 
administration of phentolamine $(5 \mathrm{mg})$ while the antinociceptive activity of subcutaneously administered morphine ( $3 \mathrm{mg} / \mathrm{Kg}$ ) and pentazocine $(15 \mathrm{mg} / \mathrm{Kg}$ ) was significantly potentiated by intraventricular injection of phentolamine (10 ug) (Sewell and Spencer, 1975). Intraventricular administration of propranolol (10 ug) did not potentiate the antinociceptive activity of concurrent administration of subcutaneous doses of morphine $(2.5 \mathrm{mg} / \mathrm{Kg})$, pentazocine (15 mg/Kg) or clonidine $(0.3 \mathrm{mg} / \mathrm{Kg}$ ) (Sewell and Spencer, 1975).

Intraperitoneal administration of clonidine $(2.5$ and $10.0 \mathrm{mg} / \mathrm{Kg}$ ) in rats was effective in inhibiting tail-withdrawal from hot water (Fielding et al., 1977, in press). Naloxone $(5 \mathrm{mg} / \mathrm{Kg})$ did not antagonize the antinociceptive action of clonidine $(2.5 \mathrm{mg} / \mathrm{Kg}$ ) (Fielding et al., 1977 , in press).

\section{Tail Flick Test}

The tail flick test measures the ability of drugs to alter the time required of mice or rats to remove their tails from a radiant heat source. A drug is considered to produce analgesia in this test if the time required for removal of the tail from the heat is significantly increased. Subcutaneous administration of clonidine was reported to produce a dose-dependent $\left(E D_{50} 0.7 \mathrm{mg} / \mathrm{Kg}\right)$ inhibition of the tail flick response inmice (Fielding et al., 1977, 1978). The antinociceptive action of clonidine in this test was not 
antagonized by naloxone $(1.0 \mathrm{mg} / \mathrm{Kg}$ ) (Fielding et al., 1977 , 1978 ) or phenoxybenzamine $(10.0 \mathrm{mg} / \mathrm{Kg}$ ) (Fielding et al.. in press).

Subcutaneous administration of clonidine $(0.016 \mathrm{mg} / \mathrm{Kg})$ potentiated the analgesic activity of marphine in the tail flick test approximately 5-fold while morphine $(0.16 \mathrm{mg} / \mathrm{Kg})$ potentiated the antinociceptive action of clonidine 4-fold (Spaulding et al., 1978). Naloxone reversed the enhanced effect of clonidine by morphine (Spaulding et al., 1978). Tolerance to the antinociceptive action of clonidine in the tail-withdrawal and tail flick procedures was not observed (Fielding et al., 1977). Furthermore, cross-tolerance to the antinociceptive action of clonidine in morphinepelleted mice was not observed (Spaulding et al., 1978).

\section{Randall-Selitto Test}

The Randall-Selitto test measures the ability of drugs to alter the reaction to pressure applied to an inflamed paw by an "analgesia meter." A drug is considered to produce analgesia in this procedure when the amount of pressure required to induce a reaction is significantly increased.

In a modified version of the Randall-selitto test, Fielding et al. (1977, in press) reported that subcutaneous administration of clonidine $(0.125-1.0 \mathrm{mg} / \mathrm{Kg})$ produced a dose-dependent increase in the threshold to pain produced by pressure on an inflamed paw. 


\section{Writhing Tests}

Writhing tests measure the ability of drugs to alter writhing induced by other chemical agents. A drug is considered to produce analgesia in this test when the number of writhes induced by the chemical agent is significantly decreased.

Subcutaneous administration of clonidine $(0.0125-0.05$ $\mathrm{mg} / \mathrm{Kg}$ ) into mice produced a dose-dependent inhibition of writhing induced by phenyl-p-benzoquinone (Fielding et al., 1977, in press). The anti-writhing action of clonidine was not antagonized by naloxone $(1.0 \mathrm{mg} / \mathrm{kg}$ ) (Fielding et al., 1977, in press) or phenoxybenzamine (Fielding et al., 1977). Clonidine, oxymetazoline and 1-noradrenaline bitartarate were equi-effective in antagonizing the nociceptive action of acetic acid or acetylcholine when administered subcutaneously in mice while phenylephrine was ineffective (Bentley et al., 1977). Clonidine was the most potent antagonist (Bentley et al., 1977). Piperoxane ( 8 and 16 $\mathrm{mg} / \mathrm{Kg}$ ) antagonized the antinociceptive action of oxymetazoline and noradrenaline and partially antagonized the antinociceptive effect of clonidine while phentolamine (16 mg/ $\mathrm{kg}$ ) had no antagonistic effect on any of the three drugs (Bentley et al., 1977). Clonidine and oxymetazoline were more potent when administered intracisternally; however, their antinociceptive action when administered by this route was not antagonized by piperoxane (16 mg/ $\mathrm{kg}$ ) administered subcutaneously or $(50 \mathrm{ug} / \mathrm{Kg}$ ) intracisternally (Bentley et al. , 1977). 
In summary, these investigations demonstrate that clonidine produces a dose-dependent analgesia as measured by a variety of procedures considered to induce pain in laboratory animals. Clonidine-induced analgesia does not seem to be the result of an impairment of motor function since the threshold for a motor response (Paalzow, 1974) or flight reaction (Schmitt et al., 1974) is unaffected at doses which produce analgesia. The analgesic action of clonidine appears to be mediated centrally since other alpha-sympathomimetics of the imidazoline series which do not cross the blood-brain barrier possess antinociceptive activity only when administered intracerebroventricularly (Schmitt et al., 1974). However, the antinociceptive action of clonidine in writhing tests may be due to its stimulatory action on alpha-adrenoceptors located on sensory nerve endings in the peritoneum since other peripherally acting alpha-agonists are also antinocicpetive in these tests (Bentley et al., 1977). Depending on the dose, route of administration and species, it appears that clonidine may increase (Spaulding et al., 1978) or decrease (Sewell and Spencer, 1975) the analgesic action of morphine. However, unlike narcotics tolerance to the antinociceptive action of clonidine is not observed (Fielding et al., 1977) nor is cross-tolerance observed in morphine-dependent mice (Spaulding et al..' 1978). The lack of naloxone antagonism of the antinociceptive action of clonidine (Paalzow and Paalzow, 1976; Fielding et al., 1977, 1978) suggests that the analgesic 
action of clonidine is not mediated through an interaction with opiate receptors. Based on the results of studies investigating the effect of other drugs on clonidine-induced analgesia (Paalzow and Paalzow, 1976; Sewell and Spencer, 1975; Fielding et al., 1977, 1978; Bentley et al., 1977) it appears that several neurochemical systems may mediate the antinociceptive action of clonidine.

\section{Antiwithdrawal}

Recently, Redmond et al. (1976) and Redmond (1977) reported that the effects of electrical or pharmacological activation of the locus coeruleus in monkeys were strikingIy similar to those noted during opiate withdrawal. Thus it was suggested that the symptoms of opiate withdrawal were the result of excess noradrenergic activity within the locus coeruleus (Redmond, 1977).

Fielding et al. (1977; in press) reported that clonidine $(0.01-0.16 \mathrm{mg} / \mathrm{Kg})$ decreased morphine withdrawal wet shakes when intraperitoneally administered to morphinedependent rats during withdrawal produced by discontinuation of morphine administration. Similarly, Tseng et al. (1975) and Vetulani and Bednarczyk (1977) reported that clonidine (0.1-0.8 mg/ Kg) decreased wet shakes produced by administration of narcotic antagonists in morphine-dependent rats. Furthermore, clonidine ( $5 \mathrm{ug} / \mathrm{Kg}$ ) has been reported to eliminate opiate withdrawal signs in narcotic addicts undergoing voluntary detoxification (Gold et al., 1978; Washton, et al., 1978). 
The ability of clonidine to decrease narcotic withdrawal does not seem to be mediated through a drug action at opiate receptors. Naloxone did not antagonize the ability of clonidine to decrease wet shakes in rats (Fielding et al.. in press) nor did naloxone precipitate withdrawal in a clonidine-maintained opiate-free individual or block the decrease in opiate withdrawal symptoms in humans (Washton et al., 1978). Because opiate withdrawal symptoms have been suggested to be the result of excessive noradrenergic activity within the locus coeruleus (Redmond, 1977), the ability of clonidine to reduce opiate withdrawal symptoms may be the result of its stimulatory action at presynaptic alphanoradrenergic receptors of the locus coeruleus thus decreasing noradrenergic activity. This suggestion is supported by the finding that the opiate withdrawal-like symptoms produced by electrical or pharmacological activation of the locus coeruleus are blocked by clonidine (Redmond, 1977). Clonidine has also been reported to decrease the sweating, tremor and anxiety associated with alcohol withdrawal in humans (Bjorkqvist, 1975).

In conclusion, studies of the effect of clonidine in the treatment of narcotic and alcohol withdrawal suggest that clonidine may provide a non-opiate treatment for narcotic withdrawal (Washton et al., 1978) and may be useful in the treatment of other drug withdrawal states associated with anxiety and increased noradrenergic activity. 
J. Food and Water Consumption

Investigations of the neurochemical mechanisms underlying feeding and drinking behavior suggest that alphanoradrenergic mechanisms may elicit these behaviors (for review see Seiden and Dykstra, 1977). In dogs, clonidine increased food intake at low doses and reduced it at high doses (Le Douarec et al., 1972). In rats clonidine reduced food intake (Le Douarec et al., 1972). Piperoxane antagonized the inhibitory effect of clonidine on food intake in rats while yohimbine and phentolamine provided partial antagonism. However, many alpha-adrenergic receptor blockers such as tolazoline, dibenamine and phenoxybenzamine were ineffective as were beta-adrenergic receptor blockers (Le Douarec et al., 1972).

Intrahypothalamic injection of clonidine increased food intake in satiated rats (Le Douarec et al., 1972). Similarly, Holman et al. (1971) reported that following intraventricular administration of clonidine $(25-75 \mathrm{ug} / \mathrm{kg})$ in rats approximately one-third of the rats began eating continuously and sometimes periods of eating alternated with periods of sleep.

In an investigation of the effect of clonidine on behavior associated with food intake, Poignant and Rismondo (1975) reported that clonidine $(0.05-0.2 \mathrm{mg} / \mathrm{Kg})$ increased the take-up time of a standard alimentary material in hamsters without affecting the associted hoarding behavior. In contrast, amphetamine ( 1 and $2 \mathrm{mg} / \mathrm{Kg}$ ) modified both 
take-up time and hoarding behavior (Poignant and Rismondo, 1975).

Clonidine reduced water intake and induced diuresis in rats given the opportunity to drink water after 18 hours of water deprivation (Le Douarec et al., 1971). The reduction in water intake was antagonized by piperoxane, tolazoline and phentolamine; however, other alpha-adrenergic receptor blockers such as dibenamine and phenoxybenzamine were ineffective (Le Douarec et al., 1971). Beta-adrenergic blockers as well as the cholinergic drugs atropine and mecamyline were devoid of any antagonistic activity (Le Douarec et al. , 1971).

In conclusion, clonidine may increase or decrease food intake depending on the dose, species, route of administration and food deprivation state of the animal (Le Douarec et al., 1972). However, clonidine's effect on water intake seems to be solely inhibitory (Le Douarec et al., 1971). Feeding elicited by intrahypothalamic (especially the perifornical area) injection of norepinephrine in sated rats is blocked by the administration of alpha-noradrenergic receptor blockers (for review see Seiden and Dykstra, 1977), therefore clonidine's action to increase food intake in satiated rats may be the result of its stimulatory action at post-synaptic, alpha-receptors. However, because of the differential antagonism of the clonidine-induced decrease in food and water intake by alpha-adrenergic blocking agents, it appears that the receptors involved in mediating 
these inhibitory effects ofclonidine have some properties in common with classical alpha-adrenergic receptors but are different in some way (Le Douarec et al., 1971, 1972). Since intrahypothalamic administration of norepinephrine in sated monkeys is reported to elicit drinking (Myers, 1969), the clonidine-induced decrease in the water intake of water deprived rats may be related to a stimulatory action of clonidine at pre-synaptic alpha-adrenergic receptors, thus decreasing noradrenergic transmission. However, it may be that clonidine's action on water intake depends on the water deprivation state (i.e. sated or deprived) of the subject.

\section{R. Body Temperature}

Thermoregulation normally involves the integration of both behavioral and physiological mechanisms. Investigations of the role of central neurotransmitters in thermoregulation suggests the involvement of both catecholamines and serotonin (Stricker and Zigmond, 1976; Cooper et al., 1978).

Wendt and Caspers (1968) reported a suppression of sweating in man during heat exposure and exercise after oral administration of 75 and $150 \mathrm{ug}$ (about 1 and $2 \mathrm{ug} / \mathrm{Kg}$ ) clonidine, while Laverty and Taylor (1969) observed a fall in body temperature when clonidine $(0.1-2.5 \mathrm{mg} / \mathrm{Kg})$ was administered subcutaneously into rats. Similarly, TsoucarisKupfer and Schmitt (1972) found that subcutaneous or intraperitoneal administration of clonidine $(0.5-1.5 \mathrm{mg} / \mathrm{Kg})$ 
induced hypothermia in rats, the intensity and duration of which was dose-dependent. Intraventricular injection of clonidine (15 ug) (Tseng et al., 1975), but not (2-3 ug) (Tsoucaris-Kupfer and Schmitt, 1972) lowered body temperature in rats and produced a dose-dependent (0.02-0.2 umol) hypothermia in young chicks (Marley and Nistico, 1975). Intrahypothalamic administration of clonidine ( $3 \mathrm{ug}$ or 0.04 umol) is also reported to produce hypothermia (Tsoucaris-Kupfer and Schmitt, 1972; Marley and Nistico, 1975).

The hypothermia produced by the various routes of clonidine administration was antagonized by the alpha-blocking agents phentolamine, phenoxybenzamine, piperoxane, tolazoline and dibenamine (Tsoucaris-Kupfer and Schmitt, 1972; Reid et al., 1975; Marley and Nistico, 1975). Piperoxane was the most effective antagonist (Tsoucaris-Kupfer and Schmitt, 1972). The beta-adrenergic receptor antagonists, propranolol, pindolol and ko 1366 were also reported to be effective in decreasing the hypothermic effect of clonidine (Tsoucaris-Kupfer and Schmitt, 1972). However, Reid et al. (1975) and Marley and Nistico (1975) reported that propranolol did not alter the hypothermic action of clonidine. Similarly, Tsoucaris-Kupfer and Schmitt (19722), reported that atropine and haloperidol were effective in decreasing the hypothermic effect of clonidine while mecamyline and imipramine were ineffective. However, Maj et al. (1975) and Marley and Nistico (1975) reported that atropine did 
not affect clonidine-induced hypothermia and Reid et al. (1975) reported that the relatively selective dopamine receptors antagonist did not alter the hypothermic effect of clonidine. Furthermore, Marley and Nistico (1975) reported that haloperidol did not attenuate the hypothermic effect of clonidine. Other alpha-sympathomimetic imidazolines such as naphazoline, tetryzoline and oxymetazoline, which do not cross the blood-brain barrier (Walland, 1977); were also effective in producing hypothermia after peripheral administration (Tsoucaris-Kupfer and Schmitt, 1972). Furthermore, depletion of brain catecholamines by intracisternal administration of 6-OHDA failed to alter the hypothermic response to clonidine (Reid et al., 1975). Therefore, the hypothermic effect of clonidine may be due to an action at both central and peripheral sites.

Scheel-Rruger and Hasselager (1974) reported that the hypothermia induced by clonidine $(0.5 \mathrm{mg} / \mathrm{Kg})$ in rats could be antagonized by apomorphine $(2 \times 2.5 \mathrm{mg} / \mathrm{Kg})$. It was suggested that the hypothermic effect of clonidine was due to its action on serotonin turnover since apomorphine also produced a significant antagonism of the clonidine-induced decrease of 5-hydroxy-indole acetic acid levels, the time course of which correlated with its antagonism of clonidineinduced hypothermia (Scheel-Kruger and Hasselager, 1974). However, Marley and Nistico (1975) reported that intraventricular pretreatment with the serotonin receptor blocker, methysergide ( 0.1 umol) did not attenuate the hypothermic 
effect produced by intraventricular injection of clonidine (0.05-0.2 umol).

Finally, Tseng et al. (1975) reported that intraperitoneal $(0.1-0.4 \mathrm{mg} / \mathrm{Kg}$ ) or intraventricular (5 and $15 \mathrm{ug}$ ) administration of clonidine inhibited precipitated shakes and potentiated escape attempts induced by naloxone in morphine-dependent rats. These forms of morphine-withdrawal were previously suggested (Wei et al., 1974) to be related to heat gain and heat loss mechanisms, respectively.

In conclusion, these findings demonstrate that clonidine produces hypothermia via several routes of administration. Because of the antagonism of clonidine-induced hypothermia by alpha-adrenergic blocking agents it appears that the hypothermic action of clonidine is mediated by its stimulatory action at alpha-adrenergic receptors. This is supported by the finding that hypothermia induced by intraventricular administration of norepinephrine is antagonized by phentolamine (Burks, 1972). However, as suggested by Scheel-Rruger and Hasselager (1974) the hypothermic effect of clonidine may be secondary to its action on noradrenergic receptors and may be the result of the clonidine-induced decrease in serotonin turnover (Anden et al., 1970; ScheelKruger and Hasselager, 1974; Rochette and Bralet, 1975). Feldberg (1964) reported that intraventricular administration of serotonin produces hyperthermia, therefore it would follow that a reduction in serotonin turnover produced by clonidine would produce hypothermia. Finally, it cannot be 
stated with certainty whether or not the hypothermic action of clonidine occurs at central or peripheral alpha-adrenergic receptors or both, since other imidazoline sympathomimetics which do not cross the blood-brain barrier also produce hypothermia when administered peripherally.

\section{Conclusion}

In addition to its action on the noradrenergic system clonidine has also been reported to affect other central neurotransmitter systems. Similarly, in addition to its antihypertensive action, clonidine is reported to produce several other pharmacological effects. 
METHODS

\section{subjects}

The subjects were drug-naive male hooded rats of the Long-Evans strain (Charles River Breeding Laboratories, Wilmington, Mass.) weighing between 300-400 grams at the beginning of the investigation. Throughout the experiment the subjects were given continuous access to food and water. The animals were surgically prepared with chronic intravenous (jugular) catheters according to the method of Smith and Davis (1975) with the following modifications: 1) sodium pentobarbital was used as the anesthetic; 2) the cannula was constructed from PE 50 tubing; 3) nitrofurazone powder was not applied to muscle before suturing together.

\section{Surgical Procedure}

subjects were anesthetized with sodium pentobarbital $(50 \mathrm{mg} / \mathrm{Kg}$ ) administered intraperitoneally. On the ventral surface the fur was shaved from the upper chest and lower neck and on the dorsal surface from the back of the neck just behind the ears. Gauze soaked in a 958 ethanol solution was used to cleanse these areas. With the animals in a supine position a skin incision (approximately $2 \mathrm{~cm}$ in length), which extended from the upper chest toward the lower neck was made with a scalpel on the right side of 
the animal above the jugular vein. Utilizing blunt dissection technique the underlying chest muscles were separated until the right jugular vein was exposed. The vein was then isolated (using needlepoint tweezers) by carefully removing the fat and connective tissue surrounding it. A trocar was placed under the vein to keep it isolated. sterile surgical silk (Ethicon 000 Silk; Ethicon Inc., Somerville, N.J.) was tied in a loose knot around the vein as far caudad as possible. Using needlenose scissors, an incision was made halfway through the vein. A catheter (polyethylene 50 (PE50)) tubing; (Clay Adams, Parsipanny, N.J.) filled with physiological saline was inserted into the lumen of vein for $1 / 2$ " of its length. The silk was immediately tied tightly around the vein and cannula. Silk was tied a second time around the vein and cannula just cephalad to the first tie. Saline (approximately $.2 \mathrm{ml}$ ) was administered through the catheter into the vein to compensate for any blood loss and to check for leaks. The cannula was considered to be in the vein when blood could be withdrawn as the plunger was pulled back. Using hollow metal tubing, pointed at one end, the catheter was passed subcutaneously under the right forelimb and out through the shaved area on the dorsal surface of the neck. The catheter was further secured by tying it (with Ethicon 000 silk) to underlying muscle at two other points, thus forming a triangle with the first ties. Sterile surgical gut (Ethicon 5-0 Chromic) was used to suture the overlying 
muscle together. Finally, sterile srugical silk was used to close the skin incision. Combiotic ${ }^{R}(60,000$ units; Pfizer, New York, N.Y.) was injected intramuscularly into a hind leg to give protection against possible infection. Animals were subsequently placed in velcro harnesses so that a saddle was strapped behind their forelegs. The catheter was passed through the harness and through a protective metal coil attached to the harness. subjects were allowed 24 hours to recover from this surgical procedure before being placed in the self-administration apparatus.

\section{Apparatus}

The self-administration apparatus consisted of conventional plexiglass operant chambers $26 \times 20 \mathrm{~cm}$ and $26 \mathrm{~cm}$ high enclosed in lightproof, ventilated, sound-attenuating chambers. The outer chambers contained a houselight turned on between 8:00 A.M. and 8:00 P.M. A response lever $4 \mathrm{~cm}$ wide extended $3 \mathrm{~cm}$ into the operant chambers $3.5 \mathrm{~cm}$ above the floor in the center of the short wall. As the catheter emerged from the protective metal coil it passed through the roof of the operant chamber and through the roof of the outer chamber to where it was eventually connected to a pneumatic driven Hamilton Precision Iiquid Dispenser (PLD) syringe (Hamilton Co., Reno, Nevada) located on top of the outer chamber. Depression of the response lever (weight required 15 grams) activated the PLD syringe to deliver a constant volume (100 ul/ Kg) of a drug solution in less 
than one second into the jugular vein of the subject via the catheter. All programing and response recording was performed utilizing electromechanical equipment (Lehigh Valley Electronics, Lehigh Valley, Pa.). Each day at the

same time the number of lever presses was recorded.

\section{Drugs}

Clonidine hydrochloride (Boehringer Ingelheim Ltd., Ridgefield, Ct.), fentanyl citrate (McNeil Laboratories, Inc., Fort Washington, Pa.), and naloxone hydrochloride (Endo Laboratories, Inc., Garden City, N.Y.) were dissolved in 0.98 sodium chloride. Haloperidol, azaperone and aceperone (Janssen Pharmaceutica N.V., Beerse, Belgium) were dissolved in 0.38 tartaric acid.

\section{Experimental Design}

A total of 90 rats were used in this investigation. Three rats were allowed to self-administer fentanyl 10.1 $\mathrm{ug} / \mathrm{Kg} /$ injection) while 46 rats were allowed to self-administer fentanyl at a dose of $1 \mathrm{ug} / \mathrm{Kg} / \mathrm{injection}$. Thirtyeight rats were allowed to self-administer clonidine (15 ug/ $\mathrm{kg} /$ injection) whereas three rats were allowed to self-administer saline. All solutions were self-administered on a continuous reinforcement (CRF) schedule. 
A. Fentanyl Self-Administration

1. Effect of Increasing the Fentanyl Dose Per Injection When, after four days of self-administration, lever pressing rates of three rats allowed to self-administer fentanyl $(0.1 \mathrm{ug} / \mathrm{Kg} /$ injection) did not differ from lever pressing rates of rats allowed to self-administer saline, the fentanyl dose was increased to $1 \mathrm{ug} / \mathrm{Kg} /$ injection. The effect of increasing the fentanyl dose on self-administration behavior was measured by comparing the response rates at each dose of fentanyl.

2. Effect of Clonidine and Saline Substitution for the Fentanyl Solution

Twenty-one of the 46 rats allowed to self-administer fentanyl ( $\mathrm{l} \mathrm{ug} / \mathrm{Kg} /$ injection) did not receive any other treatment. However, for four of the 46 rats allowed to selfadminister fentanyl ( $\mathrm{ug} / \mathrm{Kg} /$ injection), clonidine (15 ug/ $\mathrm{kg} /$ injection) was substituted for the fentanyl solution when a stable rate of fentanyl-reinforced responding was achieved. A stable rate of fentanyl-reinforced responding was considered to have been achieved when the number of lever presses to obtain fentanyl injections for each rat on two consecutive days was within $20 \%$ of the mean number of lever presses for those two days. Similarly, for two out of the 46 rats, clonidine ( $1 \mathrm{ug} / \mathrm{Kg} /$ injection) was substituted for fentanyl and for three out of the 46 rats saline was substituted. Following substitution, subjects were allowed to 
self-administer clonidine or saline for four consecutive days. The effect of substituting clonidine and saline for the fentanyl solution was measured by comparing the rate of self-administration following clonidine and saline substitution to the rate of fentanyl self-administration before substitution.

3. Effect of Adding Various Drugs to the Fentanyl Solution for Self-Administration of the Drug Mixture

For the remaining 16 of the 46 rats allowed to selfadminister ( $1 \mathrm{ug} / \mathrm{Kg} / \mathrm{injection),} \mathrm{three} \mathrm{different} \mathrm{butyro-}$ phenones and naloxone were added to the fentanyl solution when a stable rate of fentanyl-reinforced responding was achieved. A stable rate of fentanyl-reinforced responding was considered to have been achieved when the number of lever presses to obtain fentanyl injections for each rat on two consecutive days was within $10 \%$ of the mean number of lever presses for those two days. Naloxone $(\mathrm{N}=3)$, haloperidol $(N=4)$, aceperone $(N=5)$ or azaperone $(N=4)$ were added to the fentanyl solution for self-administration of the drug mixture so that the subjects received $64 \mathrm{ug} / \mathrm{Kg} /$ injection. Each drug remained in the fentanyl solution for two or three consecutive days. Thereafter, the drugs were removed from the fentanyl solution and the subjects were allowed to self-administer fentanyl alone. The effect of the response contingent drug injections on fentanylreinforced responding was measured by comparing the number 
of lever presses to obtain the drug mixture with the number of lever presses for fentanyl alone before adding the drugs to the fentanyl solution. The number of lever presses for the drug mixture were expressed as a percentage of the mean number of lever presses for fentanyl alone for the two days before adding the drugs. The effect of the response-contingent drug injections on fentanyl-reinforced responding was considered significant if, utilizing Scheffe's Test, $p<0.05$.

\section{B. Clonidine Self-Administration}

1. Effect of Increasing the Fixed-Ratio Requirement Twenty-two out of 38 rats allowed to self-administer clonidine (15 ug/ $\mathrm{kg} / \mathrm{injection}$ ) did not receive any other treatment. However, in one rat allowed to self-administer clonidine on a CRF schedule the response requirement to obtain each clonidine injection was progressively increased to a FR-3 and then to a FR-10 schedule of clonidine reinforcement. The response requirement was increased when the number of lever presses to obtain clonidine injections on the CRF schedule was within $10 \%$ of the mean for those three days. The subject was allowed to self-administer clonidine at each FR schedule for three consecutive days. The effect of increasing the response requirement on clonidine-reinforced responding was measured by comparing the number of lever presses to obtain clonidine-injections at each FRrequirement and also by comparing the total amount of clonidine intake at each FR requirement. Assuming independence 
of the data the effect of increasing the FR requirement on the above measures was considered significant if, utilizing Tukey's Test, $\mathrm{p}=<0.05$.

2. Effect of Adding Various Drugs to the Clonidine Solution for Self-Administration of the Drug Mixture

For the remaining 15 of the 38 rats allowed to selfadminister clonidine (15 ug/ $\mathrm{kg} /$ injection), naloxone or three different butyrophenones were added to the clonidine solution when a stable rate of clonidine-reinforced responding was achieved. A stable rate of clonidine-reinforced responding was considered to have been achieved when the number of lever presses to obtain clonidine injections for each rat on two consecutive days was within $10 \%$ of the mean number of lever presses for those two days. Naloxone $(\mathrm{N}=3)$, haloperidol $(\mathrm{N}=7)$, aceperone $(\mathrm{N}=3)$ or azaperone $(\mathrm{N}=3)$ were added to the clonidine solution so that the subjects received $64 \mathrm{ug} / \mathrm{Kg} /$ injection. Each drug remained mixed with the clonidine solution for self-administration of the drug mixture for three consecutive days. Thereafter, the drugs were removed from the clonidine solution and subjects were allowed to selfadminister clonidine (15 ug/ $\mathrm{kg} /$ injection) alone. The effect of the response-contingent drug injections on clonidine-reinforced responding was measured as described for the effect of these drugs on fentanyl-reinforced responding. Similarly, the effect of the respone contingent drug injections was considered significant if, utilizing Scheffe's Test, $p=<0.05$. 
RESULTS

Acquisition of Fentanyl self-Administration

As shown in Figure 1, subjects readily began to selfadminister fentany 1 ( $1 \mathrm{ug} / \mathrm{kg} /$ injection) when an intravenous injection of this drug was made contingent on lever pressing on a continuous reinforcement (CRF) schedule. From day 1 to day 5 there was a gradual increase ( $m=74.5)$ in lever pressing to obtain fentanyl injections, thereafter the rate of self-administration stabilized. It is also shown that rats do not self-administer a lower dose 10.1 $u g / \mathrm{kg} /$ injection) of fentanyl nor saline when their intravenous delivery is made contingent on a CRF schedule. Selfadministration rates of the latter (Figure 1) reflect lever pressing produced by random locomotor activity.

In rats previously allowed to self-administer fentanyl (0.1 ug/ $\mathrm{kg} /$ injection) on a CRF schedule, the substitution of a higher dose ( $1 \mathrm{ug} / \mathrm{kg} / \mathrm{injection}$ ) of fentanyl to be delivered on a CRF schedule promoted self-administration behavior (Figure 2). On the fourth day of substitution (day 8) self-administration rates similar to those on day 4 of drug-naive animals (Figure 1) were observed [252 $\pm 73(3)$ vs. $239 \pm 49(21)]$

Acquisition of Clonidine Self-Administration

As shown in Figure 3 , subjects readily began to selfadminister clonidine (15 ug/ $\mathrm{kg} /$ injection) when an intravenous 


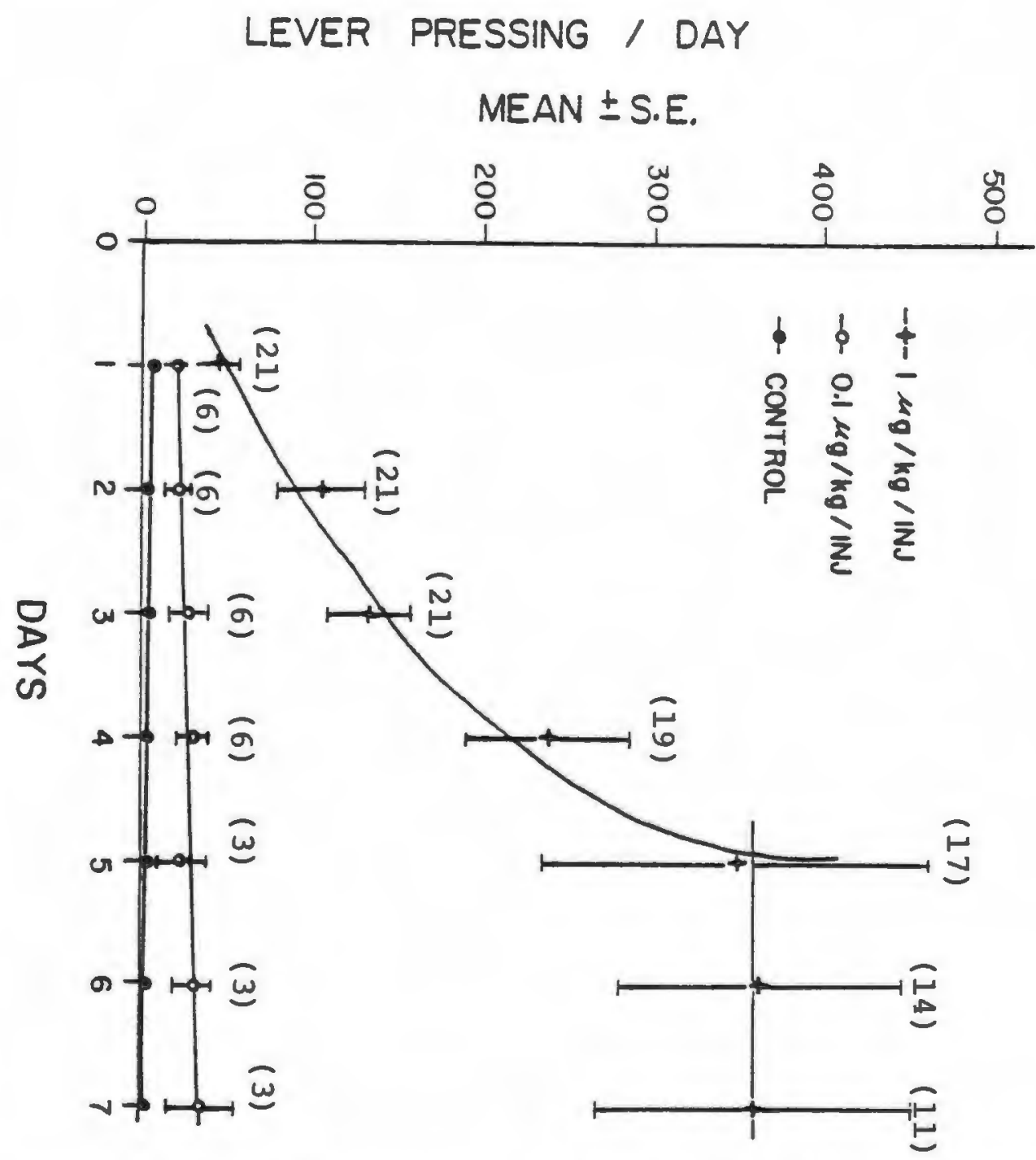

Figure 1. Acquisition of fentanyl self-administration in drug-naive rats when fentanyl ( $1 \mathrm{ug} / \mathrm{kg} /$ injection) was delivered on a continuous reinforcement (CRF) schedule. Lack of acquisition of self-administration when $0.1 \mathrm{ug} / \mathrm{Kg} / \mathrm{inj}$ fentanyl or saline $(\mathrm{N}=3)$ was delivered on a CRF schedule. Each value represents the mean $+S . E$. number of lever presses for the number of $s u \bar{b}$ jects indicated in parantheses. 


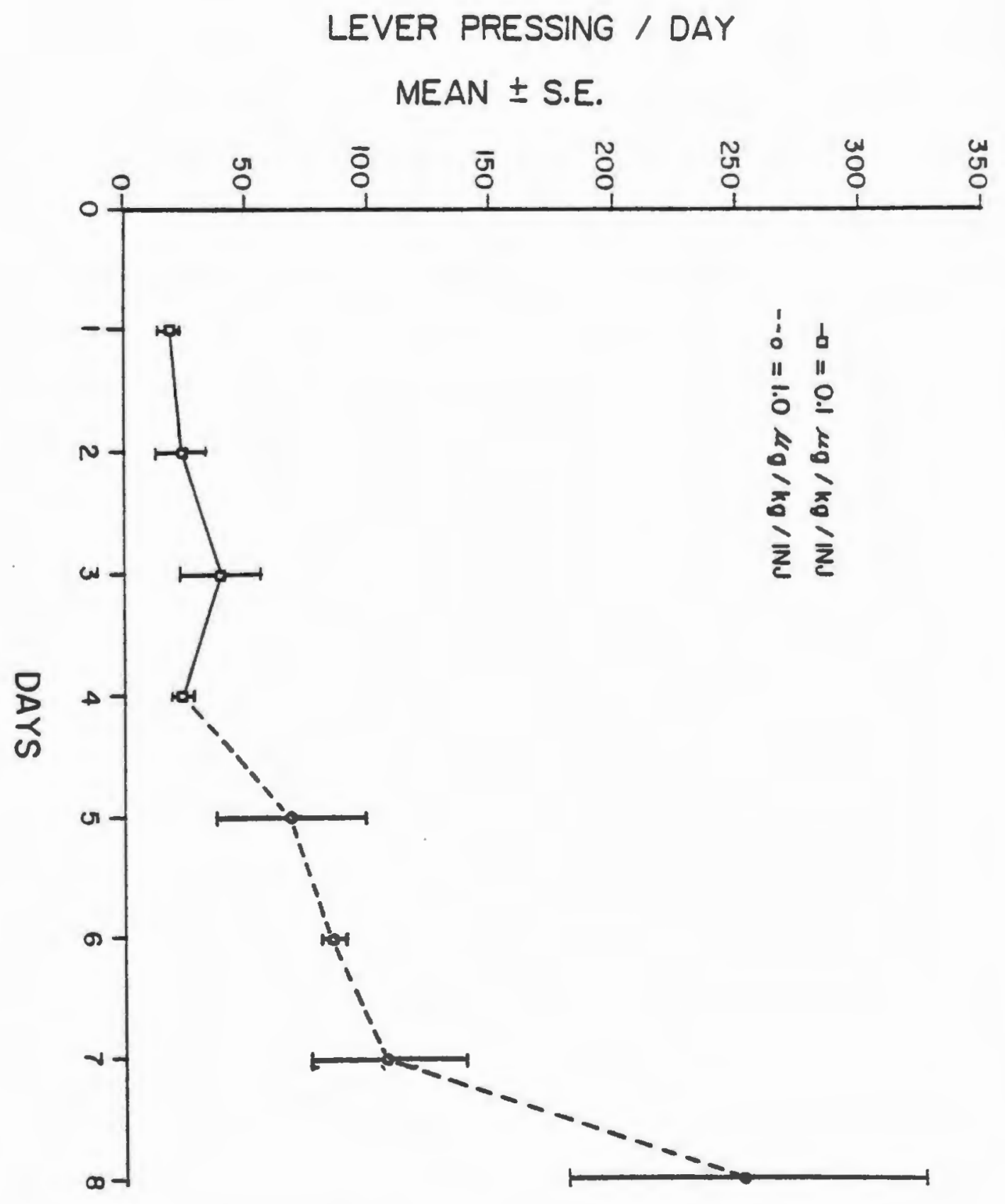

Figure 2. Acquisition of self-administration behavior upon substitution of a $1 \mathrm{ug} / \mathrm{Kg} / \mathrm{inj}$ fentanyl solution to be delivered on a CRF schedule for a $0.1 \mathrm{ug} / \mathrm{Kg} / \mathrm{inj}$ fentanyl solution delivered on a CRF schedule. Each value represents the mean $\pm S . E$. for three animals. 


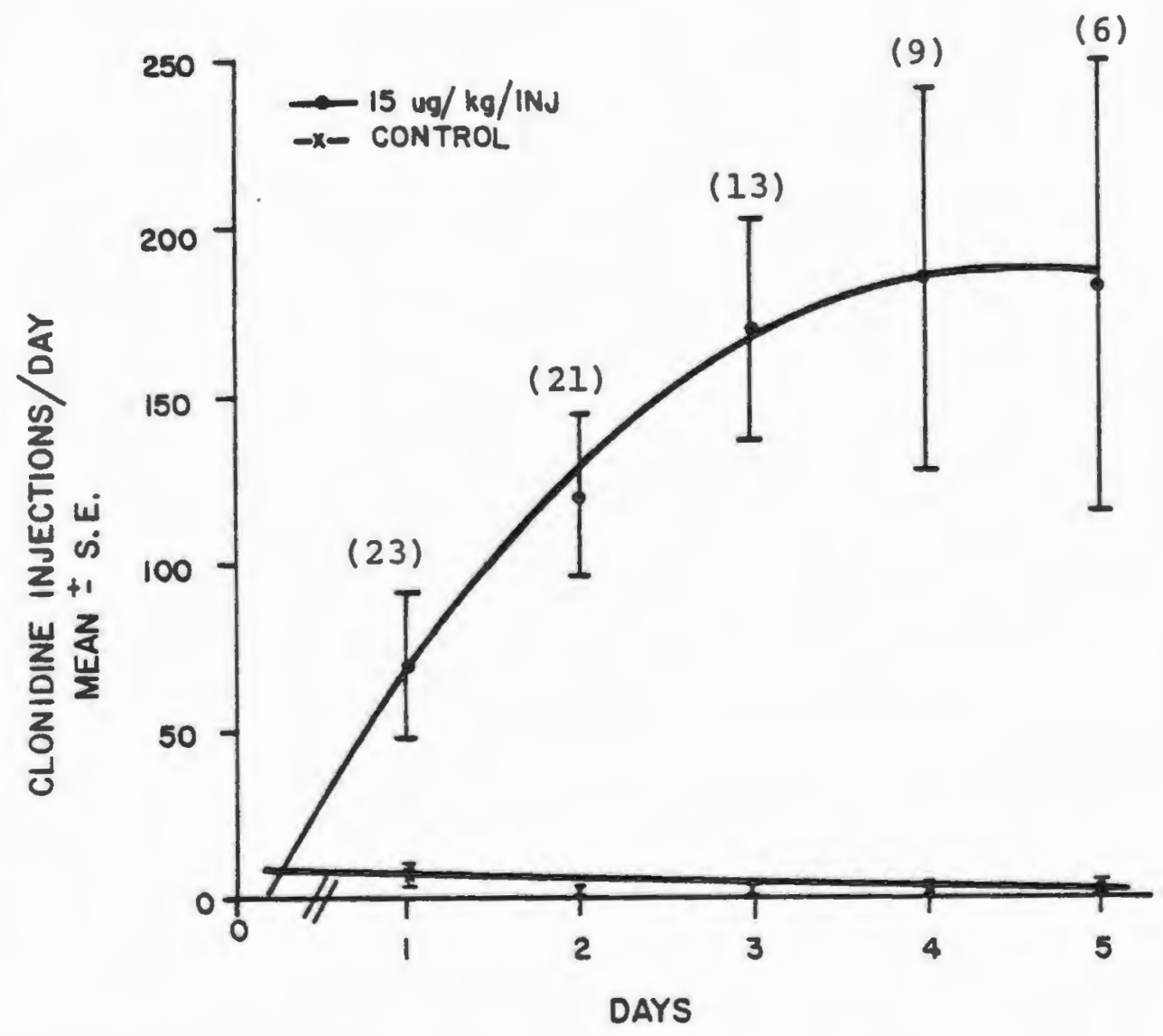

Figure 3. Acquisition of clonidine self-administration in drug-naive rats when clonidine (15 ug/ $\mathrm{kg} / \mathrm{inj}$ ) was made delivered on a CRF schedule. Lack of acquisition of self-administration when saline $(\mathrm{N}=3)$ control was delivered on a CRF schedule. Each value represents the mean $+S . E$. number of lever presses for the number of subjects indicated in parentheses. 
injection of this drug was made contingent on lever pressing. An increase $(m=49.9)$ in lever pressing to obtain clonidine injections was observed from day 1 to day 3, thereafter selfadministration rates stabilized. Five out of the 23 subjects that began to self-administer clonidine died. The mean number of lever presses for lethality of these subjects was $108 \pm 12$.

\section{Effect of Increasing the Fixed Ratio Requirement on Lever} Pressing to Obtain Clonidine Injections

When the fixed ratio (FR) requirement to obtain each clonidine injection was increased from FR-1 to FR-3 a small but significant ( $p<.05$; Tukey Test) increase in lever pressing to obtain clonidine injections was observed (Figure 4). However, total daily clonidine intake (Table 1) at the FR-3 schedule was decreased significantly ( $p<.05$; Tukey Test) from the FR-1 schedule. On the other hand, when the the FR requirement was increased from FR-3 to FR-10 a significant increase $(p<.01$, Tukey Test) in lever pressing (Figure 4) to obtain clonidine injections was observed such that total daily clonidine intake at the FR-3 and FR-10 schedules of clonidine reinforcement remained approximately the same (N.S., Tukey Test) at both schedules (Table 1). Clonidine intake at the FR-3 and FR-10 schedules of reinforcement was significantly below ( $p<.05$; Tukey Test) that observed at the FR-1 schedule of clonidine reinforcement. 


\section{LEVER PRESSING/DAY MEAN \pm S.E.}



Figure 4. Effect of increasing the fixed ratio (FR) requirement on the rate of clonidine self-administration in one rat. A significant increase in lever pressing to obtain each clonidine injection was observed when the FR requirement was increased from FR-1 to FR-3 ( $p<.05$; Tukey Test) and from FR-3 to FR-10 ( $p<.001$; Tukey Test). Values are the mean $\pm S . E$. for 3 days at each FR requirement. 
Table 1. Effect of Increasing the Fixed Ratio (FR) Requirement on the Total Daily Clonidine Intake of one Rat.

Fixed Ratio Requirement

Clonidine Intake/Day ${ }^{1}$

( $\mathrm{mg} / \mathrm{Kg}$ )

$\begin{array}{ll}1 & 1.28 \pm 0.17 \\ 3 & 0.71 \pm 0.13^{2} \\ 10 & 0.60 \pm 0.01^{2,3}\end{array}$

${ }^{1}$ Values are the mean $\pm S . E$. for 3 days at each FR requirement.

${ }^{2}$ Significantly different $(p<.05 ;$ Tukey Test) from clonidine intake at $\mathrm{FR}-1$ requirement.

${ }^{3}$ Not significantly different ( $p>.05$; Tukey Test) from clonidine intake at FR-3 requirement. 
Effect of Substituting Clonidine and Saline on Self-Administration Rates in Rats Previously Self-Administering Fentany 1

As shown in Figure 5, substitution of clonidine so that the subjects received $15 \mathrm{ug} / \mathrm{Kg} / \mathrm{injection}$ maintained selfadministration behavior in rats previously self-administering fentanyl ( $1 \mathrm{ug} / \mathrm{kg} /$ injection). However, the substitution of clonidine ( $1 \mathrm{ug} / \mathrm{Kg} /$ injection) or saline for the fentanyl solution resulted in extinction of the self-administration behavior. One rat died within eleven hours following substitution of clonidine ( $15 \mathrm{ug} / \mathrm{Kg} /$ injection).

Effect of Adding Naloxone to the Clonidine and Fentanyl Solutions for Self-Administration of the Drug Mixture

As shown in Table 2, addition of naloxone to the clonidine and fentanyl solutions so that the subjects received $64 \mathrm{ug} / \mathrm{Kg} /$ injection produced a significant decrease $(\mathrm{p}<0.01$; Scheffe's Test) in the self-administration rates of rats previously self-administering fentanyl but did not on day 1 of addition, decrease the self-administration rates of rats previously self-administering clonidine $(p>0.05)$. In rats previously self-administering fentanyl, rates of self-administration remained significantly below $(p<0.01$; Scheffe's Test) pre-naloxone rates while naloxone remained mixed with the fentanyl solution. Removal of naloxone (post-naloxone) from the fentanyl solution resulted in a 


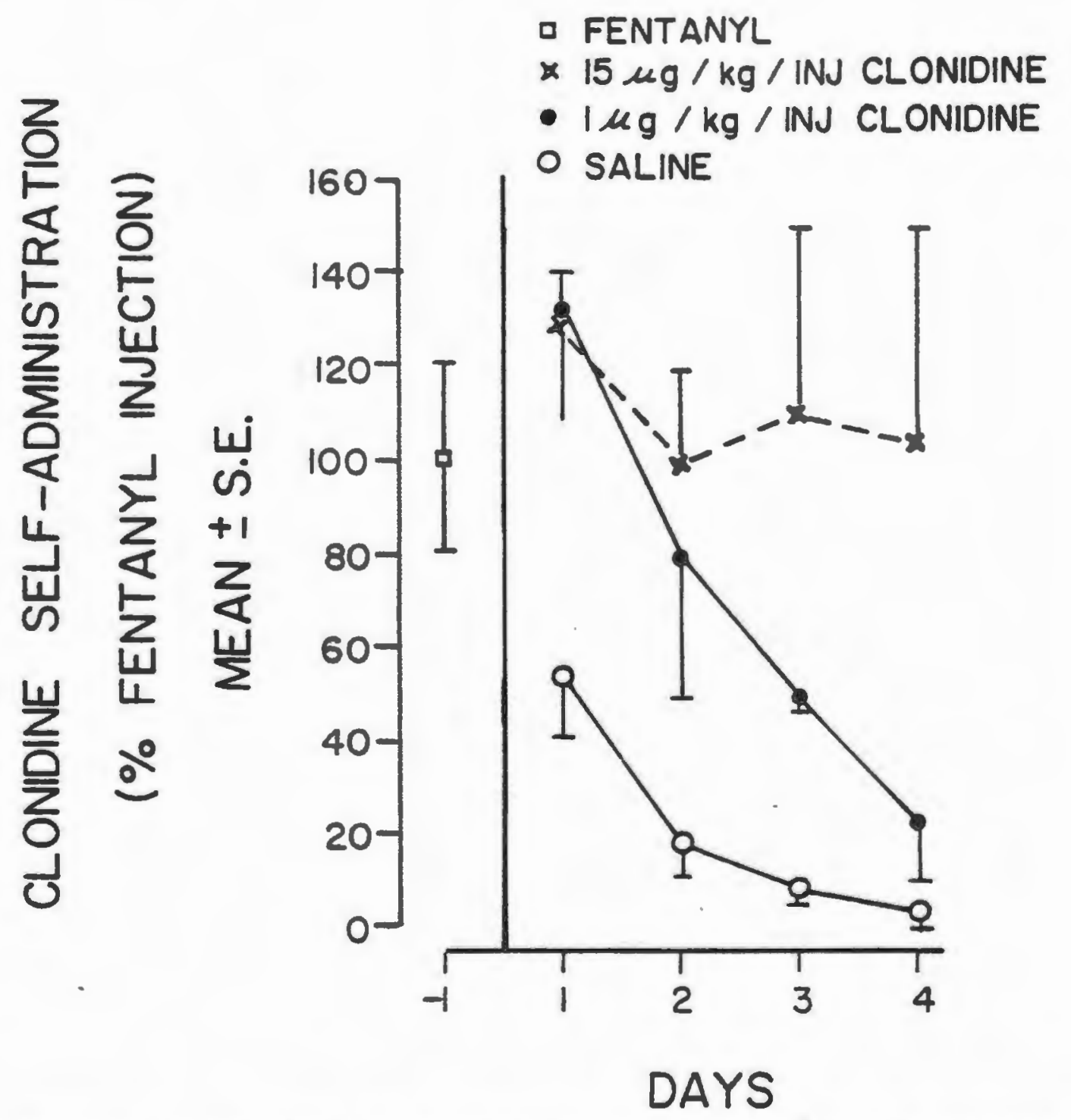

Figure 5. Effect of substituting clonidine and saline on rate of self-administration in rats previously selfadministering fentanyl ( $1 \mathrm{ug} / \mathrm{Kg} / \mathrm{inj}$ ) on a CRF schedule. The square at Day 1 is the mean + S.E. of the 3 days prior to substitution for all subjects. Substitution of clonidine ( $15 \mathrm{ug} / \mathrm{Kg} / \mathrm{inj}$ ) $\mathrm{N}=4$; ( $\mathrm{ug} / \mathrm{Kg} / \mathrm{inj}$ ) $\mathrm{N}=2$; saline $\mathrm{N}=3$. Values are expressed as a percentage of the mean \pm S.E. of Day 1 . 
Table 2. Effect of Adding Naloxone to the clonidine and Fentanyl Solutions for Self-Administration of the Drug Mixture. I

DAY \& Clonidine Alone 2 \& Fentanyl Alone ${ }^{2}$

$\begin{array}{lllr}\begin{array}{l}\text { Pre- } \\ \text { Naloxone }\end{array} & 100 \pm 14(3) & 100 \pm 2(3) \\ \text { Naloxone } & 1 & 114 \pm 14(3) & 25 \pm 10(3) \\ & 2 & 153(2) & 6 \pm 2(3) \\ & 3 & 173(2) & 7 \pm 3(3) \\ \begin{array}{c}\text { Post- } \\ \text { Naloxone }\end{array} & 1 & & 34 \pm 13(3) \\ & 2 & & 126 \pm 28(3)\end{array}$

${ }^{1}$ Naloxone (64 ug/ $\mathrm{kg} / \mathrm{inj}$ ) was added to clonidine (15 ug/ $\mathrm{kg} /$ inj) and fentanyl ( $1 \mathrm{ug} / \mathrm{Kg} / \mathrm{inj}$ ) solutions for selfadministration of the drug mixture on a CRF schedule.

2 Pre-naloxone value was obtained by taking the mean $\pm S . E$. of the percentages of the mean number of lever presses of the two days prior to adding naloxone for each rat. Other values are mean $+S . E$. and are expressed as a percentage of the pre-naloxone rate for the number of rats indicated in parentheses. Only mean is presented where $\mathrm{N}$ was less than three. Decreasing $N$ was the result of technical difficulties. 
return towards pre-naloxone rates of self-administration. Data indicated that self-administration rates following removal of naloxone (post-naloxone) from the fentanyl solution were not significantly different $(P>.05$; Scheffe's Test) from self-administration rates before the addition of naloxone (pre-naloxone) to the fentanyl solution. However, post-naloxone self-administration rates were significantly higher ( $p<0.01$, Scheffe's Test) than the rates of self-administration when naloxone was mixed with the fentanyl solution.

In rats previously self-administering the clonidinenaloxone mixture, removal of naloxone from the clonidine solution tended to result in an increase in self-administration rates above pre-naloxone rates. Rates of selfadministration following the removal of naloxone did not appear to increase above self-administration rates of the clonidine-naloxone mixture, however, the number of subjects was too small to determine statistical significance.

Effect of Adding Haloperidol to the Clonidine and Fentanyl Solutions for Self-Administration of the Drug Mixture

As presented in Table 3, the addition of haloperidol to the clonidine and fentanyl solutions so that the subjects received $64 \mathrm{ug} / \mathrm{Kg} /$ injection resulted in a significant decrease ( $p<0.01 ;$ Scheffe's Test) in the self-administration rates of rats previously self-administering either 
Table 3. Effect of Adding Haloperidol to the Clonidine and Fentanyl Solutions for Self-Administration of the Drug Mixture. 1

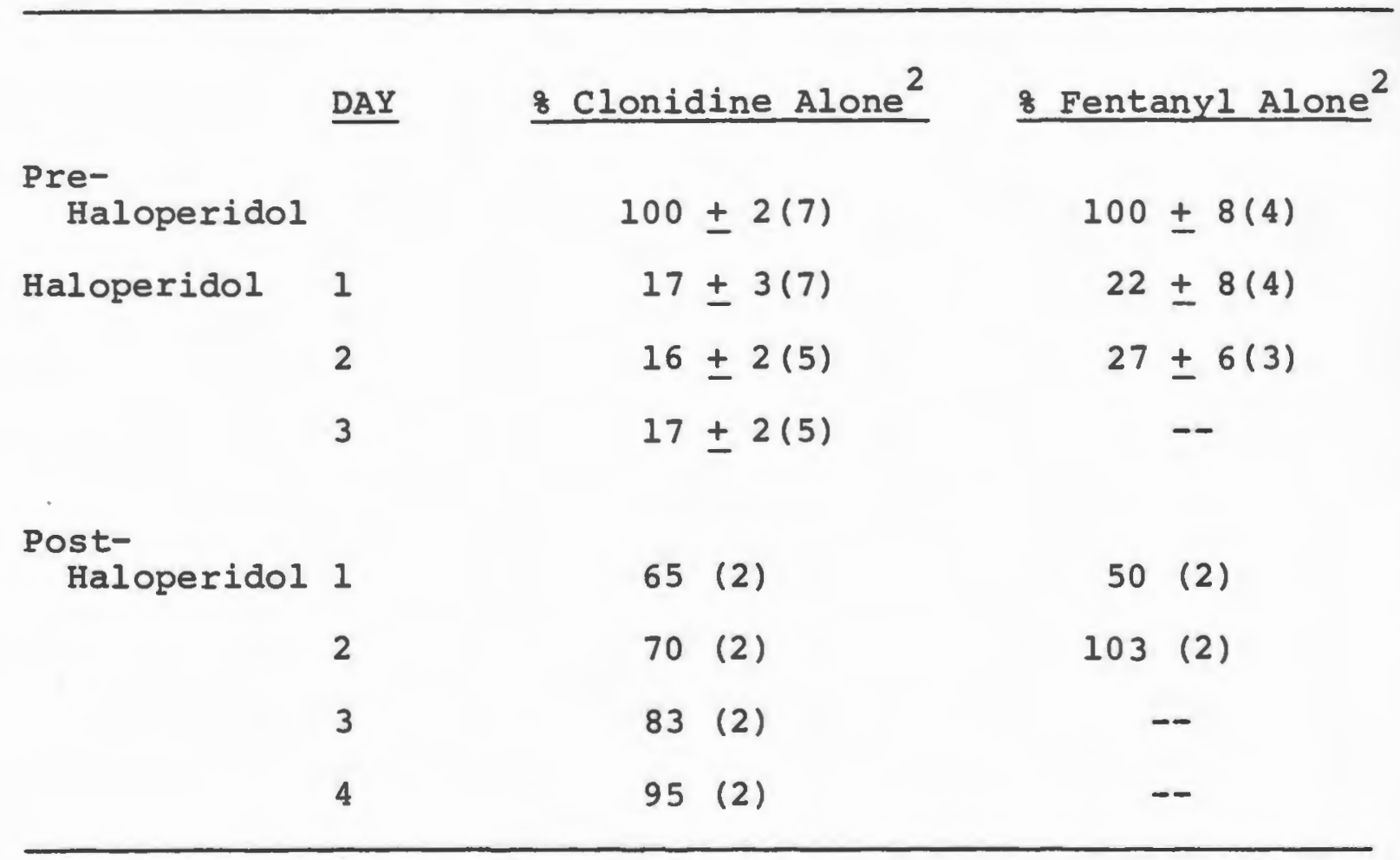

1

Haloperidol (64 ug/ $\mathrm{Kg} / \mathrm{inj}$ ) was added to clonidine (15 ug/ $\mathrm{kg} /$ inj) and fentanyl ( $\mathrm{ug} / \mathrm{Kg} / \mathrm{inj}$ ) solutions for self-administration of the drug mixture on a CRF schedule.

2

Pre-haloperidol values were obtained by taking the mean $+\mathrm{S.E}$. of the percentages of the mean of the two days prior to a'ding haloperidol for each rat. Other values are mean + S.E. and are expressed as percentage of the pre-haloperidoI rate for the number of rats indicated in parentheses. Only mean is presented where $\mathrm{N}$ was less than three. Decreasing $\mathrm{N}$ was the result of technical difficulties. 
clonidine or fentanyl alone. Depression of self-administration rates was maintained below ( $p<0.01$; Scheffe's Test) pre-haloperidol rates while haloperidol remained in the clonidine and fentanyl solutions. Self-administration rates following the removal of haloperidol (post-haloperidol) from the clonidine and fentanyl solutions tended to return to pre-haloperidol rates, however the number of subjects was too small to determine a statistical difference.

Effect of Adding Aceperone to the Clonidine and Fentanyl Solutions for Self-Administration of the Drug Mixture Addition of aceperone to the clonidine solution so that the subjects received $64 \mathrm{ug} / \mathrm{Kg} /$ injection had no significant effect ( $p>0.05$ Scheffe's Test) on rates of self-administration in rats previously self-administering clonidine alone (Table 4). The rate of clonidine self-administration of one rat following the removal of aceperone from the clonidine solution was approximately the same as the preaceperone response rate for this rat. Addition of aceperone to the fentanyl solution so that subjects received $64 \mathrm{ug} / \mathrm{kg} /$ injection resulted in a significant increase ( $p<0.01 ;$ Scheffe's Test) in the rates of self-administration of rats previously self-administering fentanyl alone. The rates of self-administration remained significantly above ( $p<0.01$; Scheffe's Test) pre-aceperone rates while aceperone remained in the fentanyl solution. Removal of aceperone from the fentanyl solution tended to result in 
Table 4. Effect of Adding Aceperone to the Clonidine and Fentanyl Solutions for Self-Administration of the Drug Mixture.1

\begin{tabular}{|c|c|c|c|}
\hline & $\underline{D A Y}$ & $\approx$ Clonidine Alone ${ }^{2}$ & 8 Fentanyl Alone ${ }^{2}$ \\
\hline \multicolumn{3}{|l|}{ Pre- } & $100 \pm 3(5)$ \\
\hline \multirow[t]{3}{*}{ Aceperone } & 1 & $136 \pm 30(3)$ & $186 \pm 25(5)$ \\
\hline & 2 & $146 \pm 5(3)$ & $221 \pm 53(4)$ \\
\hline & 3 & $125 \pm 12(3)$ & $238 \pm 51(3)$ \\
\hline \multicolumn{4}{|l|}{ Post- } \\
\hline & 2 & 94 (1) & $320 \quad(2)$ \\
\hline & 3 & $88(1)$ & $408 \quad(2)$ \\
\hline \multicolumn{4}{|c|}{$\begin{array}{l}\text { I Aceperone }(64 \mathrm{ug} / \mathrm{Kg} / \mathrm{inj}) \text { was added to clonidine }(15 \mathrm{ug} / \mathrm{Kg} / \\
\text { inj) and fentanyl (I ug/Kg/inj) solutions for self-adminis- } \\
\text { tration of the drug mixture on a CRF schedule. }\end{array}$} \\
\hline \multicolumn{4}{|c|}{$\begin{array}{l}2 \\
\text { Pre-aceperone values were obtained by taking the mean } \pm \text { S.E. } \\
\text { of the percentages of the mean of the two days prior to add- } \\
\text { ing aceperone for each rat. Other values are mean }+ \text { S. . and } \\
\text { are expressed as percentage of the pre-aceperone rate for the } \\
\text { number of rats indicated in parentheses. Only mean is pre- } \\
\text { sented where } N \text { was less than three. Decreasing } N \text { was the } \\
\text { result of technical difficulties. }\end{array}$} \\
\hline
\end{tabular}


an increase in rates of self-administration above rates of self-administration when aceperone was mixed with the fentanyl solution. However, the number of subjects was too small to determine a statistical significance.

Effect of Adding Azaperone to the Clonidine and Fentanyl Solutions for Self-Administration of the Drug Mixture Addition of azaperone to the clonidine solution so that the subjects received $64 \mathrm{ug} / \mathrm{Kg} /$ injection tended to decrease the self-administration rates of rats previously self-administering fentanyl alone (Table 5). However, the number of subjects was too small to determine a statistical significance. Addition of azaperone to the fentanyl solution so that the subjects received $64 \mathrm{ug} / \mathrm{Kg} /$ injection resulted in a significant decrease in the self-administration rates of rats previously self-administering fentanyl alone. The rates of self-administration remained below pre-azaperone rates while azaperone remained in the clonidine and fentanyl solutions. Removal of azaperone (post-azaperone) from the clonidine and fentanyl solutions tended to produce a return towards pre-azaperone rates of self-administration, however, the number of subjects was not large enough to determine a statistical significance. 
Table 5. Effect of Adding Azaperone to the Clonidine and Fentanyl Solutions for Self-Administration of the Drug Mixture.

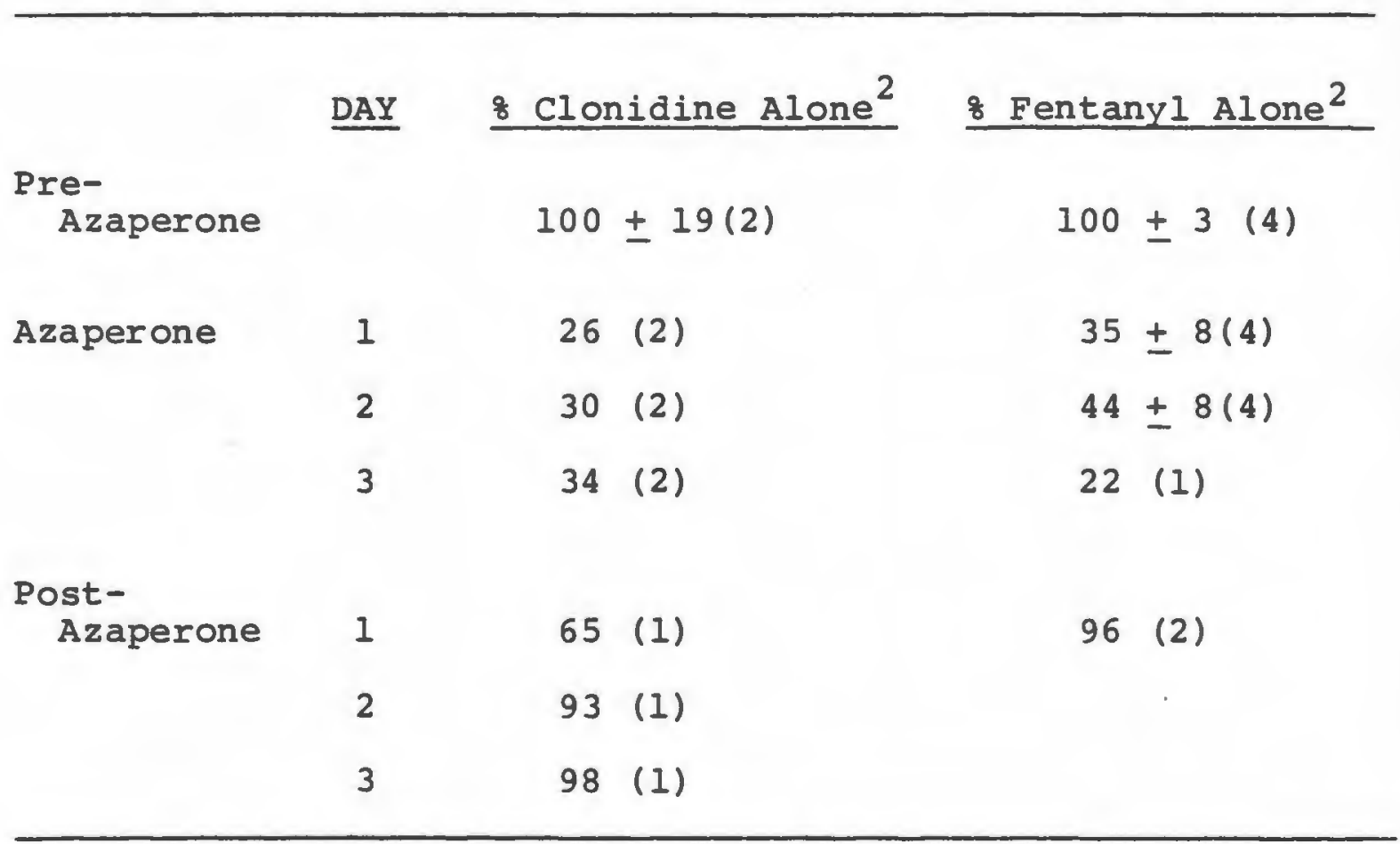

1

Azaperone (64 ug/ $\mathrm{kg} / \mathrm{inj}$ ) was added to clonidine (15 ug/ $\mathrm{kg} /$ inj) and fentanyl ( $1 \mathrm{ug} / \mathrm{Kg} / \mathrm{inj}$ ) solutions for self-administration of the drug mixture on a CRF schedule.

2

Pre-azaperone values were obtained by taking the mean \pm S.E. of the percentages of the mean of the two days prior to adding azaperone for each rat. Other values are mean + S.E. and are expressed as percentage of the pre-azaperone rate for the number of rats indicated in parentheses. Only mean is presented where $\mathrm{N}$ was less than three. Decreasing $\mathrm{N}$ was the result of technical difficulties. 


\section{DISCUSSION}

Acguisition of Fentanyl Self-Administration

A number of narcotics (for review see seiden and Dykstra, 1977) are known to maintain behavior leading to their administration (i.e. to act as positive reinforcers).

The rate and pattern of narcotic self-administration depends on several factors including the narcotic, dose per injection, amount of time the drug is available, number of responses required to obtain the drug injection or schedule of reinforcement, experience of the subject and environmental conditions.

Fentanyl is a synthetic narcotic which is approximately 80 times more potent than morphine as an analgesic (Jaffe and Martin, 1975). When an intravenous injection of fentanyl ( $1 \mathrm{ug} / \mathrm{Kg} /$ injection) was made contingent on lever pressing, drug-naive rats readily began to lever press to obtain injections of this drug; that is, they began to self-administer it. Lever pressing to obtain fentanyl injections gradully increased over the first five days from a mean of $44 \pm 12$ $(\mathrm{N}=21)$ lever presses on day one of self-administration to a mean of $350 \pm 114(\mathrm{~N}=17)$ by day five of self-administration. The mean number of lever presses to obtain fentanyl injections remained approximately the same from day five to day seven. Average daily fentanyl intake for these three days 
was $358 \mathrm{ug} / \mathrm{kg} /$ day. Therefore, it is demonstrated that fentanyl (l ug/Kg/injection) will function as a positive reinforcer as it will maintain behavior leading to its administration.

Under conditions of unlimited access, similar to those used in this investigation, Deneau et al. (1969) examined the pattern of morphine self-administration in rhesus monkeys. It was observed that morphine intake in these subjects increased daily for 30 days after which it became stable. Therefore, the pattern of fentanyl self-administration resembles the pattern of morphine self-administration in that there was a steady increase in self-administration rate and then a stabilization of self-administration rate for both narcotics. Since fentanyl is a much more rapidly acting and more potent narcotic than morphine this may explain the much faster acquisition and stabiliziation of fentanyl selfadministration. In addition, the dose per injection of each narcotic and the species difference certainly plays a role. When intravenous injection of a lower dose $(0.1 \mathrm{ug} / \mathrm{kg} /$ injection) of fentanyl was made contingent on lever pressing subjects did not acquire self-administration behavior. Thus, suggesting that this dose of fentanyl does not possess reinforcing properties. That rates of self-administration for ( $0.1 \mathrm{ug} / \mathrm{kg} /$ injection) fentanyl were not significantly different from self-administration rates when saline was available supports this suggestion. 
Self-administration behavior in rats previously allowed to self-administer fentanyl ( $0.1 \mathrm{ug} / \mathrm{Kg} /$ injection) was acquired however when the higher dose (I ug/ $\mathrm{kg} / \mathrm{injection)} \mathrm{of} \mathrm{fentanyl}$ was substituted. Rates of self-administration on day four of substitution were similar to rates of self-administration in rats not allowed to self-administer the lower dose initially. Thus a similar acquisition pattern for fentanyl ( $1 \mathrm{ug} /$ $\mathrm{Kg} /$ injection) was observed regardless of whether or not the subjects had previous experience in the operant chambers. While self-administering fentanyl ( $1 \mathrm{ug} / \mathrm{Kg} / \mathrm{injection}$ ) rats were alert and appeared healthy; occasionally, when the injection system failed (i.e. cannula became disconnected from the syringe) so that the subjects no longer received a fentanyl injection with each lever press, some rats exhibited narcotic withdrawal symptoms such as piloerection, diarrhea and "wet shakes." The appearance and severity of these symptoms depended on how long the subject had been selfadministering fentanyl and also on the subject's rate of fentanyl self-administration. Therefore, self-administration of fentanyl ( $1 \mathrm{ug} / \mathrm{kg} /$ injection) can produce physiological dependence as manifested by the appearance of a characteristic abstinence syndrome upon termination of narcotic administration. It is doubtful, however, if physiological dependence is a necessary condition for fentanyl to function as a reinforcer as it has been previously reported that narcotics can function as reinforcers at doses too low to produce physiological dependence (Schuster, 1968; Woods and Schuster 1968, 1971; Hoffmeister and Schlichting, 1972). This is 
demonstrated by higher response rates at these doses than when saline is available and also by the absence of withdrawal symptoms when the availability of narcotic injections is discontinued.

\section{Acquisition of Clonidine Self-Administration}

As discussed earlier the majority of evidence indicates that clonidine acts as an alpha-noradrenergic agonist in the central nervous system and depending on the dose administered may stimulate either pre- or post-synaptic noradrenergic receptors. Low doses $\left(4-8 \mathrm{ug} / \mathrm{Kg} \mathrm{i} \cdot \mathrm{v}_{.}\right)$have been reported to inhibit the firing of the noradrenergic neurons of the locus coeruleus (Svennson et al., 1975) and thus a pre-synaptic locus of action has been suggested, while higher doses (100 ug/Kg i.p.) have been suggested to stimulate post-synaptic noradrenergic receptors (Anden et al., 1970).

When an intravenous injection of clonidine $(15 \mathrm{ug} / \mathrm{kg} /$ injection) was made contingent on lever pressing, drugnaive rats readily began to lever press to obtain injections of the drug. The number of lever presses to obtain clonidine injections gradually increased over the first three days of self-administration from a mean of $69+22(N=23)$ lever presses on day one to a mean of $169 \pm 32(\mathrm{~N}=13)$ lever presses by day three. The mean number of lever presses to obtain clonidine injections remained approximately the same from day 3 to day 5. Average daily clonidine intake for these three days was $2.8 \mathrm{mg} / \mathrm{kg}$. 
The acquisition of clonidine self-administration was faster than the acquisition of fentanyl self-administration as demonstrated by a stable rate of clonidine-reinforced responding being achieved before a stable rate fentanyl-reinforced responding ( 3 days vs. 5 days). When daily intake of each drug did become stable, however, average daily clonidine intake was much higher than the average daily fentanyl intake $(2.81 \mathrm{mg} / \mathrm{Kg}$ vs. $0.358 \mathrm{mg} / \mathrm{Kg})$.

It cannot be stated with certainty whether or not the dose of clonidine self-administered by rats is stimulating pre- or post-synaptic noradrenergic receptors; however, behavioral and sympathomimetic signs exhibited by the rats suggest that clonidine may be stimulating post-synaptic noradrenergic receptors. If clonidine were stimulating presynaptic noradrenergic receptors this would inhibit norepinephrine release from noradrenergic nerve endings thus leading to reduced transmission in the noradrenergic system. It has been suggested that an action on pre-synaptic receptors could account for clonidine's depressant action on locomotor and/ or exploratory activity (Laverty and Taylor, 1969; Maj et al., 1972; Strombom, 1976; Tilson, 1977). On the contrary, however, rats self-administering clonidine were highly excitable and made erratic movements when disturbed, leaping up into the roof of the operant chambers. If the door of the operant chamber were left open the subjects would try desperately to escape, thus demonstrating that locomotor and/or exploratory activity was not decreased. In fact, exploratory 
may actually have increased as rats self-administering saline or fentanyl do not try to escape from the chamber when the door is left open. Clonidine has been reported to potentiate escape attempts induced by naloxone in morphine-dependent rats (Tseng et al., 1975), and to produce hyperactivity in mice following intraperitoneal administration of a large (5-30 $\mathrm{mg} / \mathrm{Kg})$ dose (Razzak, 1975).

While self-administering clonidine the subjects exhibited marked sympathomimetic signs such as exopthalamus and piloerection. These and other sympathomimetic signs such as, horripilation, tremor, and hyperactivity have been reported (Hoefke and Kobinger, 1966; Morpurgo, 1968; Razzak, 1975) when doses from 30-100 ug/Kg i.v. or $1-30 \mathrm{mg} / \mathrm{Kg} \mathrm{i.p.} \mathrm{were} \mathrm{ad-}$ ministered to mice. Furthermore, Morpurgo (1968) reported that administration of the alpha-noradrenergic receptor blocker phentolamine reversed the sympathomimetic signs.

A liquid was noted to be secreted from the eyes of subjects self-administering clonidine and eye pigmentation was observed to change from a black color to an orange-brownish color. In cats and monkeys intravenous administration of clonidine $(10 \mathrm{ug} / \mathrm{kg}$ ) was reported to reduce eye pressure in such a way that indicated marked vasoconstriction (Bill and Heilmann, 1975). Furthermore, Knapp and Galloway (1975) reported that the eyes of a patient taking several drugs for hypertension, one of which was clonidine, began to turn a reddish color. However, a beta-blocker and not clonidine was thought to be responsible for this ocular reaction. 
Constipation is a known side effect of clonidine and indeed subjects self-administering clonidine became severely constipated as evidenced by the absence of fecal matter on the wood shavings underneath the floor of the operant chamber. Dix and Johnson (1977) reported that rats chronically treated with clonidine maintained a poor coat condition. Subjects self-administering clonidine also maintained a poor coat condition. Occasionally, when the injection system failed and the subject no longer received clonidine injections upon lever pressing, symptoms such as "wet shakes" and diarrhea were observed. Saperia (1975) reported that a man was troubled by diarrhea for four days following consumption of a large amount ( $5 \mathrm{mg}$ ) of clonidine.

clonidine has been reported to produce irritability and aggression in mice and rats (Morpurgo, 1968; Laverty and Taylor, 1969; Dix, 1977) and also to enhance morphine-withdrawal and apomorphine-induced aggression in rats (Gianutsos et al., 1976). Rats self-administering clonidine assumed an attack posture and demonstrated aggressiveness towards the experimenter when a gloved hand was put into the operant chamber. Morpurgo (1968) reported that the clonidine-induced aggression was blocked by dopamine receptor antagonists such as haloperidol but poorly antagonized by norepinephrine receptor blockers and therefore concluded that the aggressiveness appears to be independent of clonidine's sympathomimetic effects. 
When access to cocaine was unlimited, Deneau et al., (1969) reported that monkeys would self-administer the drug until convulsions and death occurred, usually within 30 days. Similarly, approximately $22 \%$ of subjects self-administering clonidine did so until death occurred, and this invariably occurred on day one of self-administration. Profuse salivation and complete loss of eye pigmentation was noted in these subjects. Several cases of clonidine overdose have been reported in humans (Saperia, 1975; Wing et al., 1975; Hunyor et al., 1975; Moore and Philipi, 1976); however in none of these reports did overdose lead to death. Human overdose was always accompanied by severe hypertension and it was suggested (Wing et al., 1975) that the clonidine overdose is a result of dominance of the peripheral alpha-agonist action of this drug (Rand and Wilson, 1968) over its central hypotensive effects. Bradycardia was also noted in each case of human overdose and was treated by administration of atropine. Therefore, the cardiovascular effects of clonidine may be responsible for the death of subjects self-administering it.

Since clonidine will maintain behavior leading to its administration in rats, it can be said to act as a positive reinforcer. Behavioral and sympathomimetic signs exhibited by rats self-administering clonidine suggest that the drug is stimulating post-synaptic noradrenergic receptors.

Effect of Increasing the Fixed-Ratio Requirement on Clonidine Self-Administration Behavior

In general experiments investigating the effect of 
schedules of reinforcement on drug self-administration demonstrate that drug reinforcers generate response rates and patterns characteristic of rates and patterns generated by other reinforcers such as food or water (McKearney and Morse, 1964; Thompson and Schuster, 1964; Woods and Schuster, 1968; Pickens and Thompson, 1971, 1972; Goldberg, 1973; Dougherty and Pickens, 1973; Balster and Schuster, 1973; Anderson and Thompson, 1974; Downs and Woods, 1974; Iglauer and Woods, 1974; Goldberg et al., 1975; Goldberg and Kelleher, 1976; for review (see Spealman and Goldberg, 1978), electric shock (McKearney, 1968, 1969, 1970), or termination of a stimulus associated with occasional electric shocks (Kelleher and Morse, 1964; Morse and Kellher, 1966).

Intravenous administration of drugs of several pharmacological classes, including narcotic analgesics, narcotic antagonists, barbiturates and benzodiazepines dissociative anesthetics and psychomotor stimulants, has maintained responding by laboratory animals under fixed ratio: (FR) schedules of reinforcement (for review see spealman and Goldberg, 1978).

Delivery of an intravenous clonidine injection maintained responding in drug-naive rats when the drug was delivered on a FR-I schedule of reinforcement. When the FR requirement to obtain each clonidine injection was increased from 1 to 3 responses per reinforcement, total daily clonidine intake decreased even though a significant increase in responding was observed. When the FR requirement was further 
increased to FR-10, however, responding increased so that total daily clonidine intake at the FR-3 and FR-10 schedules of reinforcement were the same.

Similar observations were made by Weeks (1962) who examined morphine intake under different FR schedules of reinforcement. When the FR requirement to obtain each morphine injection was increased from 1 to 5 , morphine intake decreased even though responding to obtain the drug increased. However, when the FR requirement was increased to an FR-10, response rate doubled from its FR-5 level so that morphine intake remained the same at the FR-5 and FR-10 schedules of morphine reinforcement.

Goldberg et al. (1971) increased the FR requirement for rhesus monkeys to obtain each intravenous pentobarbital injection from 1 to 3 to 5 to 10 and observed a corresponding decrease in both response rate and total pentobarbital intake as the FR requirement was increased. Thus, even though both clonidine (Nickerson and Ruedy, 1975) and pentobarbital (Harvey, 1975) produce central nervous system depression, the effect of increasing the FR requirement on clonidine self-administration behavior does not resemble the effect of increasing the FR requirement on pentobarbital self-administration behavior. These differential results may possibly suggest that the neurochemical mechanisms underlying the reinforcing properties of clonidine and pentobarbital are different. 
When the psychomotor stimulants cocaine (Pickens, 1968; Pickens and Thompson, 1968; Goldberg et al., 1971) and amphetamine (Pickens and Harris, 1968) are delivered on FR schedules of reinforcement an increase in responding is observed as the FR requirement is increased so that total intake of these drugs remains constant. Therefore, in some respects the effect of increasing the FR requirement to obtain clonidine injections resembles the effect of increasing the FR requirement to obtain psychomotor stimulants as increasing FR requirement to obtain each clonidine injection from 3 to 10 resulted in an increase in responding so that total clonidine intake remained the same at these FR schedules of reinforcement.

Effect of Substituting Clonidine and Saline on Self-Administration Behavior in Rats Previously Self-Administering Fentanyl

It has recently been reported that clonidine and morphine have similar pharmacological effects on noradrenergic neurons (Gomes et al., 1976; Redmond, 1977). Of relevance to this discussion are the findings that both clonidine and morphine inhibit the firing of the noradrenergic nucleus locus coeruleus (Svensson et al., 1975; Korf, 1974) and that opiate receptors are located on locus coeruleus cell bodies (Kuhar et al., $1974)$.

Recently, Redmond et al. (1976) and Redmond (1977) reported that the effects of electrical or pharmacological activation of locus coeruleus in monkeys were strikingly similar to those noted after opiate withdrawal in humans (anxiety 
state). Both clonidine and morphine blocked the effects of activation of the locus coeruleus (Redmond, 1977) and furthermore the time course correlated with the decreased neuronal activity in locus coeruleus (Svennson et al., 1975; Cedarbaum and Aghajanian, 1976; Cedarbaum and Aghajanian, 1977) and decreased norepinephrine release (Braestrup, 1974; Maas et al., 1976) produced by these drugs. Clonidine has been demonstrated to decrease certain narcotic withdrawal signs, such as body shakes, induced by discontinuation of narcotic administration (Fielding et al., 1977; in press) or by administration of narcotic antagonists (Tseng et al., 1975; Vetulani and Bednarczyk, 1977) in morphine-dependent rats. Gold et al. (1978) reported that clonidine eliminated opiate withdrawal signs in narcotic addicts and that all of the subjects in the study reported dramatic relief of distress. In an earlier study Bjorkqvist (1975) reported that clonidine decreased the sweating, tremor and anxiety accompanying alcohol withdrawal in humans.

Also of interest is the finding that clonidine produces analgesia in rats and mice (Paalzow, 1974; Paalzow and Paalzow, 1976; Fielding et al., 1977; in press) and that the antinociceptive effects of clonidine are not reversed by naloxone (Paalzow and Paalzow, 1976; Fielding et al., in press) suggesting that clonidine does not bind to opiate receptors. The above reports suggesting a similarity between clonidine and narcotics are particularly interesting in view of the fact that self-administration behavior was maintained in 
rats self-administering the narcotic fentanyl when clonidine (15 ug/Kg/injection) was substituted for the fentanyl solution.

In general, all drugs that are abused by man are selfadministered by laboratory animals, while the reverse does not always hold true the similarities between clonidine and narcotics noted above and the abuse of narcotics by humans and their self-administration by laboratory animals suggest that clonidine may have abuse potential. There are no reports of clonidine abuse among people, however, this could be due to its route of administration (orally) and also its prescription for hypertension. It is very interesting that patients in the Gold et al. (1978) study chose to be maintained on clonidine rather than methadone upon discharge from the hospital. While the authors do not report on the subjective effects produced by clonidine in these opiate addicts, the subjective effects are of considerable importance. It could be that intravenous administration of clonidine by narcotic addicts produces the same subjective effects, "euphoria," as those produced by narcotics. However, clonidine does not generalize to morphine in rats trained to discriminate morphine from saline (Lal et al., 1977). Therefore, clonidine may not produce the same subjective effects as narcotics since these effects are considered related to their discriminative stimulus properties (Lal and Gianutsos, 1976; Lal et al., 1977), although in these discrimination studies both clonidine and morphine were administered 
intraperitoneally. It cannot be stated with certainty therefore whether or not clonidine produces the same subjective effects as narcotics when administered intravenously.

one subject died within eleven hours of the substitution of clonidine (15 ug/ $\mathrm{kg} /$ injection) for fentanyl. Complete loss of eye pigmentation (eyes white) was noted. In another rat the substitution of clonidine (15 ug/ $\mathrm{kg} /$ injection) led to self-mutilation of the forelimbs. Razzak (1975) reported that intraperitoneal administration of a large dose (50 mg/ $/ \mathrm{kg}$ ) of clonidine produced self-mutilation in mice.

Self-administration was not maintained in rats previously self-administering fentanyl; however, when a lower dose of clonidine (1 ug/ Kg/injection) or saline was substituted for the fentanyl solution, Thompson and Pickens (1970) noted that when the opportunity to self-administer a narcotic or a psychomotor stimulant was withdrawn, there was an initial increase in responding followed by a gradual decrease. The increase in responding following the discontinuation of administration of a positive reinforcer is referred to as an "extinction burst." This phenomenon was noted when clonidine (l ug/Kg/injection) was substituted for fentanyl. On day one of substitution of clonidine ( $1 \mathrm{ug} / \mathrm{Kg} / \mathrm{injection}$ ) an increase in responding above that observed for fentanyl alone was noted, thereafter responding gradually declined.

Substitution of saline for the fentanyl solution also produced extinction of lever pressing behavior; however, no extinction burst was observed. This could be because lever 
pressing was measured every 24 hours and therefore an initial increase in lever pressing during the early hours of substitution was masked. Winger et al. (1975) reported that responding decreased less rapidly when saline was substituted for drug than when responding had no consequence. The somewhat different extinction patterns observed following the substitution of clonidine ( $1 \mathrm{ug} / \mathrm{Kg} / \mathrm{injection}$ ) and saline for the fentanyl solution could therefore be due to the mere presence and absence of drug effect as perceived by the subject.

Effect of Adding Naloxone to the Clonidine and Fentanyl Solutions for Self-Administration of the Drug Mixture

Narcotic antagonists are effective in preventing and reversing the pharmacological actions of opiates and can elicit narcotic-withdrawal in opiate-dependent organisms. Naloxone can be considered a relatively pure opiate antagonist which produces no discernable subjective effects when administered to non-opiate dependent subjects (Jaffe and Martin, 1975).

As mentioned earlier, clonidine produces several pharmacological actions similar to narcotics. Therefore, it was of interest to examine the effect of naloxone on clonidine and fentanyl self-administration behavior.

When added to the clonidine solution so that the subjects received $64 \mathrm{ug} / \mathrm{Kg} /$ injection, naloxone did not decrease 
rates of self-administration of rats previously self-administering clonidine ( $15 \mathrm{ug} / \mathrm{Kg} /$ injection) alone. These findings are in agreement with the results of the recent studies of Paalzow and Paalzow (1976) and Fielding et al. (1977, in press) which demonstrate that clonidine-induced analgesia is not antagonized by naloxone. They are also consistent with the report of Meyer et al. (1977) who demonstrated that naloxone; in doses capable of suppressing operant behavior, causing body weight loss and other symptoms of withdrawal in morphine-dependent rats (Gellert and Sparber, 1977), failed to disrupt operant behavior in clonidine-dependent rats. Therefore, clonidine's reinforcing effects do not appear to be mediated through an interaction at the opiate receptor. In another study investigating the effect of a narcotic antagonist on the self-administration of a non-narcotic drug, Goldberg et al. (1972) reported that nalorphine had no effect on rates of cocaine self-administration in monkeys.

Narcotic antagonists have been demonstrated to maintain responding that postpones or terminates their administration (i.e. to act as negative reinforcers) in morphine-dependent monkeys (Goldberg, 1971,1972; Downs and Woods, 1975; Woods et al., 1975) and rats (Smith, 1973). In drug-naive animals narcotic antagonists with weak antagonistic properties such as pentazocine and propiram will maintain behavior leading to their administration (i.e. to act as positive reinforcers) (Woods and Villareal, 1970; Hoffmeister and Schlichting, 1972; Goldberg et al., 1972) while narcotic antagonists with 
strong antagonistic properties such as cyclazocine and nalorphine do not function as positive reinforcers (Deneau et al., 1969; Hoffmeister and Schlichting, 1972) and may act as negative reinforcers (Hoffmeister and Wuttke, 1973).

Low doses of narcotic antagonists have been reported to increase morphine self-administration (Weeks and Collins, 1964; Thompson and Schuster, 1964; Goldberg et al., 1969, 1971, 1972) while high doses decrease responding to obtain morphine injections (Goldberg et al., 1972). Furthermore, narcotic antagonists have been demonstrated to block the ability of narcotics to impart secondary reinforcing properties on previously neutral stimuli (Davis and Smith, 1974; Marcus et al., 1976).

When naloxone was added to the fentanyl solution so that the subjects received $64 \mathrm{ug} / \mathrm{Kg} /$ injection there was a significant decrease in the self-administration rates of rats previously self-administering fentanyl ( $1 \mathrm{ug} / \mathrm{Kg} / \mathrm{injec}-$ tion) alone. Response rates remained significantly suppressed below pre-naloxone rates while naloxone remained in the fentanyl solution but gradually returned toward prenaloxone rates when naloxone was removed from the fentanyl solution. Similar results were obtained by Woods et al. (1975) who examined the effect of response-contingent naloxone injections on codeine-reinforced responding in rhesus monkeys. Naloxone produced a dose-dependent decrease in codeine-reinforced responding when added to the codeine 
solution for self-administration of the codeine-naloxone mixture. Furthermore, codeine-reinforced responding remained suppressed while naloxone remained in the codeine solution and gradually returned to pre-naloxone rates over three sessions following removal of naloxone. Woods et al., (1975) suggest that response-contingent naloxone injections function as a punishing stimulus which decreases selfadministration (lever pressing) behavior. Since almost identical results were obtained in this and the woods et al. study, decreased fentanyl-reinforced responding following addition of naloxone to the fentanyl solution may also be explained by the punishing effects of response-contingent naloxone injections. 
Effect of Adding Some Butyrophenone to the Clonidine and Fentanyl Solution for Self-Administration of the Drug Mixture

\section{Haloperidol}

Chemically, haloperidol is the prototype of the butyrophenone series of neuroleptic compounds (Janssen, 1967). The $E D_{50}$ values for haloperidol in the norepinephrine and amphetamine antagonism tests in rats are 2.10 and 0.38 $\mathrm{mg} / \mathrm{Kg}$, respectively (Janssen and Van Bever, 1978). Thus haloperidol is an extremely potent antagonist of dopamine receptors, a property which affords this drug tremendous efficacy in the treatment of psychoses.

Hanson and Cimini-Venema (1972) reported that low doses of haloperidol $(0.6 \mathrm{mg} / \mathrm{Kg}$, twice daily) increased morphine self-administration in rats while doses of $0.24 \mathrm{mg} / \mathrm{kg}$ and higher, twice daily, significantly decreased morphine selfadministration. Similarly, Pozuelo and Kerr (1972) reported that haloperidol decreased morphine intake in morphinedependent monkeys and Glick and Cox (1975) reported a doserelated antagonism of morphine self-administration produced by haloperidol. Utilizing a conditioned reinforcement test, Smith and Davis (1975) demonstrated that haloperidol-induced decreases in morphine self-administration was the result of a motor deficit and was not the result of antagonism of the reinforcing action of morphine. However, investigations of the effects of neuroleptics on psychomotor stimulant selfadministration (Davis and Smith, 1975; Yokel and Wise, 
1975, 1976) indicate that neuroleptics attenuate the reinforcing effects of this class of drugs at doses which do not produce motor deficits.

The results of these studies suggest that haloperidol and other neuroleptics may have potential value in the treatment of narcotic and psychomotor stimulant abuse. This suggestion is supported by the finding that amphetamine euphoria is reduced after pimozide, a diphenulbutylpiperidine neuroleptic (Janssen et al., 1968), administration to humans (Gunne et al., 1972). Furthermore, Karkalas and Lal (1973) reported that haloperidol suppressed heroin abstinence and reduced craving for the drug.

Lever pressing rates of rats previously self-administering clonidine ( $15 \mathrm{ug} / \mathrm{Kg} /$ injection) or fentanyl ( $\mathrm{lug} / \mathrm{kg} /$ injection) alone significantly decreased when haloperidol was added to the clonidine and fentanyl solutions so that the subjects received $64 \mathrm{ug} / \mathrm{Kg} /$ injection. The addition of haloperidol did not preferentially affect clonidine- or fentanyl-reinforced responding; rather, haloperidol produced a similar reduction in lever pressing when added to either drug solution. Suppression of clonidine- and fentanyl-reinforced responding remained stable while haloperidol remained in the drug solutions. Clonidine- and fentanyl-reinforced responding tended to return to prehaloperidol rates upon removal of haloperidol from both drug solutions; however, the number of subjects was too small to determine statistical significance. 
Unfortunately, all of the animal studies cited above measured the effect of subcutaneous or intraperitoneal administration of neuroleptics on narcotic and psychomotor stimulant self-administration, whereas making a direct comparison between the effect of adding the neuroleptic haloperidol to the clonidine and fentanyl solutions is difficult. The addition of haloperidol to the clonidine and fentanyl solutions could have decreased response rates in rats previously self-administering clonidine and fentanyl alone for several reasons.

Investigations of the neurochemical basis for reinforcement resulting from the self-administration of narcotics (Davis and Smith, 1972; Davis and Smith, 1973a; Glick et al., 1973) and psychomotor stimulants (Davis and Smith, 1972; Davis and Smith, 1973b) have implicated central catecholaminergic brain mechanisms. Attempts to discriminate between brain noradrenergic and dopaminergic mechanisms suggest the involvement of noradrenergic receptors in opiate reinforcement (Davis et al., 1975), while both noradrenergic and dopaminergic receptors appear to be involved in psychomotor stimulant reinforcement (Davis et al., 1975; Davis and Smith, 1975). In view of the known anti-catecholaminergic activity of haloperidol it could be suggested that decreased self-administration rates in rats previously self-administering either clonidine or fentanyl alone ae the result of attenuation of the reinforcing property underlying the action of these drugs. 
Neuroleptics are also known, however, to produce sedation and motor deficits. Therefore, reduced lever pressing produced by haloperidol may be the result of a performance deficit. Wise (1978) has reviewed evidence showing that neuroleptics interfere with reward processes at doses that do not cause significant performance impairment. Wise states that "data from studies of intravenous stimulant reward suggest the use of moment to moment analysis of the pattern of neuroleptic effects...". This type of analysis is to prevent the incorrect observations which can result when response rates are measured over an entire test session. For example, Yokel and Wise $(1975,1976)$ reported that low doses of the neuroleptic drugs pimozide and (+)butaclamol increased lever pressing for intravenous amphetamine injections. Higher doses produced an initial increase in lever-pressing followed by cessation of responding. The authors suggest that low doses of neuroleptics decrease the rewarding effects of amphetamine and that subjects increase lever pressing to overcome the neuroleptic attenuation of the rewarding effects. Higher doses were suggested to completely block the rewarding effects and thus following an initial extinction burst, gradual extinction of lever pressing is observed. A response pattern similar to the latter occurs when saline is substituted for a drug reinforcer. Had response rates been averaged over the entire session, however, Yokel and Wise would not have made the same observations since response 
rates in these studies were depressed over the entire test session. Since the effect of adding haloperidol on lever pressing rate in rats previously self-administering either clonidine or fentanyl alone was measured over a 24 hour period an initial increase in response rate (an indicator of reward attenuation) would have been masked, therefore it cannot be stated with certainty whether or not haloperidol was decreasing the reinforcing property of clonidine and fentanyl or was producing sedation and motor deficits. Finally, by definition, punishment is said to have occurred when the future probability of behavior that precedes the delivery of the punishing stimulus is reduced (Azrin and Holz, 1966). Therefore, the addition of haloperidol to the clonidine and fentanyl solutions could have produced a punishing (aversive) stimulus which resulted in the reduction of lever pressing so observed.

\section{Aceperone}

Aceperone is a butyrophenone neuroleptic which is virtually devoid of anti-dopaminergic activity (Janssen et al., 1967; Janssen, 1978) and should be considered as a specific alpha-adrenergic blocking agent and not as an antipsychotic (Janssen and Van Bever, 1978). $E D_{50}$ values for aceperone in the norepinephrine and amphetamine antagonism tests in rats are 0.60 and $160 \mathrm{mg} / \mathrm{Kg}$, respectively (Janssen and Van Bever, 1978). 
When aceperone was added to the clonidine solution, so that the subjects received $64 \mathrm{ug} / \mathrm{Kg} /$ injection, no significant change in the rates of self-administration of rats previously self-administering clonidine ( $15 \mathrm{ug} / \mathrm{Kg} /$ injection) alone was observed. As discussed earlier, the marked sympathomimetic signs exhibited by rats self-administering clonidine and results of other investigators suggested that the reinforcing action of clonidine was mediated by an interaction of post-synaptic alpha-noradrenergic receptors. Therefore, one would expect that the alpha-noradrenergic receptor antagonist, aceperone, would have some effect on the reinforcing effects of clonidine. Braestrup (1974) reported that aceperone produced a significant increase in the brain concentration of the major norepinephrine metabolite, 3-methoxy-4-hydroxy-phenylglycol (MOPEG), while clonidine significantly decreased MOPEG concentration. It is suggested by Braestrup (1974) that aceperone increases release of norepinephrine while clonidine decreases norepinephrine release.

Aceperone- and clonidine-induced changes in norepinephrine release may be accomplished by two mechanisms. Blockade of either pre- or post-synaptic alpha-noradrenergic receptors by aceperone would lead to increased norepinephrine release while stimulation of either pre- or post-synaptic receptors by clonidine would lead to a decrease in norepinephrine release. Thus, if clonidine were stimulating 
post-synaptic receptors and aceperone were blocking postsynaptic receptors one would expect antagonism of the reinforcing action of clonidine by aceperone. However, if clonidine were stimulating post-synaptic receptors and aceperone were blocking pre-synaptic receptors, no antagonism would be expected. In fact, the latter mechanism could be hypothesized to result in potentiation of the reinforcing action of clonidine. The differential affinity of aceperone for the pre- and post-synaptic alpha-adrenergic receptors is not known. It may also be suggested that both drugs are acting at the post-synaptic receptor but the dose of aceperone is insufficient to antagonize clonidine's agonist action. Clearly, more work is needed to investigate these results. The use of other alpha-adrenergic receptor blockers with differential actions at the pre- and post-synaptic such as piperoxane and phenoxybenzamine would be of interest.

When aceperone was added to the fentanyl solution so that the subjects received $64 \mathrm{ug} / \mathrm{Kg} /$ injection a significant (approximately two-fold) increase in the response rates of rats previously self-administering fentanyl (l ug/ $\mathrm{kg} /$ injection) alone was observed. The rates of self-administration remained fairly stable and significantly above preaceperone rates, while aceperone remained in the fentanyl solution. These results could be interpreted in two ways. As mentioned earlier, low doses of neuroleptics are reported to increase narcotic and psychomotor-stimulant self- 
administration, while higher doses produce an initial increase in responding followed by a decrease in drug selfadministration (Hanson and Cimini-Venema, 1972; Yokel and Wise, 1975, 1976). It was suggested that low doses of neuroleptics produce a partial blockade of the reinforcing actions of these drugs and thus subjects increase rates of self-administration to overcome the attenuation, while higher doses produce complete blockade of the reinforcing effects which after an extinction burst leads to extinction of the self-administration behavior. Since the noradrenergic system has been implicated in mediating the reinforcing actions of narcotics (Davis and Smith, 1975), blockade of alpha-noradrenergic receptors by aceperone could lead to attenuation of the reinforcing action of fentanyl and thus subjects increase lever pressing to overcome the aceperone action. If this interpretation is correct, then increasing the dose of aceperone added to the fentanyl solution should eventually produce complete blockade of the reinforcing effects of fentanyl and thus extinction of fentanyl selfadministration.

An alternative interpretation, however, is that adding aceperone to the fentanyl solution makes the drug combination more reinforcing than fentanyl alone. Again, Braestrup (1974) suggested that aceperone increase norepinephrine release. This action could be seen to potentiate the reinforcing actions of narcotics which are suggested to be mediated through the noradrenergic system (Davis and Smith, 1975). 
The latter interpretation may explain the increase in response rate observed when aceperone was removed from the fentanyl solution. Weeks and Collins (1964) reported that in physiologically dependent rats, self-administering morphine reducing the injection dose resulted in an increase in the number of injections taken. Thus if adding aceperone to the fentanyl solution increases the reinforcement per injection then decreasing the reinforcement per injection by removing aceperone from the fentanyl solution could result in a compensatory increase in lever pressing such as was observed. It should be noted, however, that a sufficient number of subjects to determine statistical significance of post-aceperone data was not achieved.

\section{Azaperone}

Azaperone is a sedative neuroleptic of the butyrophenone series with outstanding anti-aggressive and anti-shock activity in animals (Niemegeers et al., 1974). The effective dose $50\left(E_{50}\right)$ for azaperone in the norepinephrine antagonism test (a measure of anti-noradrenergic activity) in rats is $0.33 \mathrm{mg} / \mathrm{Kg}$ while the $E D_{50}$ value for azaperone in the amphetamine antagonism test (a measure of antidopaminergic activity) in rats is $2.5 \mathrm{mg} / \mathrm{Kg}$ (Niemegeers et al., 1974; Janssen and Van Bever, 1978). Therefore, azaperone is a more potent antagonist of noradrenergic receptors than of dopaminergic receptors. 
Lever pressing rates of rats previously self-administering either clonidine ( $15 \mathrm{ug} / \mathrm{Kg} /$ injection) or fentanyl ( $1 \mathrm{ug} / \mathrm{Kg} /$ injection) tended to decrease when azaperone was added to the respective drug solutions so that the subjects received $64 \mathrm{ug} / \mathrm{kg} /$ injection. Addition of azaperone did not preferentially affect clonidine- or fentanyl-reinforced responding; rather, azaperone tended to produce a similar reduction in lever pressing when added to either drug solution. Suppression of clonidine- and fentanylreinforced responding remained stable while azaperone remained in the drug solutions. Fentanyl- and clonidinereinforced responding tended to return to pre-azaperone rates when azaperone was removed from the clonidine and fentanyl solutions. It should be noted however, that the number of subjects was too small to determine a statistical significance.

Like haloperidol, the addition of azaperone to the clonidine and fentanyl solutions may result in a decrease in response rates for three reasons. First, azaperone could antagonize the reinforcing actions of clonidine and fentanyl which leads to the observed decrease in selfadministration behavior. Since azaperone is a potent catecholamine receptor antagonist non-specific motor deficits produced by the drug could produce the decreased response rates. Again, since response rate was measured over a 24-hour period one cannot determine whether azaperone decreased the rewarding action of clonidine and fentanyl as 
as an initial increase in lever pressing (an indicator of reward attenuation) would have been masked.

Neuroleptics of the butyrophenone- and phenothiazinetype are well known to produce dysphoric effects in nonschizophrenic human beings (Janke and Debus, 1968). Furthermore, both types of neuroleptics have been demonstrated to maintain behavior leading to their termination or nonoccurrence (i.e. to act as negative reinforcers) in rhesus monkeys (Hoffmeister, 1975; Hoffmeister and Wuttke, 1975; Hoffmeister, 1977). Therefore, perhaps the best explanation for the decreased response rates observed is that the addition of azaperone to the clonidine and fentanyl solutions forms a punishing stimulus which results in a reduction in lever pressing behavior. 
In summary it was demonstrated that laboratory rats will self-administer the alpha-noradrenergic receptor agonist clonidine when a dose of $15 \mathrm{ug} / \mathrm{Kg} / \mathrm{injection} \mathrm{is} \mathrm{made}$ contingent on a continuous reinforcement schedule. That clonidine was self-administered for its positive reinforcing property and not because of the drug's non-specific behavioral effects was demonstrated by an increase in the response rate to obtain clonidine injections as the response requirement to obtain each clonidine injection was increased.

It was also demonstrated that rats will self-administer fentanyl ( 1 but not $0.1 \mathrm{ug} / \mathrm{kg} /$ injection). Extinction of self-administration behavior in rats self-administering fentanyl following the substitution of saline for the fentanyl solution indicates that fentanyl was self-administered for its positive reinforcing effects.

In rats self-administering fentanyl (l ug/ $\mathrm{kg} / \mathrm{injection),}$ it was demonstrated that substitution of clonidine (15 but not $1 \mathrm{ug} / \mathrm{Kg} / \mathrm{injection)}$ for the fentanyl solution maintained self-administration behavior.

Pilot experiments demonstrated that addition of the narcotic antagonist naloxone to the clonidine and fentanyl solutions resulted in a significant decrease in fentanyl- 
reinforced responding but did not appear to decrease clonidine-reinforced responding. These data suggest that clonidine reinforcement is mediated by opioid independent mechanisms. Preliminary experiments also demonstrated that addition of haloperidol and azaperone to the clonidine and fentanyl solutions tended to result in a decrease in clonidine- and fentanyl-reinforced responding; however, the exact nature of this effect was unclear. Similarly, in a pilot experiment it was determined that addition of aceperone to the clonidine and fentanyl solutions had no effect on clonidine-reinforced responding but resulted in a twofold increase in fentanyl-reinforced responding. The exact basis of these results remains to be determined.

In conclusion, self-administration of the alpha-noradrenergic receptors agonist clonidine and increased selfadministration rates to obtain clonidine injections as the response requirement to obtain each clonidine injection was increased suggests that stimulation of alpha-noradrenergic receptors can result in positive reinforcement. All drugs that are abused by humans are self-administered by laboratory animals and most drugs that are self-administered by laboratory animals are self-administered by man. Therefore, intravenous self-administration of clonidine by rats suggests that clonidine may possibly possess abuse potential by humans if self-administered intravenously. Also, because of the known abuse of narcotics by humans, maintainence by clonidine of self-administration behavior of 
rats previously self-administering the synthetic narcotic fentanyl supports this suggestion.

Preliminary experiments suggest that fentanyl- and clonidine-reinforced responding are similarly affected by the addition of haloperidol and azaperone to the fentanyl and clonidine solutions. However, the exact nature of these effects remains to be determined. Furthermore, preliminary experiments with aceperone suggest that fentanyland clonidine-reinforced responding are affected differentially by the addition of aceperone to the fentanyl and clonidine solutions. Finally, decreased fentanyl- but not clonidine-reinforced responding by response-contingent naloxone injections suggests that clonidine reinforcement is not mediated by opioid dependent mechanisms. 
REFERENCES

Aghajanian, G.K. and Bunney, B.S.: Pharmacological characterization of dopamine "autoreceptors" by microiontophonetic sing-ecell recording studies. In Nonstriatal Dopaminergic Neurons, edited by E. Costa and G. L. Gessa, pp. 433-438 , Raven Press, New York, 1977.

Ahlenius, S., Anden, N.E., and Engel, J.: Importance of catecholamine release by nerve impulses for free operant behavior. Physiol. Behav. 7: 931-934, 1971.

Anden, N.E., Dahlstrom, A., Fuxe, K. and Larsson, K.: Functional role of the nigro-neostriatal dopamine neurons. Acta Pharmacol. Toxicol. 24: 263-274, 1966.

Anden, N.E., Corrodi, H., Fuxe, K. and Hokfelt, T.: Evidence for a central 5-hydroxytryptamine receptor stimulation by lysergic acid diethylamide. Brit. J. Pharmacol. 34: 1-7, 1968 .

Anden, N.E., Corrodi, H., Fuxe, K., Hokfelt, B., Rydin, C. and Svensson, T.: Evidence for a central noradrenaline receptor stimulation by clonidine. Life sci. 9: $513-523,1970$.

Anden, N.E., Butcher, S.G. and Engel, J.: Central dopamine and noradrenaline receptor activity of the amines formed from $m$-tyrosine, alpha-methyl-m-tyrosine and alpha-methyl dopa. J. Pharm. Pharmacol. 22: 548-550, $1970 \mathrm{a}$.

Anden, N.E., Strombom, U. and Svensson, T.H.: Dopmaine and noradrenaline receptor stimulation: Reversal of reserpeine-induced suppression of motor activity. Psychopharmacologia 29: 289-298, 1973.

Anden, N.E., Gabrowska, M. and Strombom, U.: Different alphaadrenoceptors in the central nervous system mediating the biochemical and functional effects of clonidine and receptor blocking agents. Nauryn-Schmiedebergs Archives Pharmacologia 292: 43-52, 1976.

Anderson, W.W. and Thompson, J.: Ethanol self-administration in water satiated rats. Pharmacol. Biochem. Behav. 2 : 447-454, 1974 .

Azrin, N.H. and Holz, W.C.: Punishment. In: Operant Behavior: Areas of research and application, edited by W.K. Honig pp. 380-447, Appleton-Century-Crofts, New York, 1966. 
Balster, R.L. and Schuster, C.R.: Fixed-interval schedule of cocaine reinforcement: effect of dose and infusion duration. J. of Exp. Anal. Behav. 20: 119-129, 1973.

Baxter, B.L., Gluckman, M.I., stein, L. and Scerri, R.A.: Self-injection of apomorphine in the rat: positive reinforcement by a dopamine receptor stimulant. Pharmacol. Biochem. Behav. 2: 387-391, 1974.

Belluzi, J.D., Ritter, S., Wise, C.D., Stein, L.: Substania nigra self-stimulation: dependence on noradrenergic pathways. Behav. Biol. 13: 103-111, 1975.

Bentley, G.A., Copeland, I.W. and Starr, J.: The actions of some alpha-adrenoceptor agonists and antagonists in an antinociceptive test in mice. Clin. Exp. Pharmacol. Physiol. 4: 405-419, 1977.

Bill, A. and Heilmann, K.: Ocular effects of clonidine in cats and monkeys (Macacu irus). Exp. Eye Res. 21: $481-488,1975$.

Bjonkqvist, S.E.: Clonidine in alcohol withdrawal. Acta Psychiat. Scand. 52: 256-263, 1975.

Boissier, J.R., Gindialli, J.F., Fichelle, J., Schmitt, H. and Schmitt, H.: Cardiovascular effects of 2-(2,6-dichlorophenylamine)-2-imidazole (St 155). Europ. J. Pharmacol. 2: 333-339, 1968.

Braestrup, C.: Effects of phenoxybenzamine aceperone and clonidine on the level of 3-methoxy-4-hydroxy-phenylglycol (MOPEG) in ratbrain. J. Pharm. Pharmacol. 26 : $139-141,1974$.

Bullock, S.A., Kruse, H., and Fielding, S.: The effect of clonidine on conflict behavior in rats: is clonidine an anxiolytic agent? Pharmacologist 20: 223, 1978.

Burks, T.F.: Central alpha-adrenergic receptors in thermoregulation. Neuropharmacol. 11: 615-624, 1972 .

Cedarbaum, J.M. and Aghajanian, G.K.: Noradrenergic neurons of the locus coeruleus: inhibition by epinephrine and activation by the K-antagonist piperoxane. Brain Res. 112: 413-419, 1976 .

Cedarbaum, J.M. and Aghajanian, G.K.: Catecholaminergic receptors on locus coeruleus neurons: pharmacological characterization. Eur. J. Pharmacol. 44: 375-385, 1977. 
Colelli, B., Meyer, D.R. and Sparber, S.B.: Clonidine antagonizes disruption of fixed ratio operant behavior in morphine pelleted rats given naloxone. Pharmacologist $18: 236,1976$.

Constantine, J.W. and McShane, W.K.: Analysis of the cardiovascular effects of 2- (2,6-dichlorophenylamine)-2imidazoline hydrochloride (Catapresan). Eur. J. Pharm. 4: 109-123, 1968 .

Cornfeldt, M.I., Fielding, S., Kruse, H., Billey-Nichuck, J., Dobson, C. and Wilker, J.: Clonidine: inhibition of amphetamine-induced circling and other psychopharmacological effects. Pharmacologist 20: 162, 1978 .

Cubeddu, L., Barnes, F.M., Langer, S.Z. and Weiner, N.: Release of norepinephrine and dopamine- $\mathcal{B}$-hydroxylase by nerve stimulation. 1. Role of neuronal and extraneuronal uptake of $\alpha$-presynaptic receptors. J. Pharmacol. Exp. Ther. 190: 431-450, 1974.

Dahlstrom, A. and Fuxe, K.: Evidence for the existence of monamine-containing neurons in the central nervous system. I. Demonstration of monoamines in the cell bodies of brain stem neurons. Acta Physiologica Scand. 62 : $1-55,1965$.

Davis, W.M. and Smith, S.G.: Alpha-methyl-tyrosine to prevent self-administration of morphine and amphetamine.

Curr. Ther. Res. 14: 814-819, 1972.

Davis, W.M. and Smith, S.G.: Blocking of morphine based reinforcement by alpha-methyltyrosine. Life sci. 12 : 185-191, 1973a.

Davis, W.M. and Smith, S.G.: Blocking effect of alphamethyltyrosine on amphetamine based reinforcement. J. Pharm. Pharmacol. 25: 174-177, 1973b.

Davis, W.M. and Smith, S.G.: Noradrenergic basis for reinforcement associated with morphine action in nondependent rats. In Drug Addiction, Vol. 3, pp. 155-168, edited by J.M. Singh and H. Lal, Symposia specialists, Miami, 1974.

Davis, W.M. and Smith, S.G.: Naloxone use to eliminate opiateseeking behavior: need for extinction of conditioned reinforcement. Biol. Psychiat. 9: 181-189, 1974a.

Davis, W.M., Smith, S.G. and Khalsa, J.H.: Noradrenergic role in the self-administration of morphine and amphetamine. Pharmacol. Biochem. Behav. 3: 477-484, 1975. 
Davis, W.M. and Smith, S.G.: Effect of haloperidol on (+) amphetmaine self-administration. J. Pharm. Pharmacol. 27 : $540-542,1975$.

Delbarre, B. and Schmitt, H.: Sedative effects of alphasympathomimetic drugs and their antagonism by adrenergic and cholinergic blocking drugs. Eur. J. Pharmacol. 13: $356-363$, 1971 .

Deneau, G., Yangita, T. and Seevers, M.H.: Self-administration of psychoactive substances by the monkey. A measure of psychological dependence. Psychopharmacologia 16: 30-48, 1969.

Dix, R.K. and Johnson, E.M.: Withdrawal syndrome upon cessation of chronic clonidine treatment in rats. Eur. J. Pharmacol. 44: 153-159, 1977.

Donaldson, I., Dolphin, A., Jenner, P., Marsden, C.D. and Pycock, C.: The roles of noradrenaline and dopamine in contraversive circling behavior seen after unilateral electrolytic lesions of the locus coeruleus. Eur. J. Pharmacol. 39: 179-191, 1976.

Dougherty, J. and Pickens, R.: Fixed-interval schedules of intravenous cocaine presentation in rats. J. Anal. Behav. 20: 111-118, 1973.

Downs, D.A. and Woods, J.H.: Codeine-and cocaine-reinforced responding in rhesus monkeys: effects of dose on response rates under a fixed-ratio schedule. J. Pharmacol. Exp. 191: 179-188, 1974 .

Downs, D.A. and Woods, J.H.: Fixed-ratio escape and avoidance escape from naloxone in morphine-dependent monkeys: effects of naloxone dose and morphine pretreatment. J. Exp. Anal. Beh. 23: 415-427, 1975.

Farnebo, L.O. and Hamberger, B.: Drug-induced changes in the release of $3 \mathrm{H}$-monoamine from field stimulated rat brain slices. Acta Physiologica Scand. : 35-44, 1971.

Feldberg, W. and Myers, R.O.: Effects on temperature of amines injected into the cerebral ventricles. A new concept of temperature regulation. J. Physiol. 173: 226-237, 1964.

Fibiger, H.C.: Drugs and reinforcement mechanisms: a critical review of the catecholamine theory. Ann. Rev. Pharmacol. Tox. 18: 37-56, 1978 . 
Fielding, S., Wilker, J., Hynes, M., Szewzak, M., Novick, W. and Lal, H.: Antinociceptive and withdrawal actions of clonidine: A comparison with morphine. Fed. Proc. 36 : $1024,1977$.

Fielding, S., Wilker, J., Hynes, M., Szewczak, M., Novick, W. and Lal, H.: A comparison of clonidine with morphine for antinociceptive and antiwithdrawal actions. $\mathrm{J}$. Pharmac. Exp. Ther., in press.

Florio, V., Bianchi, L. and Lonogo, V.G.: A study of the central effects of sympathomimetic drugs: EEG and behavioral investigations of clonidine and naphazoline. Neuropharmacol. 14: 707-714, 1975.

Franklin, K.B.J. and Herberg, L.J.: Self-stimulation and catecholamines. Drug-induced mobilization of the 'Reserve'-pool re-established responding in catecholamine-depleted rats. Brain Res. 67: 429-437, 1974.

Franklin, K.B.J. and Herberg, L.J.: Presynaptic $\alpha$-adrenoceptors: The depression of self-stimulation by clonidine and its restorationby piperoxane but not by phentolamine or phenoxybenzamine. Eur. J. Pharma . 43: 33-38, 1977.

Gazzani, J.I. and Izquierdo, I.: Possible peripheral adrenergic and central dopaminergic influences on memory consolidation. Psychopharmacology 49: 109-112, 1976.

Gellert, V.F. and Sparber, S.B.: A comparison of the effects of naloxone upon body weight loss and suppression of fixed-ratio operant behavior in morphine-dependent rats. J. Pharmacol. Exp. Ther. 201: 44-54, 1977.

German, D.C. and Bowden, D.M.: Catecholamine systems as the neural substrate for intracranial self-stimulation: a hypothesis. Brain Res. 73: 381-419, 1974.

Gianutsos, G., Hynes, M.D. and Lal, H.: Enhancement of morphine-withdrawal and apomorphine-induced aggression by clonidine. Psychopharm. Comm. 2: 165-171, 1976.

Glick, S.D., zimmerberg, B. and Charap, A.D.: Effects of alpha-methyl-para-tyrosine on morphine dependence. Psychopharmacology 32: 365-371, 1973.

Glick, S.D. and Cox, R.D.: Dopaminergic and cholinergic influences on morphine self-administration in rats. Res. Comm. Clin. Pathol. Pharmacol. 12: 17-24, 1975.

Glick, S.D. and Cox, R.: Differential sensitivity to apomorphine and clonidine following frontal cortical damage in rats. Eur. J. Pharmacol. 36: 241-245, 1976. 
Gogoak, V.G. and Stumpf, Ch.: The effects of $2-(2,6-d i-$ chlorophenylamino)-2-imidazoline hydrochloride on the EEG-arousal reaction in rabbits. Arzneim. Forsch. 16: 1050-1052, 1966 .

Gold, M.S., Redmond, D.E. Jr. and Kleber, H.D.: Clonidine in opiate withdrawal. Lancet 1: 929-930, 1978.

Goldberg, S.R., Woods, J.H. and Schuster, C.R.: Morphine: Conditioned increases in self-administration in rhesus monkeys. Science. 166: 1306-1307, 1969.

Goldberg, S.R., Woods, J.H. and Schuster, C.R.: Nalorphineinduced changes in morphine self-administration in rhesus monkeys. J. Pharmacol. Exp. Ther. 176: 464-471, 1971a.

Goldberg, S.R., Hoffmeister, F., Schlichting, U.U. and Wuttke, W. Aversive properties of nalorphine and naloxone in morphine-dependent rhesus monkeys. J. Pharmacol. Exp. Ther. 179 : 268-276, $1971 b$.

Goldberg, S.R., Hoffmeister, F., Schlichting, U.V. and Wuttke, W.: A comparison of pentobarbital and cocaine selfadministration in rhesus monkeys: effects of dose and fixed-ratio parameter. J. Pharmacol. Exp. Ther. 179: 277-283, 197lc.

Goldberg, S.R., Hoffmeister, F. and Schlichting, U.U.: Morphine antagonists: modification of behavioral effects of morphine dependence. In Drug Addiction: I. Experimental Pharmacology edited by J.M. SIngh, L. Miller and H. Lal pp. 31-48, Futura Publishing Co., New York, 1972.

Goldberg, S.R.: Comparable behavior maintained under fixedratio and second-order schedules of food presentation, cocaine injection or d-amphetamine injection in the squirrel monkey. J. Pharmacol. Exp. Ther. 186: 18-30, 1973.

Goldberg, S.R., Kelleher, R.T. and Morse, W.H.: Second-order schedules of drug injection. Fed. Proc. 34: 1171-1176, 1975.

Goldberg, S.R. and Kelleher, R.T.: Behavior controlled by fixed-interval, fixed-ratio and multiple schedules of cocaine injection in squirrel monkeys and rhesus monkeys. J. Exp. Anal. Behav. 25: 93-104, 1976.

Gomes, C., Svensson, T.H. and Trolin, G.: Effects of morphine on central catecholamine turnover, blood pressure and heart rate in the rat. Nauyn-Schmeidebergs Arch. Pharmacol. 294: 141-147, 1976. 
Gunne, L.M., Anggard, E., and Jonsson, L.E.: Clinical trials with amphetamine-blocking drugs. Psychiat. Neurol. Neurochirimie 75: 225-226, 1972.

Hanson, H.M. and Cimini-Venama, C.A.: Effects of haloperidol on self-administration of morphine in rats. Fed. Proc. 31: 503,1972 .

Harris, R., Snell, D., Loh, H.H. and Way, E.L.: Behavioral interactions of apomorphine, clonidine and naloxone: possible pre-synaptic involvement. Proc. West. Pharmacol. Soc. 19: 448-451, 1976 .

Harris, R.A., Snell, D., Loh, H.H., and Way, E.L.: Behavioral interactions between naloxone and dopamine agonists. Pharmacol. 43: 243-246, 1977.

Harvey, S.C.: Hypnotics and sedatives. In: The Pharmacological Basis of Experimental Therapeutics, edited by L.S. Goodman and A.G. Gilman, 102-123 New York, Macmillan Publishing Co.

Hastings, L. and Stutz, R.M.: The effect of alpha- and betaadrenergic antagonists on the self-stimulation phenomenon. Life Sci. 13: 1253-1259, 1973.

Herman, Z.S., Brus, R., Drybanski, A., Szkilnik, R. and Slominska-zurek, J.: Influence of 6-hydroxydopamine on the behavioral effects induced apomorphine or clonidine in rats. Psychopharmacology 50:73-80, 1976.

Hoffmeister, F. and Schlichting, U.U.: Reinforcing properties of some opiates and opioids in rhesus monkeys with histories of cocaine and codeine self-administration. Psychopharmacologia 23: 55-74, 1972 .

Hoffmeister, F. and Wuttke, W.: Negative reinforcing properties of morphine antagonists in naive rhesus monkeys. Psychopharmacologia 33: 247-258, 1973.

Hoffmeister, F.: Negative reinforcing properties of some psychotropic drugs in drug-naive rhesus monkeys. J. Pharmacol. Exp. Ther. 192: 468-477, 1975.

Hoffmeister, F. and Wuttke, W.: Psychotropic drugs as negative reinforcers. Pharmacol. Rev. 27: 419-428, 1975.

Hoffmeister, F.: Reinforcing properties of perphenazine, haloperidol and amitryptiline in rhesus monkeys. J. Pharmacol. Exp. Ther. 200: 516-522, 1977.

Hoefke, W. and Kobinger, W.: Pharmacological effects of 2-(2,6 dichlorophenylamino)-2-imidazoline hydrochloride, a new antihypertensive substance. Arzneim. Forsh. 16: $1038-1050$, 1966 . 
Holman, R.B., Shillito, E.E. and Vogt, M.: sleep produced clonidine (2-(2,6-dichlorophonylamino)-2-imidazoline hydrochloride). Br. J. Pharmacol. 43: 685-695, 1971.

Hunt, G.E., Atrens, D.M., Chechet, G.B., and Becker, F.T.: $\alpha$-Noradrenergic modulation of hypothalamic selfstimulation: studies employing clonidine, 1-phenylephrine and $\alpha$-methyl-p-tyrosine. Eur. J. Pharmacol. 37: 105-111, 1976.

Hunyor, S.N., Bradstock, K., Somerville, P.J. and Lucas, N.: Clonidine overdose. Brit. Med. 4: 23, 1975.

Iglaver, C. and Woods, J.H.: Concurrent performances: Reinforcement by different doses of intravenous cocaine in rhesus monkeys. J. Exp. Anal. Behav. 22: 179-196, 1974 .

Jaffe, J.H. and Martin, W.R.: Narcotic analgesics and antagonists. In: The Pharmacological Basis of Therapeutics edited by I.S. Goodman and A. Gilman, pp. 245-283, Macmillan Publishing Co., New York, 1975.

Jahn, U. and Mixich, G.: Wet dog shake behavior in normal rats elicited by benzylidenaminooxycarbonic acid derivatives. Psychopharmacologia, 46: 191-196, 1976.

Janke, W. and Debus, G.: Experimental studies on antianxiety agents with normal subjects: Methodological considerations and review of main effect. In. Psychopharmacology: A Review of Progress, 1957-1967, edited by D.H. Efron, pp. 205-230, U.S. Government Printing office, Washington, D.C., 1968.

Janssen, P.A.J.: The pharmacology of haloperidol. Int. J. Neurophsychiat. 3: 10-18, 1967.

Janssen, P., Niemegeers, C., Schellekens, K. and Lenaerts, F.: Is it possible to predict clinical effects of neuroleptic drugs (major tranquilizers) from animal data? Arzneim. Forsch. Drug Res. 17: 841-854, 1967.

Janssen, P.A.J., Niemegeers, C.J.E., Schellekens, K.H.I., Dresse, A., Lenaerts, F.M., Pinchard, A., Shaper, W.K.A., Van Neuten, J.M. and Verbruggen, F.J.: Pimozide, a chemical novel, highly potent and orally long-acting neuroleptic drug. I. The comparative pharmacology of pimozide, haloperidol, and chlorpromazine. Arzneim: ForschDrug Res. 18: 261-279, 1968. 
Janssen, P.A.J. and Ven Bever, W.F.M.: Structure-activity relationships of the butyrophenones and diphenylbutylpiperidines. In: Handbook of Psychopharmacology Vol. 10 edited by $L$. Iversen, S. Iversen, and S. Snyder, pp. 1-35, Plenum Press, New York, 1978.

Jenner, P.G. and Pycock, C.J.: Interaction of clonidine with dopamine-dependent behaviors in rodents. Brit. J. Pharmacol. 58: 469, 1976.

Jonsson, L.E., Gunne, L.M. and Anggard, E.: Effects of alpha-methyltyrosine in amphetamine-dependent subjects. Pharmac. Clin. 27-29, 1969.

Jonsson, L.E., Anggard, E. and Gunne, L.M.: Blockade of intravenous amphetamine euphoria in man. Clin. Pharmacol. Ther. 12: 889-896, 1971.

Karkalas, J. and Lal, H.: A comparison of haloperidol with methadone in blocking heroin-withdrawal symptoms. Int. Pharmacopsychiat. 8: 248-251, 1973.

Karppanen, H.: Possible involvement of central histamine $\mathrm{H}_{2}$-receptors in the hypotensive effect of clonidine. Nature 259: 587-588, 1976.

Kelleher, R.T. and Morse, W.H.: Escape behavior and punished behavior. Fed. Proc. 23: 808-817, 1964.

Knapp, M.S. and Galloway, N.R.: Ocular reactions to betablockers. Brit. Med. J. I: 557, 1975.

Kobinger, $W$. and Walland, A.: Investigations into the mechanism of the hypotensive effect of 2-(2,6-dichlorophenylamino)-2-imidazoline HCl. Eur. J. Pharmacol. 2: 155-162, 1967.

Korf, J., Bunney, B.S. and Aghanjanian, G.K.: Noradrenergic neurons: morphine inhibition of spontaneous activity. Eur. J. Pharmacol. 25: 165-169, 1974.

Kuhar, M.J., Pert, C.B. and Snyder, S.H.: Regional distribution of opiate receptor binding in monkey and human brain. Nature 245: 1447-450, 1973.

Lal, H.: Morphine-withdrawal aggression. In: Methods in Narcotic Research, edited by S. Ehrenpreis and E.A. Neidle, pp. 149-169, Marcel Dekker, New York, 1975. 
Lal, H. (ed.): Discriminative stimulus properties of drugs, New York: Plenum Press, New: York, 1977.

Lal, H., Gianutsos, G. and Puri, S.K.: Comparison of narcotic analgesics with neuroleptics on behavioral measures of dopaminergic activity. Life Sci. 17: 29-34, 1975 .

Lal, H. and Gianutsos, G.: Discriminable stimuli produced by narcotic analgesics. Psychopharmacol. Comm. 2: 311-314, 1976.

Lal, H., Gianutsos, G. and Miksic, S.: Discriminable stimuli produced by analgesics. In: Discriminative Stimulus Properties of Drugs, edited by H. Lal pp. 23-45 , Plenum Press, New York, 1977.

Lal, H., Kaplan, L., Numan, R. and Valentino, D.: Acquisition and extinction of operant responding for intravenous injections of fentanyl in the rat. Comm. Psychopharmacol. 1: 207-212, 1977.

Laverty, R. and Taylor, K.M.: Behavioral and biochemical effects of 2-(2,6-dichlorophenylamino-2-imidazoline hydrochloride (ST 155) on the central nervous system. Brit. J. Pharmacol. 35: 253-264, 1969.

Le Douarec, J.C., Schmitt, H. and Lucet, B.: Effect of clonidine and alpha-sympathomimetics on water intake in rats deprived of water. J. Pharmacol. (Paris), 2: $435-444,1971$.

Le Douarec, J.C., Schmitt, H. and Lucet, B.: Effects of clonidine and other alpha-sympathomimetic agents on food intake: antagonism by adrenolytics. J. Pharmacol. (Paris) 3: 187-198, 1972.

Lenard, L.G. and Beer, B.: Modification of avoidance behavior in 6-hydroxydopamine-treated rats by stimulation of central noradrenergic and dopaminergic receptors. Pharmacol. Biochem. Behav. 3: 887-893, 1975.

Maas, J.W., Hattox, S.E., Landis, D.H. and Roth, R.H.: The determination of a brain arteriovenous difference for 3-methoxy-4-hydroxyphenethyleneglycol (MHPG). Brain Res. 118: 167-173, 1976.

Maj, J., Sowinska, H., Baran, L. and Kapturkiewicz, Z .: The effect of clonidine on locomotor activity in mice. Life Sci. 11: 483-491, 1972 .

Maj, J., Baran, L., Grabowska, M. and Sowinska, H.: Effect of clonidine on the 5-hydroxytryptomine and 5-hydroxyindole-acetic acid brain levels. Biochem. Pharmacol. 22: 2679-2683, 1973 . 
Maj, J., Baran, L., Sowinska, H. and Zielinski, M.: The influence of cholinolytics on clonidine action. Pol. J. Pharmacol. 27: 17-26, 1975.

Marcus, R., Carnathan, G., Meyer, R.E. and Cochin, J.: Morphine-based secondary reinforcement: Effects of different doses of naloxone. Psychopharmacol. 8: $747-750,1976$.

Marley, E. and Nistico, Q.: Central effects of clonidine, 2-(2,6-dichlorophenylamino)-2-imidazoline, hydrochloride in fowls. Brit. J. Pharmacol. 55: 459-473, 1975.

McEntee, W.J. and Mair, R.G.: Korsakoff's amnesia: A noradrenergic hypothesis. A.C.N.P. Abstracts, 1978.

Mckearney,J.W.: Maintenance of responding under a fixedinterval schedule of electric shock-presentation. Sience 160: 1249-1251, 1968.

Mckearney, J.W.: Fixed-interval schedules of electric shock presentation: Extinction and recovery of performance under different shock intensities and fixedinterval durations. J. Exp. Anal. Behav. 12: $301-313,1969$.

MCKearney, J.W.: Responding under fixed-ratio and multiple fixed-interval fixed-ratio schedules of electric shock presentation. J. Exp. Anal. Behav. 14: 1-6, 1970.

McKenzie, G.M.: Apomorphine-induced aggression in the rat. Brain Res. 34: 323-330, 1971.

Menon, M.K., Clark, W.G. and Masvoka, D.T.: Possible involvement of the central dopaminergic system in the antireserpine effect of LSD. Psychopharmacology 52: 291-297, 1977.

Meyer, D.R., El-Azhary, R., Bierer, D., Hanson, S.K., Robbins, M.S. and sparber, S.B.: Tolerance and dependence after chronic administration of clonidine to the rat. Pharmacol. Biochem. Behav. 7: 277-281, 1977.

Miksic, S., Shearman, G. and Lal, H.: Generalization stud with some narcotic and non-narcotic drugs in rats trained for morphine-saline discrimination. Psychopharmacology, in press.

Moore, M.A. and Phillipi, P.: Clonidine overdose. Lancet. 2: $694,1976$. 
Morpurgo, C.: Aggressive behavior induced by large doses of 2-(2,6-dichlorphenylamino)-2-imidazoline hydrochloride (ST 155) in mice. Eur. J. Pharmacol. 3: 374-377, 1968 .

Morse, W.H. and Kelleher, R.T.: Schedules using noxious stimuli. I.Multiple fixed-ratio and fixed-interval termination of schedule complexes. J. Exp. Anal. Behav. 9 : 267-290, 1966 .

Myers, R.D.: Central mechanisms in the hypothalamus mediating eating and drinking in the monkey. Ann. N.Y. Acad. Sci. 157: 918-933, 1969.

Nickerson, M. and Ruedy, J.: Antihypertensive agents and the drug therapy of hypertension. In: The Pharmacological Basis of Experimental Therapeutics, edited by L.S. Goodman and A.G. Gilman, Pp. 705-726, Macmillan Publishing Co., New York, 1975.

Niemegeers, C.J.E., Van Neuten, J.M. and Janssen, P.A.J.: Azaperone, a sedative neurleptic of the butyrophenone series with pronounced anti-aggressive and antishock activity in animals. Arzneim. Forsch. Drug Res. 24 : $1798-1806$, 1974 .

Ozawa, H., Miyauchi, T. and Sugawara, K.: Potentiating effect of lithium chloride on aggressive behavior induced by nialamide plus L-dopa and by clonidine. Eur. J. Pharmacol. 34: 169-179, 1975.

Paalzow, L.: Analgesia produced by clonidine in mice and rats. J. Pharm. Pharmacol. 26: 361-363, 1974.

Paalzow, G. and Paalzow, L.: Clonidine antinocicpetive activity: effects of drugs influencing central monaminergic and cholinergic mechanisms in the rat. Naunyn-Schmiediergs-Arch. Pharmacol. 292: 119-126, 1976 .

Pickens, R. and Harris, C.: Self-administration of damphetamine by rats. Psychopharmacologia 12: $158-163$, 1968 .

Pickens, R. and Thompson, T.: Cocaine reinforced behavior in rats: effects of reinforcement magnitude and fixed-ratio size. J. Pharmacol. Exp. Ther. 161: $122-129,1968$.

Pickens, R.: Self-administration of stimulants by rats. Int. J. Addiction 3: 215-221, 1968. 
Pickens, R., Meisch, R.A. and Dougherty, J.A.: Chemical interactions in metnamphetamine reinforcement. Psychol. Rep. 23: 1267-1270, 1968.

Pickens, R. and Thompson, T.: Characteristics of stimulant drug reinforcement. In: stimulus Properties of Drugs edited by T. Thompson and R. Pickens, pp. 177-191 . Appleton-Century-Crofts, New York, 1971.

Pickens, R. and Thompson, T.: Simple schedules of drug self-administration. In: Drug Addiction, Vol. 1, Experimental Pharmacology, edited by J.M. Singh, L. Miller, and H. Lal, pp. 107-120, Futura, New York, 1972 .

Poignant, J.C. and Rismondo, N.: Influence of the administration of psychopharmacological compounds on the take-up time of an alimentary material in the hamster and a study of the associated behavior. Psychopharm. 43: 47-52, 1975 .

pozuelo, J. and Kerr, F.W.: Suppression of craving and other signs of dependence in morphine-addicted monkeys by administration of alpha-methyl-para-tyrosine. Mayo Clin. Proc. 47: 621-628, 1972.

Pycock, C., Donaldson, I. MacG. and Marseden, C.D.: Circling behavior produced by unilateral lesions of the locus coeruleus in rats. Brain Res. 97: 317-323, 1975.

Pycock, C.J., Jenner, P.G. and Marsden, C.D.: The interaction of clonidine with dopamine-dependent behavior in rodents. Nauyn Schmied. Arch. Pharmacol. 297: $133-141,1977$.

Rand, M.J. and Wilson, J.: Mechanisms of the pressor and depressor actions of SE 155 (2-(2,6-dichlorophenylamino) 2-imidazoline hydrochloride, catapress. Eur. J. Pharmacol. 3: 27-33, 1968.

Razzak, A., Fujiwara, M. and Veki, S.: Automutiliation induced by clonidine in mice. Eur. J. Pharmacol. $30: 356-360,1975$.

Razzak, A., Fujiwara, M., Oishi, R., and Veki, S.: possible involvement of a central noradrenergic system in automutilation induced by clonidine in mice. Jap. J. Pharmacol. 27: 145-152, 1977.

Rech, R.H. and Moore, K.E.: An Introduction to Psychopharmacology. Raven Press, New York, 1971. 
Redmond, D.E., Jr., Huang, Y.H., Snyder, D.R., and Maas, J.W.: Behavioral effects of stimulation of the nucleus locus coeruleus in the stump-tailed monkey (Macaca arctoides). Brain Res. 116: 502-510, 1976.

Redmond, D.E., Jr.: Alterations in the function of the nucleus locus coeruleus: a possible model for studies of anxiety. In: Animal Models in Psychiatry and Neurology edited by I. Hanin and E. Usdin, pp. 293305 , Pergamon Press, Oxford, 1977.

Reid, J.L., Lewis, P.J. and Meyers, M.G.: Role of central dopaminergic mechanisms in piribedil and clonidine induced hypothermia in the rat. Neuropharmacol. 14: 215-220, 1975 .

Rochette, I., Bralet, A.M. and Bralet, J.: Effect of clonidine on the synthesis and release of noradrenaline in various regions of the rat brain. J. Pharmacol. 5: 209-220, 1974 .

Rochette, I. and Bralet, J.: Effect of the norepinephrine receptor stimulating agent "clonidine" on the turnover of 5-hydroxytryptamine in some areas of rat brain. J. Neural Trans. 37: 259-267, 1975.

Ruiz, M. and Monti, J.M.: Reversal of the 6-hydroxydopamine-induced suppression of CAR by drugs facilitating central catecholaminergic mechanism. Pharmacol. 13: 281-286, 1975 .

Saperia, J.: Clonidine overdose. Brit. Med. J. 4: 580, 1975 .

Sastry, B.S.R. and Phyllis, J.W.: Evidence that clonidine can activate histamine $\mathrm{H}_{2}$-receptors in rat cerebral cortex. Neuropharmacol. 16: 223-225, 1977.

Satoh, H., Satoh, Y., Notsu, Y. and Honda, F.: Adenosine $3^{\prime}, 5^{\prime}$-cyclic monophsophate as a possible mediator of rotational behavior induced by dopaminergic receptor stimulation in rats lesioned unilaterally in the substania nigra. Eur. J. Pharmacol. 39: 365-377, 1976.

Scheel-Kruger, J. and Hasselager, E.: Studies of various amphetamines, apomorphine and clonidine on body temperature and brain 5-hydroxytryptamine metabolism in rats. Psychopharmacologia 36: 189-202, 1974.

Schmitt, H. and schmitt, H.: Interaction between 2(2,6-dichlorophenylamino)-2-imidazoline hydrochloride (ST 155, Catapressan), and alpha-adrenergic blocking drugs. Eur. J. Pharmacol. 9: 7-13, 1970. 
Schmitt, H., Le Douarec, J.C., and Petillot, N.: Antinociceptive effects of some alpha-sympathomimetic agents. Neuropharmacol. 13: 289-294, 1974.

Schuster, C.R.: Variables affecting the self-administration of drugs by rhesus monkeys. In: Use of Nonhuman primates in Drug Evaluation. Edited by $H$. Vagtborg pp 283-296, University of Texas Press, Austin, 1968.

Seiden, L.S. and Dykstra, L.A.: Psychopharmacology: A Biochemical and Behavioral Approach. Van Nostrand Reinhold Co., New York, 1977.

Shaw, S.G. and Rolls, E.T.: Is the release of noradrenaline necessary for self-stimulation of the brain. Pharmacol. Biochem. Behav. 4: 375-379, 1976.

Shearman, G., Hynes, M., Fielding, S. and Lal, H.: Clonidine self-administration in the rat: a comparison with fentanyl self-administration. Pharmacologist, 19: $171,1977$.

Sewell, R.D.E. and Spencer, P.S.J.: Antinociceptive activity in mice after central injections of alpha- and betaadrenoceptor antagonists. Brit. J. Pharmacol. 54: $256-257,1975$.

Skolnick, P. and Daly, J.W.: Stimulation of adenosine $3^{\prime}, 5^{\prime}$-monophosphate formation by alpha and beta adrenergic agonists in rat cerebral cortical slices: effects of clonidine. Molec. Pharmacol. 11: 545-551, $1975 a$.

Skolnick, P. and Daly, J.: Stimulation of adenosine $3^{\prime}$, 5'-monophosphate formation in rat cerebral cortical slices by methoxamine: interaction with an alpha adrenergic receptor. J. Pharmacol. Exp. Ther. 193: 549-558, 1975b.

Skolnick, P. and Daly, J.W.: Interaction of clonidine with pre- and post-synaptic adrenergic recptors of rat brain: effects on cyclic-AMP generating system. Eur. J. Pharmacol. 39: 11-21, 1976.

Smith, W.M. Jr.: Nalorphine as an aversive agent. Proc. 8lst Ann. Con. Psychol. Assoc. 1053-1054, 1973.

Smith, S.G. and Davis, W.M.: Haloperidol effects on morphine self-administration: testing for pharmacological modification of the primary reinforcement mechanism. Psychol. Rec. 23: 215-221, 1973. 
Smith, S.G. and Davis, W.M.: A method for chronic intravenous drug administration in the rat. In: Methods in Narcotic Research. Ed. S. Ehrenpreis and A. Neidle pp. 3-32, Marcel Dekker, Inc., New York, 1975.

Spaulding, T.S., Venafro, J., Ma, M., Cornfeldt, M. and Fielding, S.: Interaction of morphine and clonidine in the tail flick test: potentiation studies. Pharmacologist, 20: 269, 1978.

Spealman, R.D. and Goldberg, S.R.: Drug self-administration by laboratory animals: control by schedules of reinforcement. Ann. Rev. Pharmacol. Toxicol. 18: $313-339,1978$.

Spencer, J. and Revzin, A.: Amphetamine, chlorpromazine and clonidine effects on self-stimulation in caudate or hypothalamus of the squirrel monkey. Pharmacol. Biochem. Behav. 5: 149-156, 1976.

Starke, K. and Montel, H.: Involvement of alpha-receptors in clonidine-induced inhibition of transmitter release from central monoamine neurones. Neuropharmacol 12: 1073-1080, 1973.

Stern, P. and Catovic, S.: Brain glycine and aggressive behavior. Pharmacol. Biochem. Behav. 3: 723-726, 1975.

Stricker, E.M. and Zigmond, M.J.: Recovery of function following damage to central catecholamine-containing neurons: a neurochemical model of the lateral hypothalamic syndrome. In: Progress in Psychobiology and Physiological Psychology, edited by J.M. Sprague and A.N. Epstein, Academic Press, New York, 1976.

Strombom, U.: Catecholamine receptor agonists. Effects on motor activity and rate of tyrosine hydroxylation in mouse brain. Naunyn-Schmied. Arch. Pharmacol. 292: $167-176,1976$.

Svensson, T.H., Burrey, B.S. and Aghajanian, G.K.: Inhibition of both noradrenergic and serotonergic neurons in the brain by the alpha-adrenergic agonist clonidine. Brain Res. 92: 291-306, 1975.

Thompson, T. and Schuster, C.R.: Morphine self-administration, food-reinforced, and avoidance behaviors in rhesus monkeys. Psychopharmacologia 5: 87-94, 1964.

Thompson, T. and Pickens, R.: Stimulant self-administration by animals: some comparisons with opiate self-administration. Fed. Proc. 29: 6-12, 1970 . 
Tilson, H.A., Chamberlain, J.H., Gylys, J.A. and Buyniski, J.P.: Behavioral suppressant effects of clonidine in strains of normotensive and hypertensive rats. Eur. Pharmacol. 43: 99-105, 1977.

Tseng, L.F., Loh, H.H. and Wei, E.T.: Effect of clonidine on morphine withdrawal signs in the rat. Eur. J. Pharmacol. 30: 93-99, 1975.

Tsoucaris-Kupfer, D. and Schmitt, H.: Hypothermic effect of alpha-sympathomimetic agents and their antagonism by adrenergic and cholinergic blocking drugs. Neuropharmacol. 11: 625-635, 1972 .

Ungerstedt, U., Butcher, L.L., Butcher, S.G., Anden, N.E. and Fuxe, K.: Direct chemical stimulation of dopaminergic mechanism in the neostriatum of the rat. Brain Res. 14: 461-468, 1969.

Van Zwieten, P.A.: Antihypertensive drugs with a central action. Prog. Pharmacol. 1: 1-63, 1975.

Vetulani, J. and Bednarczyk, B.: Depression by clonidine of shaking behavior elicited by nalorphine in morphine-dependent rats. J. Pharm. Pharmacol. 29: $567-568,1977$.

Vetulani, J., Leith, N.J., Stawarz, R.J. and sulser, F.: Effect of clonidine on the noradrenergic cyclic AMP generating system in the limbic forebrain and on medial forebrain self-stimulation behavior. Experientia 33: 1490-1491, 1977.

Walland, A.: Clonidine. In: Pharmacological and Biochemical Properties of Drug Substances, edited by M.E. Goldberg pp. 67-107, American Pharmaceutical Association, Washington, D.C., 1977.

Washton, A.M., Resnick, R.B. and Laplaca, R.A.: Clonidine hydrochloride: a non-opiate treatment for opiate withdrawal. Abstract ACNP, 1978.

Weeks, J.R.: Experimental morphine addiction: method for automatic intravenous injections in unrestrained rats. Science 138: 143-144, 1962 .

Weeks, J.R. and Collins, R.J.: Factors affecting voluntary morphine intake in self-maintained addicted rats. Science 138: 143-144,1964.

Wei, E., Tseng, L.F., Loh, H.H. and Way, E.L.: Morphine abstinence signs: similarity to thermoregulatory behavior. Nature 247: 398-400, 1974. 
Wei, E.: Resemblance of morphine antinociception to the central depressant actions of norepinephrine. Life sci. 17: 17-18, 1975 .

Wei, E.: Chemical stimulants of shaking behavior. J. Pharm. Pharmacol. 28: 722-723, 1976.

Wendt, F. and Caspers, I.: Koppertemperateur und Schweisssekretion vei Kopenlicker Belastung unter dem Einflurs von 2-(2,6-dichlorophenylami no)-2-imidazolin hydrochlorid. In: Hochdruck-Therapie, Symposium uber 2 (2,6-dichlorophenylamino)-2-imidazolin hydrochlorid, edited by I. Heilmeyer, H.J. Holtmeier and E.F. Pfeiffer, Stuggart, George Thieme, 1968.

Wilson, M.C. and Schuster, C.R.: The effects of chlorpromazine on psychomotor stimulant self-administration in the rhesus monkey. Psychopharmacologia 26 : 115-126, 1972 .

Wilson, M.C. and Schuster, C.R.: Aminergic influences on intravenous cocaine self-administration by rhesus monkeys. Pharmacol. Biochem. Behav. 2: 563-571, 1974.

Wing, L.M.H., Davies, D.S., Reid, J.L. and Dollery, C.T.: Clonidine overdose. Brit. Med. J. 4: 408-409, 1975.

Winger, G., Stitzer, M.L. and Woods, J.H.: Barbituratereinforced responding in rhesus monkeys: comparisons of drugs with different durations of action. J. Pharmacol. Exp. Ther. 195: 505-514, 1975.

Wise, C.D., Berger, B.P. and Stein, I.: Evidence of alphanoradrenergic reward receptors and serotonergic punishment receptors in the rat brain. Biol. Psychiat. 6: 3-11, 1973.

Wise, R.A.: Neuroletpic attenuation of intracranial selfstimulation: reward or performance deficits? Life Sci. 22: 535-542, 1978 .

Woods, J.H. and Schuster, C.R.: Reinforcement properties of morphine, cocaine and SPA as a function of unit dose. Int. J. Addictions 3: 231-237, 1968.

Woods, J.H. and Villarreal, J.E.: Patterns of cocaine-, codeine, and pentazocine-reinforced responding in the rhesus monkey. Pharmacologist 12: 230, 1970. 
Woods, J.H. and Schuster, C.R.: Opiates as reinforcing stimuli. In: Stimulus Properties of Drugs, edited by T. Thompson and R.Pickens, pp 163-175, AppletonCentury-Crofts, New York, 1971.

Woods, J.H., Downs, D.A. and Carney, J.: Behavioral functions of narcotic antagonists: response-drug contingencies. Federation Proceedings 34 : 17771784 , 1975.

Yokel, R.A. and Wise, R.A.: Increased lever pressing for amphetamine after pimozide in rats: Implications for a dopamine theory of reward. Science 187: 547-549, 1975.

Yokel, R.A. and Wise, R.A.: Attenuation of intravenous amphetamine reinforcement by centraldopamine blockade in rats. Psychopharmacology 48: 311-318, 1976.

Zamis, E.: The pharmacology of Catapress (ST 155). In Catapres in Hypertension, edited by M.E. Conolly, pp. 9-22, Buterworth, London, 1970. 